\title{
Experimental Evaluation of Non-Composite Shallow Press-Brake- Formed Steel Tub Girders
}

\author{
Lindsay T. Kelly
}

Follow this and additional works at: https://researchrepository.wvu.edu/etd

\section{Recommended Citation}

Kelly, Lindsay T., "Experimental Evaluation of Non-Composite Shallow Press-Brake-Formed Steel Tub Girders" (2014). Graduate Theses, Dissertations, and Problem Reports. 5958.

https://researchrepository.wvu.edu/etd/5958

This Thesis is protected by copyright and/or related rights. It has been brought to you by the The Research Repository @ WVU with permission from the rights-holder(s). You are free to use this Thesis in any way that is permitted by the copyright and related rights legislation that applies to your use. For other uses you must obtain permission from the rights-holder(s) directly, unless additional rights are indicated by a Creative Commons license in the record and/ or on the work itself. This Thesis has been accepted for inclusion in WVU Graduate Theses, Dissertations, and Problem Reports collection by an authorized administrator of The Research Repository @ WVU. For more information, please contact researchrepository@mail.wvu.edu. 


\title{
EXPERIMENTAL EVALUATION OF NON-COMPOSITE SHALLOW PRESS-BRAKe-FORMEd STEEL TUB GIRDERS
}

\author{
Lindsay T. Kelly \\ Thesis submitted to the \\ Benjamin M. Statler College of Engineering and Mineral Resources \\ at \\ West Virginia University \\ in partial fulfillment of the requirements \\ for the degree of \\ Master of Science \\ in \\ Civil and Environmental Engineering
}

Karl E. Barth, Ph.D., Chair
Gregory K. Michaelson, Ph.D.
P. V. Vijay, Ph.D., P.E.
Department of Civil and Environmental Engineering

Morgantown, West Virginia

2014

Keywords: steel bridge, experimental testing, finite element analysis, cold bending, lateral torsional buckling, permanent metal deck formwork, non-composite tub girder 


\title{
AbSTract \\ EXPERIMENTAL EVALUATION OF NON-COMPOSITE SHALlOW Press-Brake-Formed Steel Tub Girders
}

\author{
Lindsay T. Kelly
}

The Short Span Steel Bridge Alliance (SSSBA) is a group of bridge industry leaders (including steel manufacturers, fabricators, service centers, coaters, researchers, and representatives of related associations and government organizations) who have joined together to provide educational information on the design and construction of short-span steel bridges in installations up to 140 feet in length (Michaelson, 2014). From within the SSSBA technical working group, a shallow press-brake-formed steel tub girder was developed. This new technology consists of cold-bending standard mill plate width and thicknesses to form a trapezoidal box girder. By eliminating the need to cut and weld plates together, the system proves to be an economical and rapid construction option. The steel plate can either be weathering steel or galvanized steel, each an economical option.

The originally-proposed system consisted of a reinforced concrete deck cast on the girder in the fabrication shop, forming a composite modular unit once cured. The composite unit would then be shipped to the construction site to be installed. However, the option of implementing a castin-place deck must be explored. A critical design stage for these girders occurs during pouring of the concrete deck, when the non-composite steel section must support the construction load, including the wet concrete. During this period, the top flanges are in compression and the system is susceptible to torsional buckling and deflection phenomena. Therefore, for a cast-inplace deck option, the non-composite stability and behavior of tub girders needs to be further evaluated.

The scope of this project was to develop a complete understanding of the stability and behavior of non-composite press-brake-formed tub girders for short span bridge applications. This was performed in four stages. A complete literature review focusing on previous studies relating to non-composite trapezoidal steel tub girder behavior was conducted. Destructive flexural testing was then performed on two non-composite specimens to assess the ultimate capacity of the system. Next, nonlinear finite element models were developed and benchmarked against experimental data. Results of the experimental and FEA modeling are used to determine bracing requirements for the non-composite press-brake-formed tub girders to improve their torsional response. 


\section{ACKNOWLEDGEMENTS}

First, I would like to express my deepest appreciation to my family for their love and support through my educational pursuits. My parents and grandparents not only financially supported me, but also encouraged me to work hard and never give up on my life goals. I would also like to thank my sisters, Katie and Stephanie Kelly, boyfriend, Matthew Rector, and dear friend, Lyndsay Wehrle for your support through it all.

I wish to express my sincere gratitude to my advisor Dr. Karl Barth for giving me the opportunity to work toward my Master's Degree. His support and encouragement have provided me with a strong educational base from which I can build a successful career. Also, I would like to thank Dr. Gregory Michaelson and Dr. P. V. Vijay for serving on my academic committee. I greatly appreciate your time and support in assisting me through my graduate studies. As well as, Dr. Gregory Michaelson's contribution to the finite element analysis conducted herein, are greatly appreciated.

The financial support of the Short Span Steel Bridge Alliance, as well as donations from; Nucor-Yamato Steel, SSAB Americas, and EVRAZ North America is greatly appreciated. I would also like to thank Greiner Industries, American Tank \& Fabricating, and AZZ Galvanizing, Inc. for their efforts in fabricating the experimental girder specimens. Without their combined help the development of this research would not have been possible.

Special thanks to graduate student Bryan Gallion, undergraduate research assistants Matthew Rector and Eric Rogers, and laboratory technician Jerry Nestor for your contributions throughout the project. 


\section{TABLE OF CONTENTS}

\section{Contents}

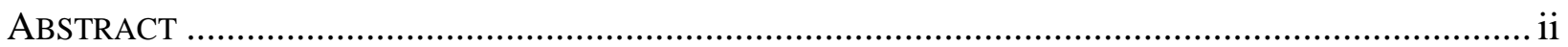

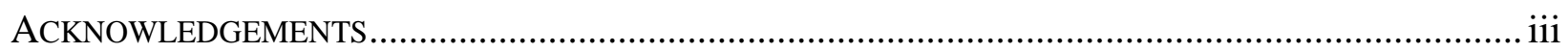

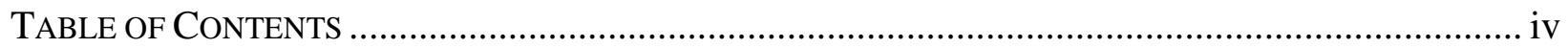

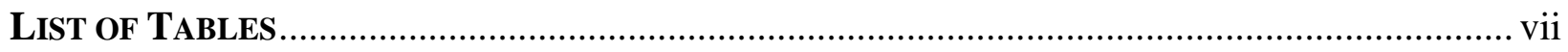

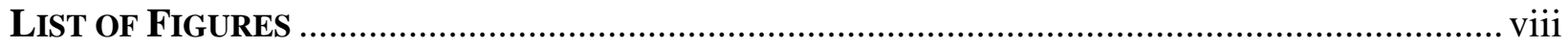

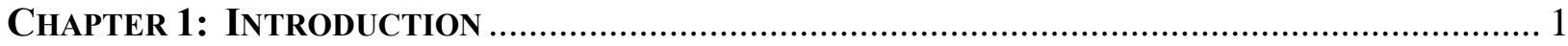

1.1 BACKGROUND / OVERVIEW ................................................................................................... 1

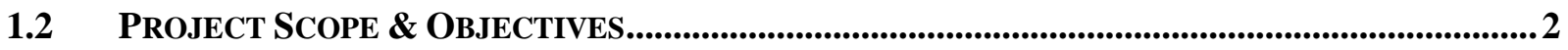

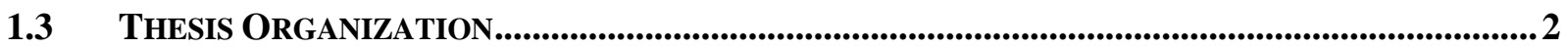

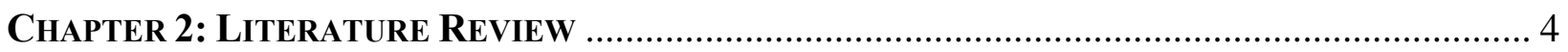

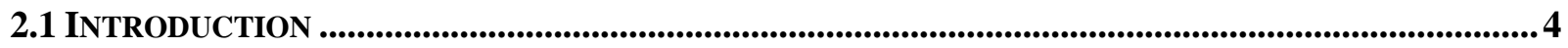

2.2 PREVIOUS RESEARCH OF PRESS-BRAKE-FORMED STEEL TUB GIRDERS.......................................4

2.2.1 Experimental Work by Taly \& Gangarao (1979) - West Virginia University.............................. 4

2.2.2 Buckling Behavior of U-Shaped Girders - University of Texas, Austin .................................... 6

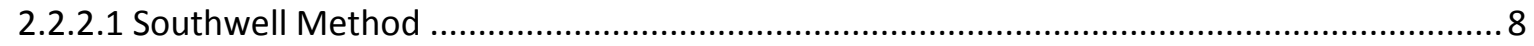

2.2.3 Top Lateral Bracing of U-Shaped Girders- University of Texas, Austin................................... 10

2.2.4 Experimental Work of S. Nakamura (2002) - Tokai University, Japan ................................... 12

2.2.5 Top Lateral Bracing For Trapezoidal Steel Box Girder Bridges - University of Texas, Austin 15

2.2.6 Texas Prefabricated Steel Tub-Girder System - University of Texas, Austin ........................... 17

2.2.7 Short Span Steel Bridge: Inverted Steel Box System - University of Nebraska, Lincoln ........... 19

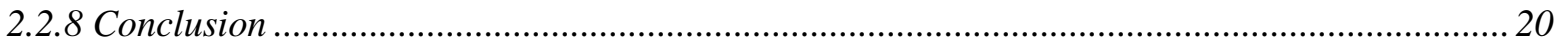

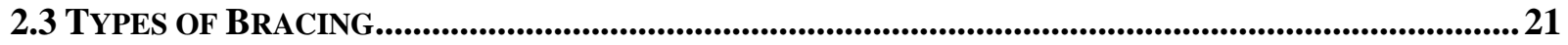

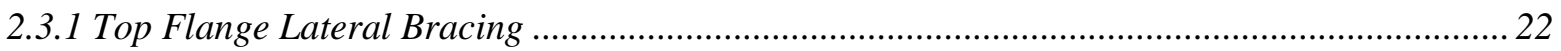

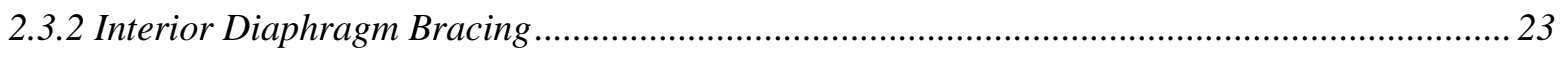

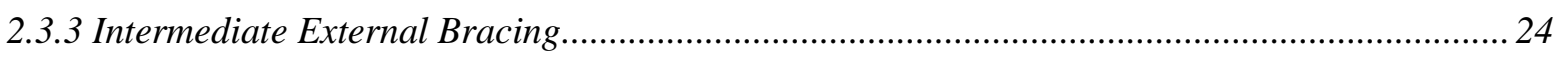

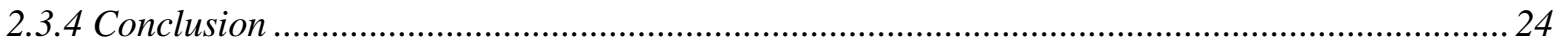

2.4 Stability OF Non-ComPosite COLD-FORMEd STEel TUB GIRDERS.......................................25 
2.4.1 Buckling Analysis Of Cold-Formed Girders Using CUFSM ............................................... 25

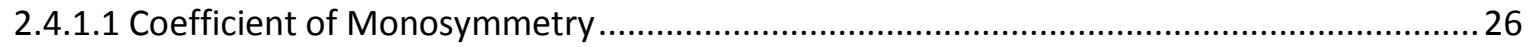

2.4.2 Torsional Behavior of Thin-Walled Sections ......................................................................... 27

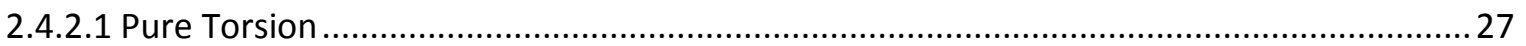

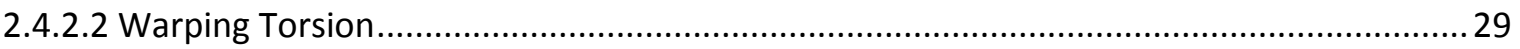

2.4.3 Location of Shear Center ................................................................................................ 30

2.5 SIP METAL DECK FORMS AS A BRACING SYSTEM .........................................................................31

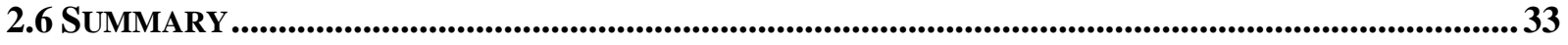

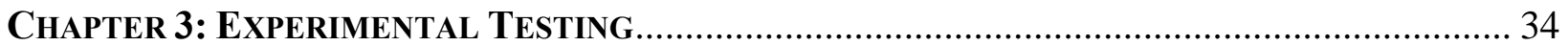

3.1 INTRODUCTION

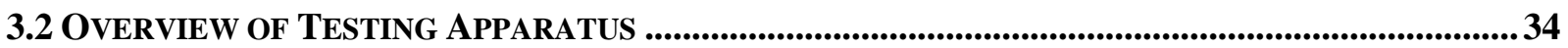

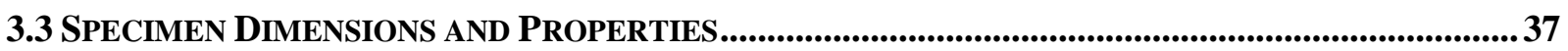

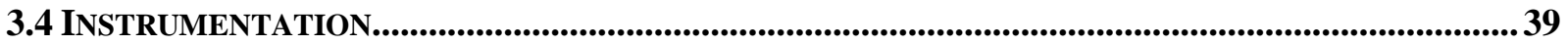

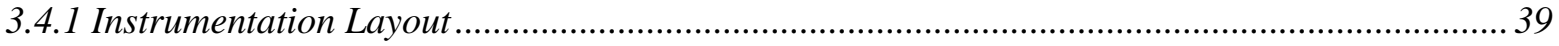

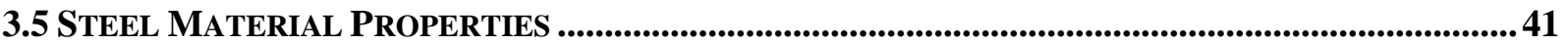

3.6 INITIAL IMPERFECTIONS .........................................................................................................................41

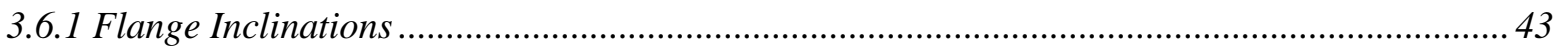

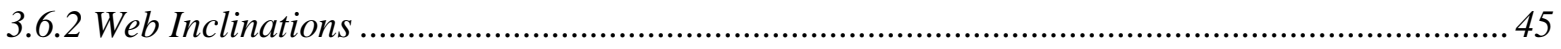

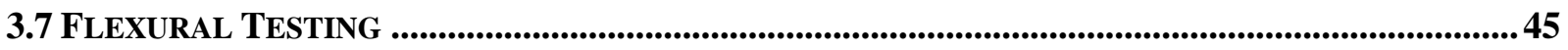

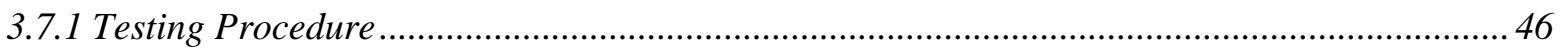

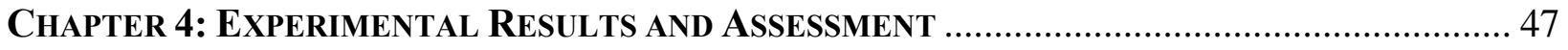

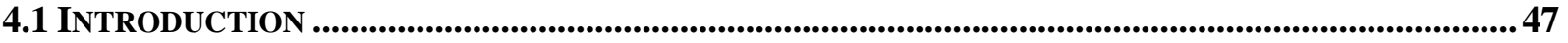

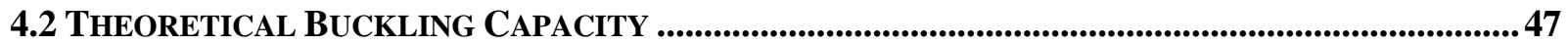

4.3 EXPERIMENT \#1 ...................................................................................................................................................48

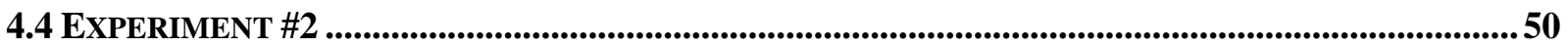

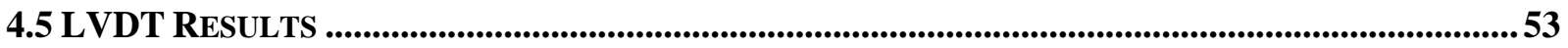

4.6 ASSESSMENT OF SECOND-ORDER EFFECTS................................................................................54

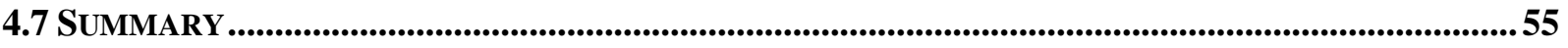

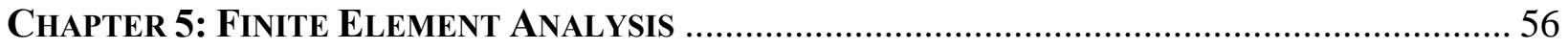

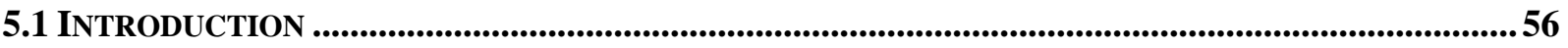

5.2 FINITE ELEMENT MODELING TECHNIQUE ............................................................................................56

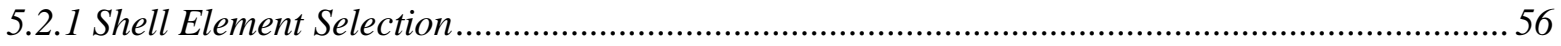




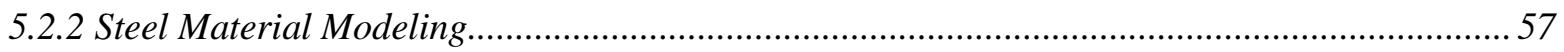

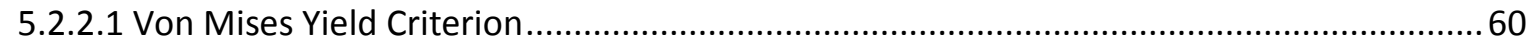

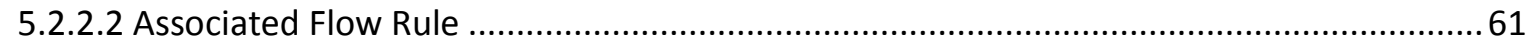

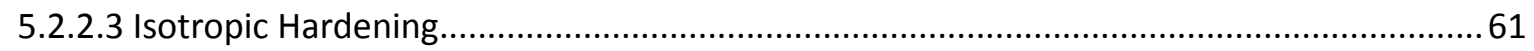

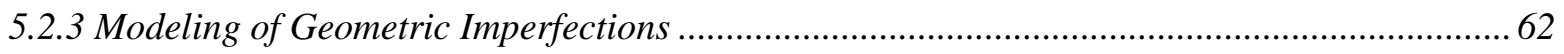

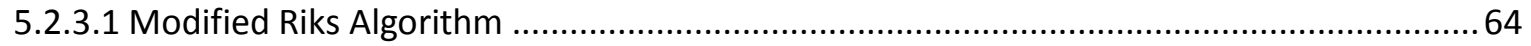

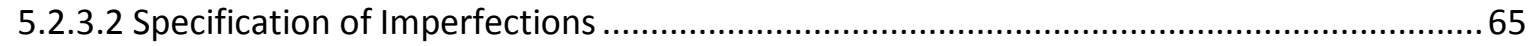

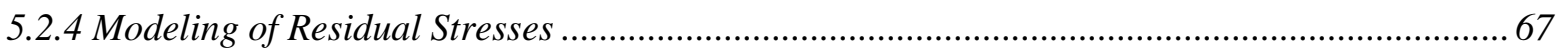

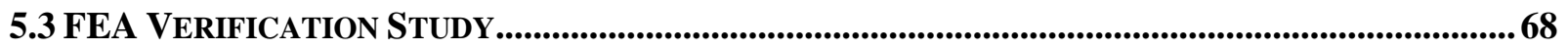

5.4 Modeling of Press-Brake Tub Girder Flexural TeSTS .............................................71

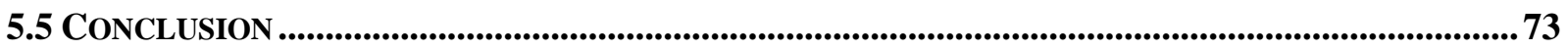

CHAPTER 6: ProJect SumMaRy AND CONCLUding REMARKS ............................................. 74

6.1 PROJECT SUMMARY ...................................................................................................................................... 74

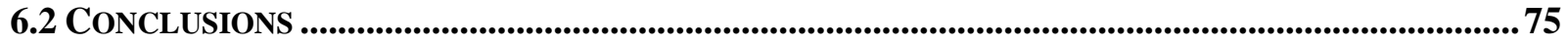

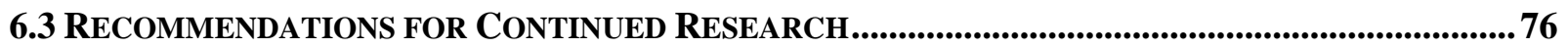

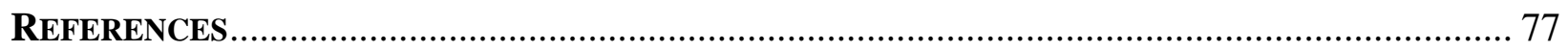




\section{LIST OF TABLES}

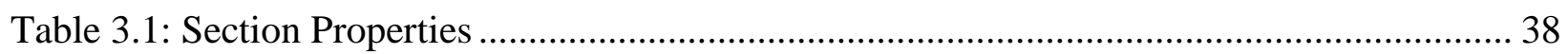

Table 5.1: Expressions for Computing Steel Stress-Strain Behavior (Galindez, 2009) .............. 59

Table 5.2: Average Steel Plate Properties (Galindez, 2009) ................................................... 59 


\section{LIST OF FIGURES}

Figure 2.1: Press-Formed Composite Box Girder by Gangarao and Taly (1979) ....................... 5

Figure 2.2: Cross-Section Properties (Gilchrist, Yura, and Frank, 1997)................................. 7

Figure 2.3: Buckled Shape for a Trapezoidal U-Girder (Gilchrist, Yura, and Frank, 1997)......... 8

Figure 2.4: Southwell Plot (Gilchrist, Yura, and Frank, 1997).............................................. 9

Figure 2.5: Metal Deck Tests (Chen, Yura, and Frank, 2002)............................................ 11

Figure 2.6: Press-Brake-Formed Specimen Proposed by (Nakamura, 2002) ........................... 13

Figure 2.7: Three Span Bridge System Proposed by (Nakamura, 2002)................................. 13

Figure 2.8: Strains with Applied Load for U1 (Nakamura, 2002) ......................................... 14

Figure 2.9: Strains with Applied Load for U2 (Nakamura, 2002) ........................................... 14

Figure 2.10: Location of Applied Load and Bracing Configuration (Chen, Williamson, Yura, and

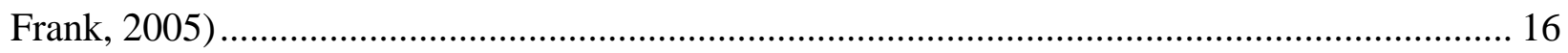

Figure 2.11: Conventional Trapezoidal Steel Tub Girder by (Freeby, 2005)........................... 18

Figure 2.12: Cross Section of Non-Composite Specimen (Glaser, 2010) ................................ 19

Figure 2.13 Categories of Bracing (Helwig and Yura, 2012) .............................................. 21

Figure 2.14: Lateral X-Brace (Chen, Yura, and Frank, 2002) ................................................. 22

Figure 2.15: Layout of SIP Metal Deck Form (Chen, Yura, and Frank, 2002) ....................... 23

Figure 2.16 Interior Diaphragm Bracing Layouts for Tub Girders (Helwig and Yura, 2012) ..... 23

Figure 2.17 External Cross Frames (Cheplak, 2001)........................................................... 24

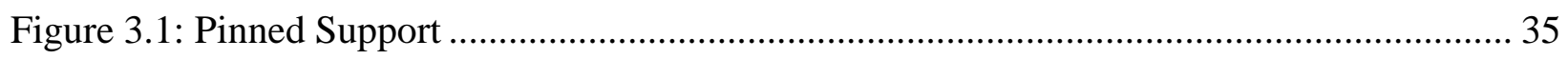

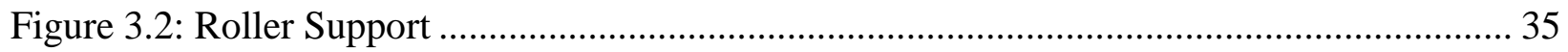

Figure 3.3: Typical Spreader Beam with Elastomeric Pads ................................................. 36

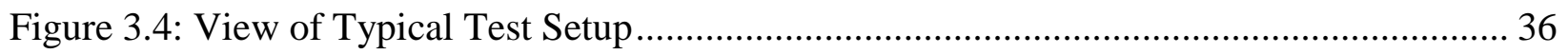

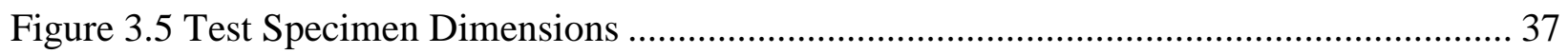

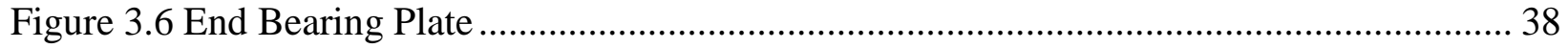

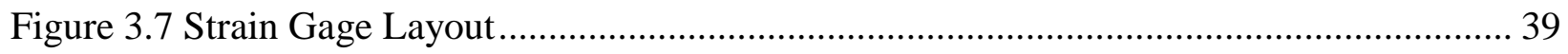

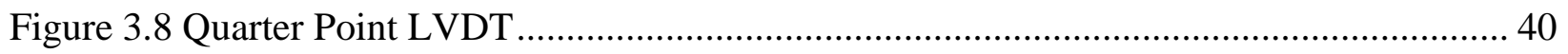

Figure 3.9: Coupon Tensile Testing Results (Michaelson, 2014) ............................................ 41

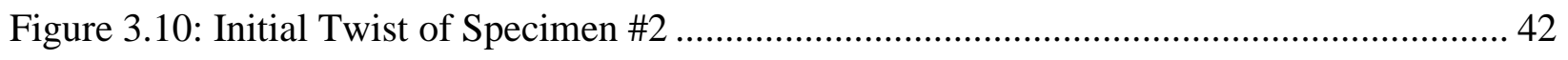

Figure 3.11: Initial Mid-span Inclination of Specimen \#2 …............................................. 42

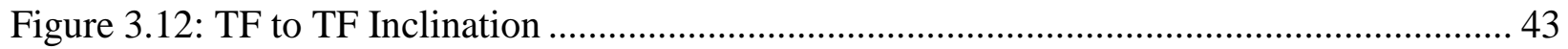




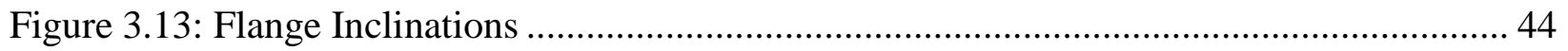

Figure 3.14: Galvanized Girder Flange Levels ................................................................... 44

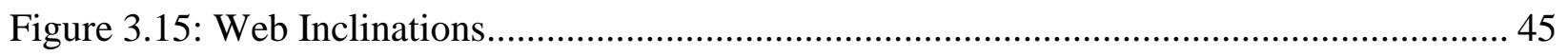

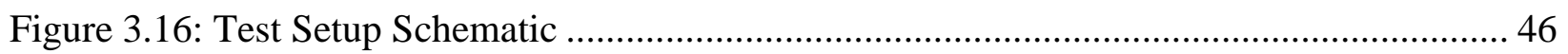

Figure 4.1: Load-Deflection Data from Experiment \#1 ....................................................... 48

Figure 4.2: Side View of Lateral Torsional Buckling of Specimen \#1 ................................... 49

Figure 4.3: Front View of Lateral Torsional Buckling of Specimen \#1 .................................. 49

Figure 4.4: Post Loading of Specimen \#1 .......................................................................... 50

Figure 4.5: Load-Deflection Data from Experiment \#2 …................................................ 51

Figure 4.6: Mid-span Moment Comparison.................................................................... 51

Figure 4.7: Side View of Lateral Torsional Buckling of Specimen \#2 _................................. 52

Figure 4.8: Front View of Lateral Torsional Buckling of Specimen \#2 ................................. 52

Figure 4.9: Deflection at Quarter Points ...................................................................... 53

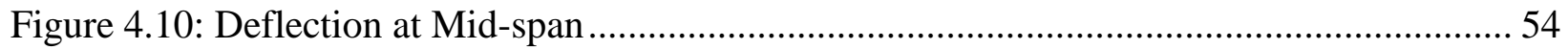

Figure 4.11: Second-Order Lateral Deflections (Michaelson, 2014) ..................................... 55

Figure 5.1: Multi-linear Stress-Strain Curve .................................................................. 58

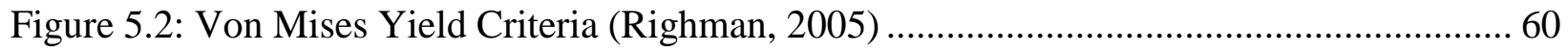

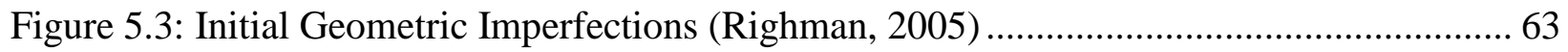

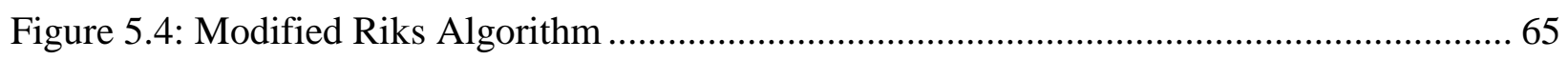

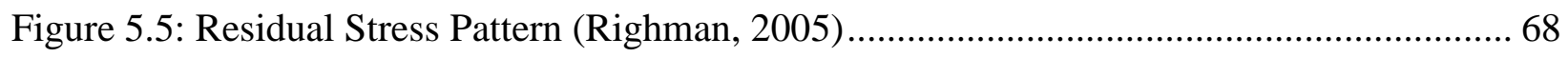

Figure 5.6: "D” Girder Configuration (Schilling and Morcos, 1988)..................................... 69

Figure 5.7: Comparison of Schilling and Morcos (1988) "D” Girder and FEA Results ............. 70

Figure 5.8: “HT-29” Girder Test (Lay et. al. 1964) ................................................................ 70

Figure 5.9: Comparison of Lay et. al (1964) "HT-29” Girder Test and FEA Results................ 71

Figure 5.10 Finite Element Model of Non-composite Press-Brake-Formed Tub Girder ............ 72

Figure 5.11 Buckled Shape of Non-composite Press-Brake-Formed Tub Girder ..................... 72

Figure 5.12: Comparison of Experimental and Analytical Results ....................................... 73 


\section{CHAPTER 1: INTRODUCTION}

\subsection{BACKGROUND / OVERVIEW}

The Short Span Steel Bridge Alliance (SSSBA) is a group of bridge industry leaders (including steel manufacturers, fabricators, service centers, coaters, researchers, and representatives of related associations and government organizations) who have joined together to provide educational information on the design and construction of short-span steel bridges in installations up to 140 feet in length (Michaelson, 2014). From within the SSSBA technical working group, a shallow press-brake-formed steel tub girder was developed. This new technology consists of cold-bending standard mill plate width and thicknesses to form a trapezoidal box girder. By eliminating the need to cut and weld plates together, the system proves to be an economical and rapid construction option. The steel plate can either be weathering or galvanized steel, each an economical option.

The originally-proposed system consisted of a reinforced concrete deck cast on the girder in the fabrication shop, forming a composite modular unit once cured. The composite unit would then be shipped to the construction site to be installed. However, the option of implementing a cast-in-place must be explored. A critical design stage for these girders occurs during pouring of the concrete deck, when the non-composite steel section must support the construction load, including the wet concrete. During this period, the top flanges are in compression and the system is susceptible to torsional buckling and deflection phenomena. Therefore, for a cast-in-place deck option, the non-composite stability and behavior of these tub girders needs to be further evaluated. 


\subsection{Project Scope \& OBJectives}

This research is focused on developing a complete understanding of the stability and torsional behavior of non-composite press-brake formed tub girders that may be used in short span bridge designs. Specifically, this is accomplished in the following manner:

- Compile a literature review focused on reviewing past studies relating to trapezoidal steel tub girders in bridge applications. Particular attention is paid to the stability of these girders in a non-composite state and the effect of bracing options on stability.

- Perform large scale destructive flexural testing of two non-composite girders to physically verify their buckling capacity and behavior.

- Develop refined FEA models to simulate the nonlinear material and geometric behavior of the steel girder specimens, which can be verified by existing experimental data.

- Finally, use the experimental testing and FEA results to determine a need for bracing options and present recommendations for future work.

\subsection{THESIS ORgANIZATION}

A brief overview of the organization of this thesis is as follows:

- Chapter 2:

- This chapter summarizes previous research on cold-bent tub girder bridge applications. In addition, a review of the members' lateral torsional buckling (LTB) behavior in a non-composite state is provided. This chapter also discusses the use of stay-in-place metal formwork to improve the LTB behavior. 
- Chapter 3:

- The experimental testing that has been conducted for this research on noncomposite press-brake formed shallow steel tub girders is discussed in this chapter. Testing consisted of destructive testing on two girder specimens. This chapter focuses on the testing program, specimen properties, instrumentation used, and initial imperfections.

\section{- Chapter 4:}

- This chapter provides the experimental results obtained from the flexural testing described in Chapter 3. This chapter focuses on the predicted buckling, second order effects, and comparisons of both experiments.

\section{- $\quad$ Chapter 5:}

○ This chapter introduces the nonlinear finite element techniques employed in this work with the use of Abaqus. Analysis details, such as nonlinear shell elements, material modeling, and modeling of geometric imperfections and residual stresses are provided. The finite element analysis is then used to correlate with the results of the experimental tests.

\section{- $\quad$ Chapter 6:}

- Lastly, this chapter provides final conclusions and recommendations drawn from this study, as well as providing a summary of proposed future work. 


\section{CHAPTER 2: LiterATURE REVIEW}

\subsection{INTRODUCTION}

Presented in this chapter is a comprehensive review of previous research studies relating to trapezoidal steel tub-girders in bridge applications. Included is a discussion on the stability and torsional response of these girders in their non-composite state. Different types of bracing options for tub girders are also reviewed. Particular attention is paid to implementing stay in place metal formwork to improve tub girder stability.

\subsection{PREVIOUS RESEARCH OF PRESS-BRAKE-FORMED STEEL TUB GIRDERS}

The notion of using prefabricated steel tub girders in short-span bridge applications has been around for many years. However, recent industry demands for a more economical solution and rapid bridge construction have made it worthwhile to explore the use of press-brake-formed tub girders as a feasible alternative to conventional bridge designs. Presented in this section is an overview of various tub girder configurations from previous research studies.

\subsubsection{Experimental Work by Taly \& Gangarao (1979) - West Virginia University}

Early studies assessing press-brake-formed girder systems can be dated back to the late 1970’s, when Taly \& Gangarao (1979) proposed a prefabricated press-formed steel box girder bridge system. In the proposed design, a 3/8-in. thick A36 steel plate is cold-bent using a pressbrake to form a trapezoidal shaped tub girder for short-span bridge applications. The girder width is 3 feet and depth ranges from 2.5-3.5 feet, depending on the desired span length. Shear stud plates are then shop welded onto the flanges. A pre-stressed concrete deck, 6 feet in width and 5 inches thick, will then be precast along the span of the girder to form a concrete-steel composite system. Figure 2.1 shows the proposed composite box girder system. For wider 
bridge applications, multiple girders are placed alongside one another and joined with longitudinal closure pours. A tub girder consisting of an all steel orthotropic deck option was also proposed.

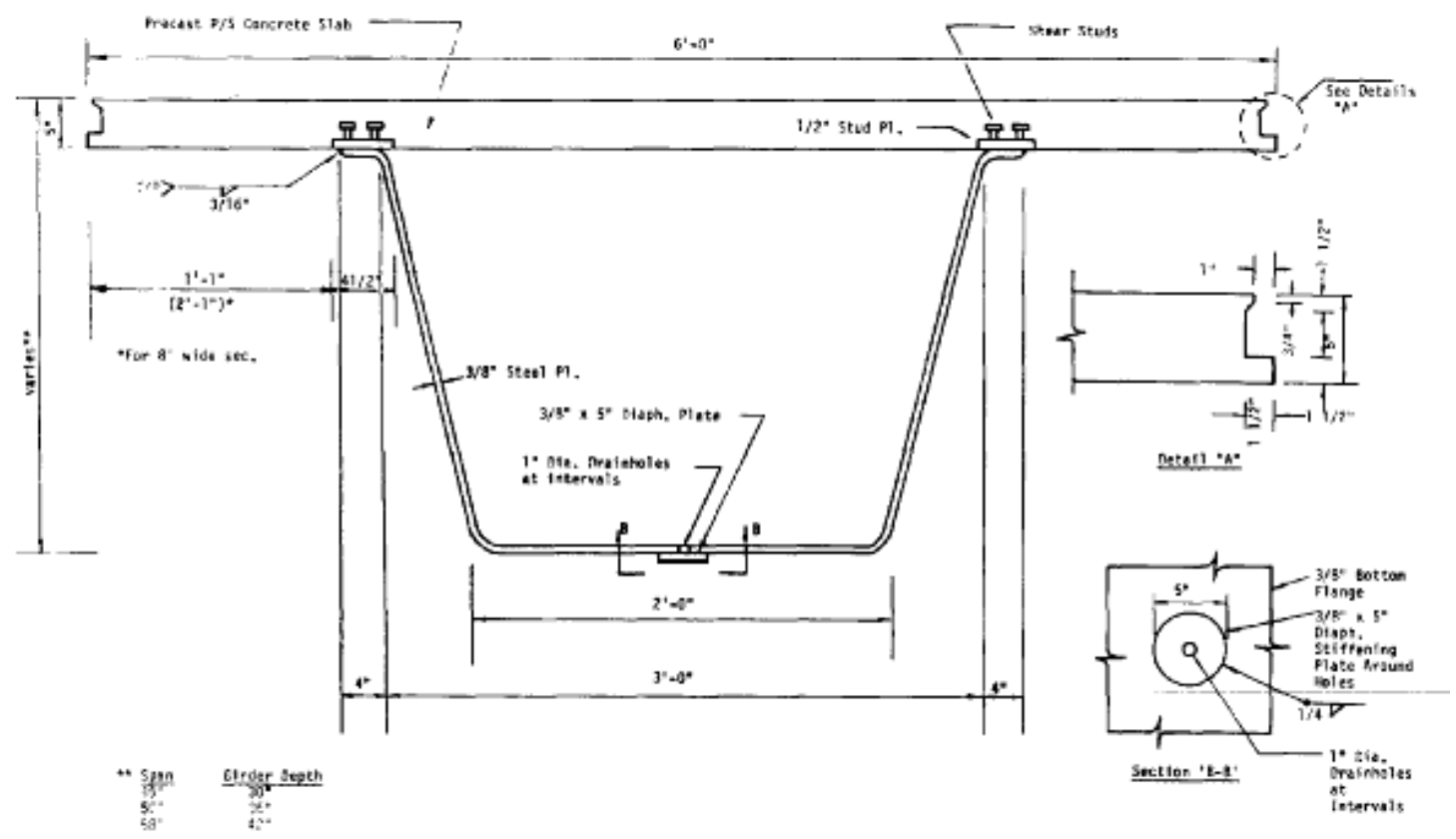

Figure 2.1: Press-Formed Composite Box Girder by Gangarao and Taly (1979)

Both design options are fabricated in the shop and shipped to the construction site as a complete composite modular unit. Prefabrication allows for decreased field labor and rapid construction. The lightweight design of the system allows for ease of transportation and overall ease of constructability. The tub girder with the concrete-steel composite deck design was found to be feasible for spans of 40 to 100 feet. In contrast, the orthotropic design option has a maximum span length of 65 feet. Taly \& Gangarao (1979) found that the closed shape of the composite tub girders provides increased torsional stiffness compared to an I-beam. 


\subsubsection{Buckling Behavior of U-Shaped Girders - University of Texas, Austin}

Gilchrist, Yura, and Frank (1997) conducted a series of experimental tests to study the buckling behavior of unbraced conventional tub girders and the effects of various bracing configurations. The test setup consisted of a simply supported $40 \mathrm{ft}$. girder with supports located $6 \mathrm{ft}$. from the girder ends, providing $6 \mathrm{ft}$. overhangs on each end and a $28 \mathrm{ft}$. center span. The specimens were loaded at the ends to achieve a uniform bending moment region between support locations. Load was applied to the bottom flange of the specimen 4.5 inches from each end of the girder.

Permanent cross frames were installed at the support locations and the ends of the girder to prevent lateral movement of the top flanges at these locations. K-brace frames were added at the locations of concentrated load to prevent lateral movement of the top flanges and web crippling at these locations. Two exterior frames were constructed to limit lateral deflection of the top flanges during testing. In order to perform multiple tests on the same specimen, the girder was designed to buckle elastically with and without bracing. The girders were fabricated using $50 \mathrm{ksi}$ steel for the flanges, and $36 \mathrm{ksi}$ steel for the webs. Figure 2.2 shows the crosssectional properties of the proposed conventional tub girder system. 


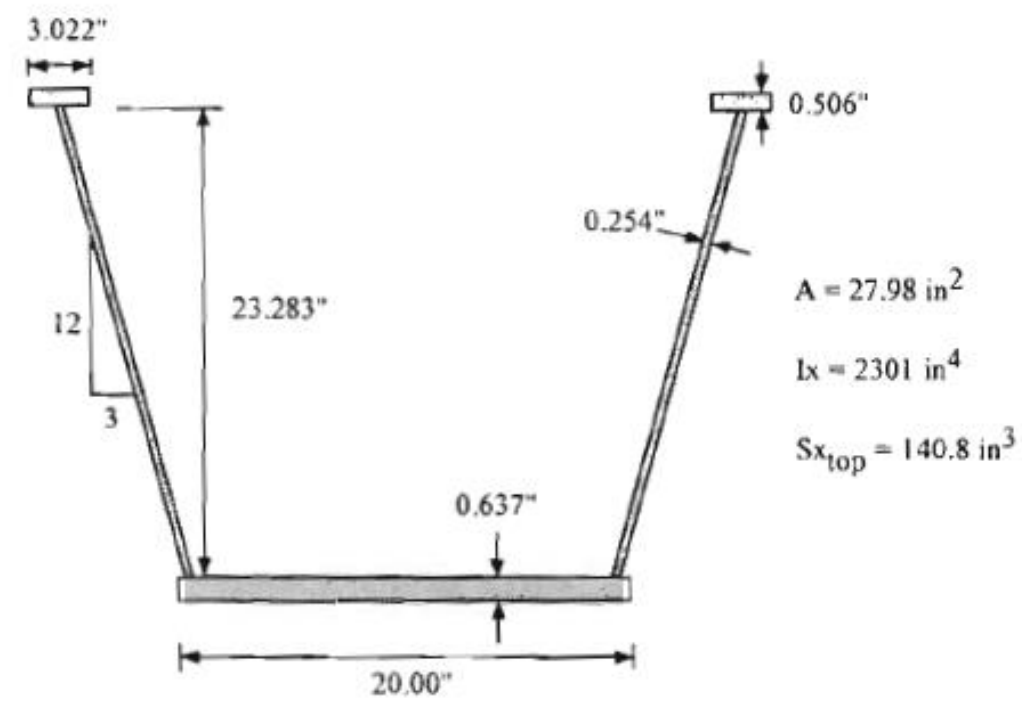

Figure 2.2: Cross-Section Properties (Gilchrist, Yura, and Frank, 1997)

The first trapezoidal girder test (T1) included the unbraced girder with a uniform moment applied between the supports. Prior to testing, a 0.53 inch initial imperfection over the $28 \mathrm{ft}$. center span was measured in the west flange. After loading, lateral displacement of the top flanges was apparent toward the west side. It was found that the initial imperfections of the west flange increased as the load was applied, resulting in $2^{\text {nd }}$ order displacements. The maximum applied end moment was $212.25 \mathrm{ft}$-kips, resulting in a buckling load of $283.58 \mathrm{ft}-\mathrm{kips}$. The second trapezoidal girder test (T2) featured 2 in. $\times 2$ in. $x 21 / 8$ in. angles to brace the north and south quarter-points. The average buckling load was found to be $385 \mathrm{ft}-\mathrm{kips}$, approximately $35.7 \%$ higher than the unbraced case.

Analytical results from the Southwell Method and finite element analysis indicated the behavior of U-shaped girders can be approximated as two "half-girders" with continuous torsional bracing and bottom flange lateral restraint. It was found that the buckling capacity of a U-shaped girder can be severely limited by distortion of the web; transverse stiffeners can be 
used to increase the capacity by as much as $100 \%$. The stiffness of the torsional brace was found to depend on the thickness and width of the bottom flange; this was found to cause a nonlinear increase in buckling capacity and switch to higher buckling modes as stiffness increases. Therefore, it is likely that the first buckling mode for U-shaped girders is multi-wave shaped shown in Figure 2.3.

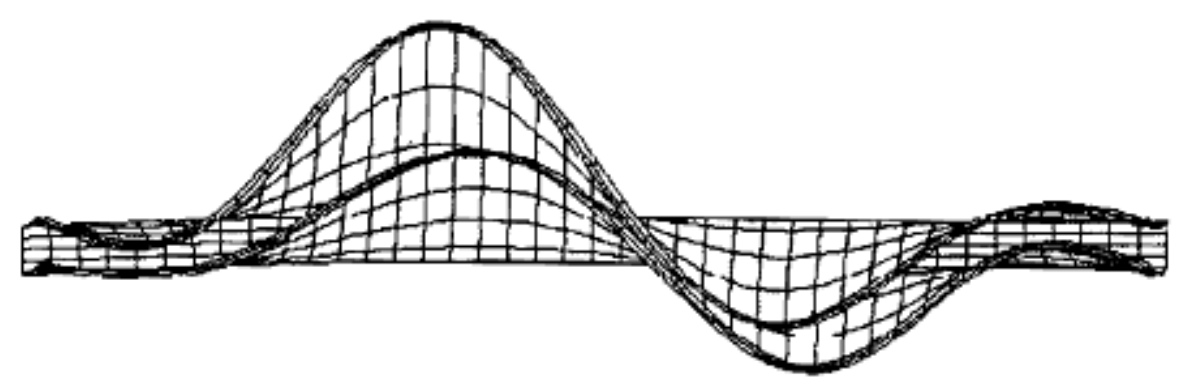

Figure 2.3: Buckled Shape for a Trapezoidal U-Girder (Gilchrist, Yura, and Frank, 1997)

Experimental results showed that any web stiffness greatly increases the buckling capacity, and web imperfections can cause a discrepancy between finite element analyses and laboratory tests. Experimental buckling loads exceeded the eigenvalue buckling load obtained with FEA by $20 \%$. A series of large displacement finite element analysis simulating the laboratory tests indicated that initial imperfections in the top flanges have minimal effect on the buckling load, and U-shaped girders have post-buckling strength at higher lateral displacements.

\subsubsection{Southwell Method}

Southwell (1932) proved that it is possible to predict the buckling load of an initially imperfect column without testing it to failure. The Southwell Method uses the relationship between load and lateral deflection to predict the buckling loads of imperfect members. The initial shape of the column is represented as a half-sine wave with an initial mid-span 
imperfection of $\Delta_{\mathrm{o}}$. The load-deflection relationship for a column is approximated in Eq. 2.1

(Timoshenko, 1961).

$$
\Delta=\frac{P}{P_{E}}\left[\frac{\Delta_{o}}{1-\frac{P}{P_{E}}}\right]
$$

Where $\Delta$ is the lateral deflection, $\mathrm{P}_{\mathrm{E}}$ is the Euler buckling load, and $\mathrm{P}$ is the axial load applied to the column. Southwell rearranged Eq. 2.1 into the form of Eq. 2.2 and considered $\Delta / \mathrm{P}$ and $\Delta$ as variables. Eq. 2.2 was then used to form the Southwell plot shown in Figure 2.4.

$$
\Delta_{o}=\frac{\Delta}{P} P_{E}-\Delta
$$

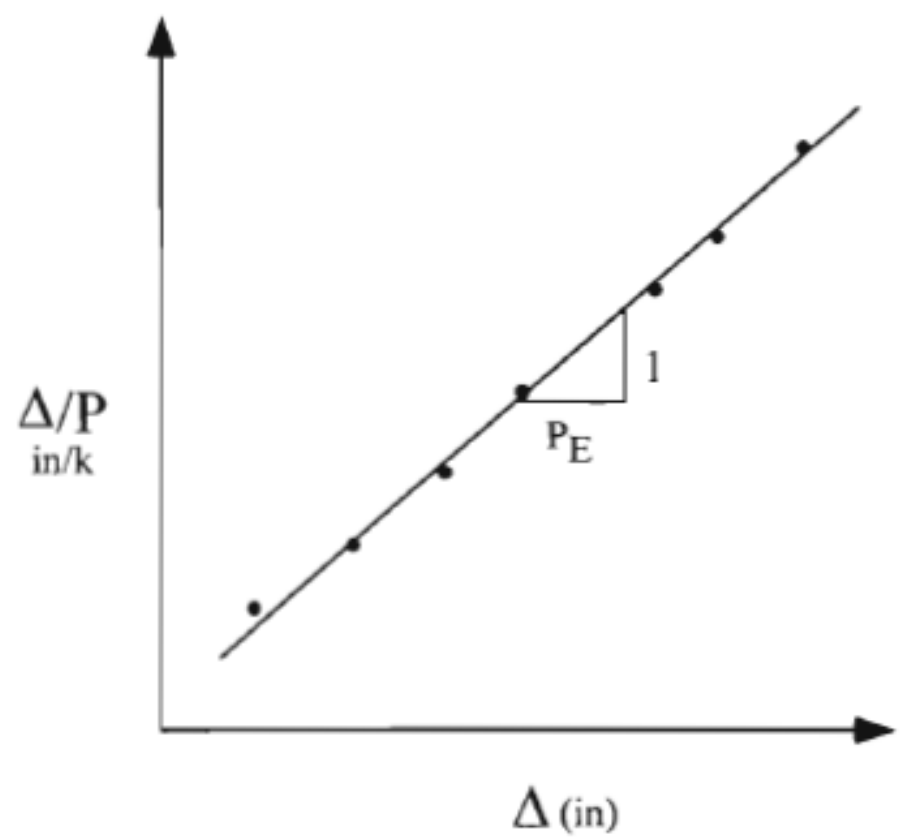

Figure 2.4: Southwell Plot (Gilchrist, Yura, and Frank, 1997)

The plot gives a straight line representation for load-deflection data points within the elastic range. The buckling load can be determined by taking the inverse of the lines slope. This method can predict the buckling load within approximately $2 \%$ depending on the magnitude 
of the experimental load. This method is valid for any buckling problem with a hyperbolic loaddeflection response similar to Eq. 2.1. For the U-girder tests, moment was used as a measure of load in Eq. 2.1 since it is proportional to the in-plane stress in the top flange of the girder (Gilchrist, Yura, and Frank, 1997).

\subsubsection{Top Lateral Bracing of U-Shaped Girders- University of Texas, Austin}

Chen, Yura, and Frank (2002) researched the performance of metal deck bracing systems on U-shaped girders and their effects on torsional stiffness. This research was a continuation of the research conducted by Gilchrist, Yura, and Frank (1997) and includes the same test setup mentioned in Section 2.2.2. The purpose of these tests were to examine whether the use of metal decking as a top lateral bracing system would provide similar bending strength as the Xbrace system.

The same girder configuration and cross-section properties discussed in Section 2.2.2 were used. The metal decking used was a Vulcraft 2 VLI20 form with 2 in. rib heights and oriented perpendicular to the length of the girder. The metal deck panels were attached to the inside lips of the top flanges using powder-actuated fasteners. Four tests were conducted with different metal deck configurations. The first test, TD-U, was an unbraced test having no deck panels. Test two, TD-1, consisted of four deck panels. The third test, TD-2, consisted of six deck panels. The last test, TD-3, consisted of eight deck panels. All of these tests were confined to the elastic range and are shown in Figure 2.5. 


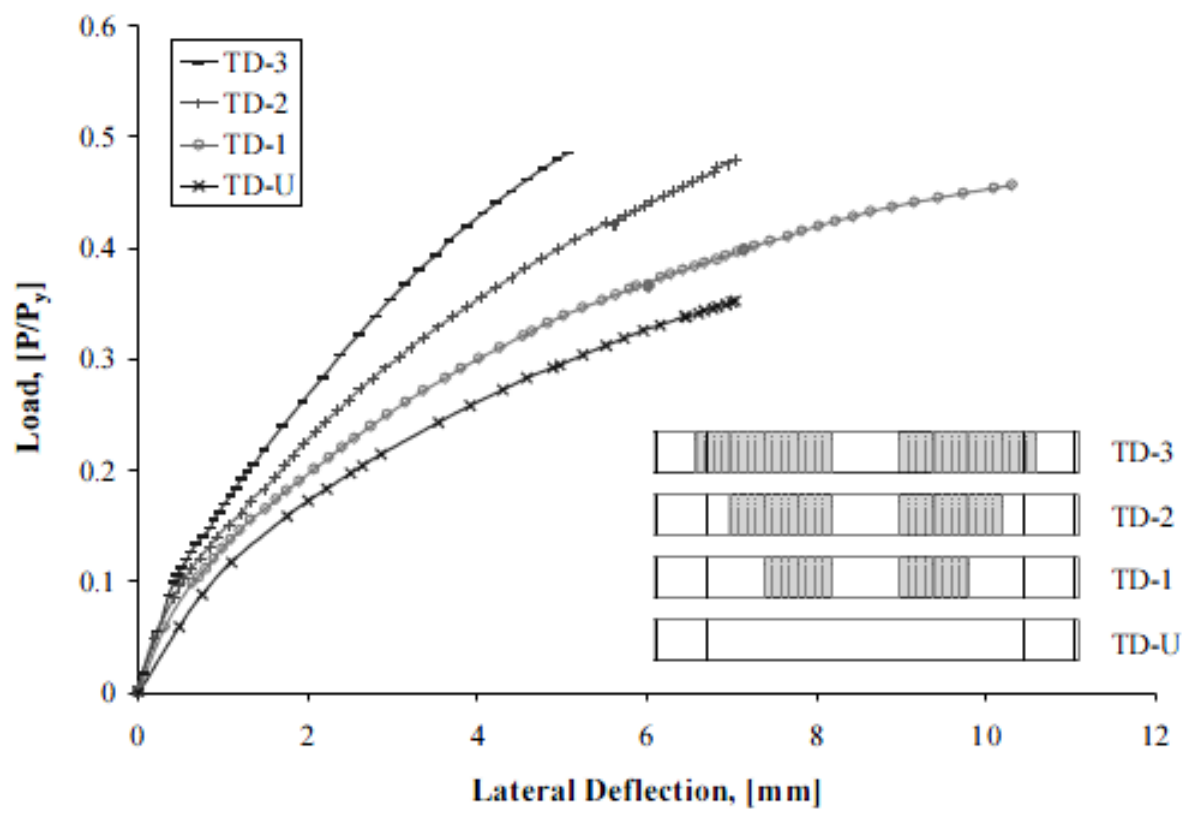

Figure 2.5: Metal Deck Tests (Chen, Yura, and Frank, 2002)

The researchers found that at a given load, the lateral deflections decreased as the number of deck panels increased. The decreased lateral deflections are indicative of increased girder stability and demonstrate increases in bending strength very similar to the X-brace system. It was found that metal decking does not have an effect on stiffness decreasing due to problems with shortening, which the X-bracing exhibited. Although an ulimate capacity test was not run due to time constraints, the metal deck bracing system was shown to perform better or equal to the welded X-brace system. The overall results of this study showed promising potential in using metal decking as a top lateral bracing system for U-shaped girders. 


\subsubsection{Experimental Work of S. Nakamura (2002) - Tokai University, Japan}

Nakamura (2002) proposed a concrete-steel composite bridge using a press-brake to cold form steel U-shaped sections, shown in Figure 2.6. This girder specimen is one of three to be used in the proposed bridge system illustrated in Figure 2.7. This bridge system consists of girder $\mathrm{U} 1$ in the center and girders $\mathrm{U} 2$ and $\mathrm{U} 3$ at intermediate supports. The composite center span girder (U1) is in the positive bending moment area and left hollow. The girder specimens (U2) and (U3) are in negative bending areas at the intermediate supports. Girder U2 was filled with concrete, connected to the reinforced concrete slab with shear studs, and pre-stressed by two pre-stressed steel reinforcing (PC) bars to increase the strength against bottom flange buckling. Girder U3 was also filled with concrete to increase bending strength, but was not pre-stressed.

Experimental bending tests were carried out to investigate the individual behavior of each girder specimen. The strains of U1 measured on the lower flange (B1), web bottom (B2), web top (B3), and upper flange (B4), upper surface of reinforced concrete slab (K3), and reinforcing bars (J5) are shown in Figure 2.8. After yielding, the strains of the lower flange and bottom web became plastic and increased sharply. The slab concrete smoothly transferred from the elastic to plastic state and collapsed at 3,200 $\mu$. These results showed that the girder (U1) behaved as a composite beam at the center of the span. The strains of U2 measured on the lower flange (B1), web center (M3), web top (B3), and PC bar (C2), concrete slab (K3), and reinforcing bars (J5) are shown in Figure 2.9. Nakamura (2002) found that the proposed design has sufficient bending strength and stiffness capacity. In addition, it was concluded through a feasibly analysis there is a 20-30\% construction cost savings when compared to conventional plate girders. 


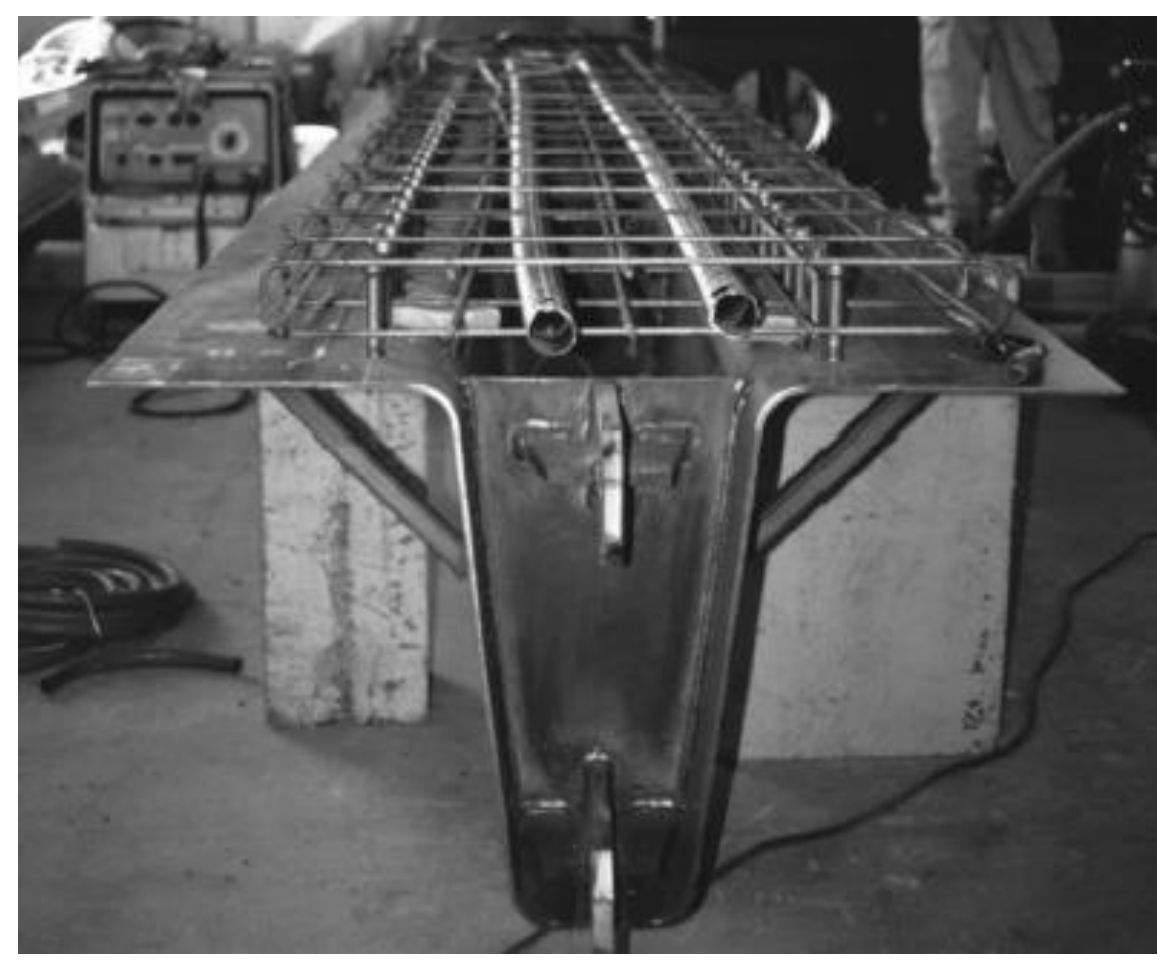

Figure 2.6: Press-Brake-Formed Specimen Proposed by (Nakamura, 2002)

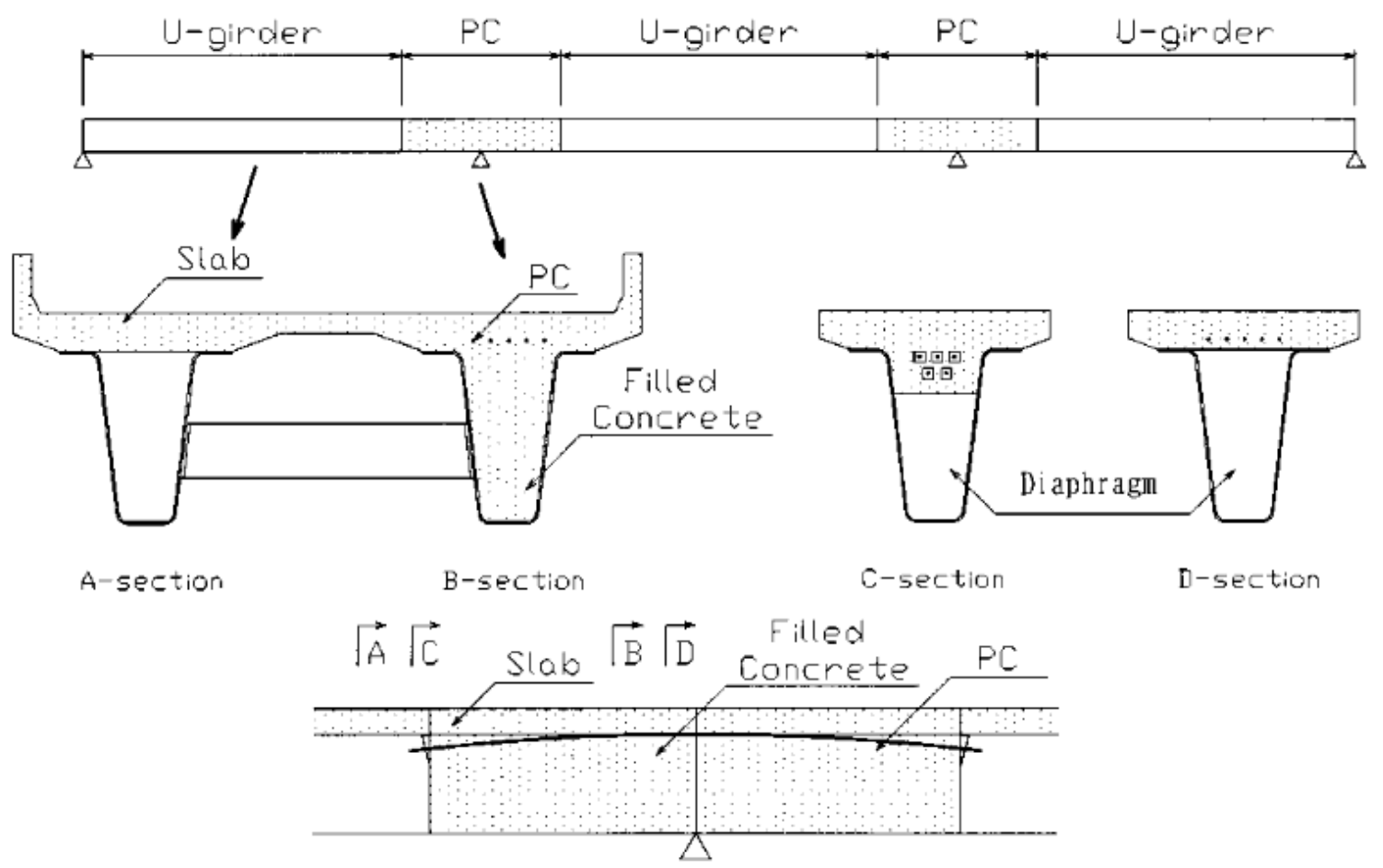

Figure 2.7: Three Span Bridge System Proposed by (Nakamura, 2002) 

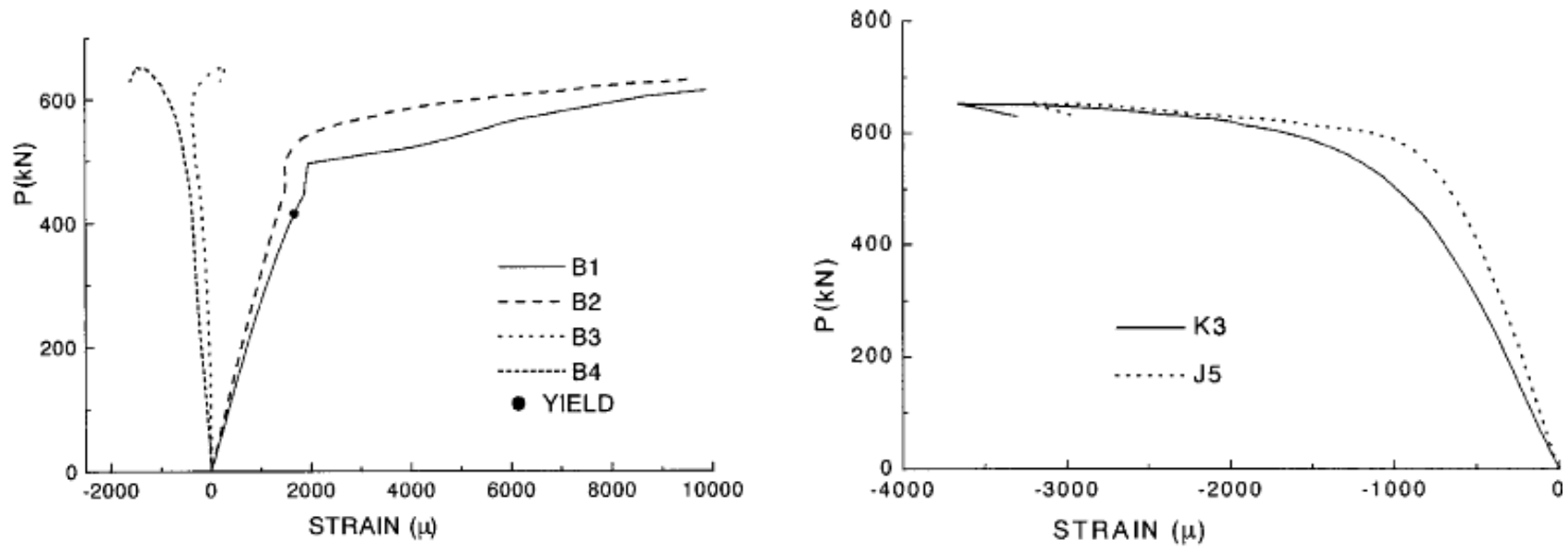

Figure 2.8: Strains with Applied Load for U1 (Nakamura, 2002)
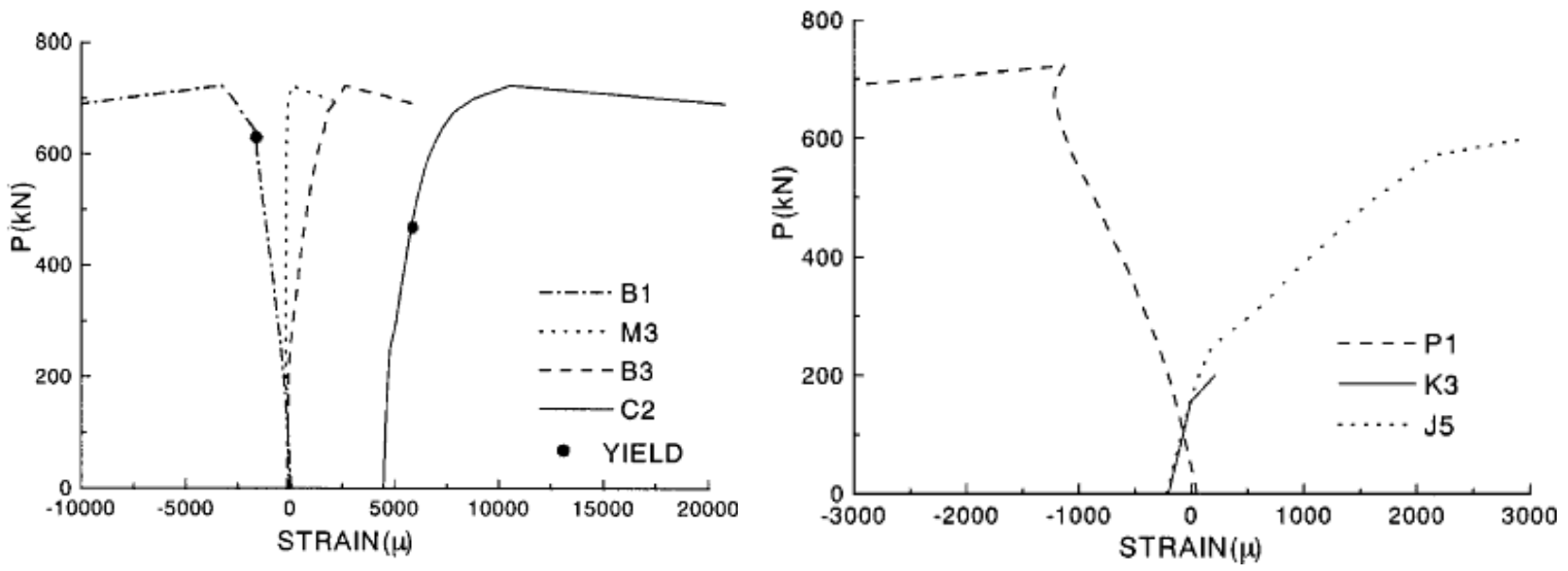

Figure 2.9: Strains with Applied Load for U2 (Nakamura, 2002) 
2.2.5 Top Lateral Bracing For Trapezoidal Steel Box Girder Bridges - University of Texas, Austin

Chen, Williamson, Yura, and Frank (2005) conducted a series of laboratory and field tests on full-scale conventional trapezoidal steel box-girders during construction. The objective of these tests was to evaluate the potential use of permanent metal deck forms as a lateral-bracing system, verify the accuracy of finite element models, and obtain experimental data on a bridge structure with real-world boundary conditions.

The field test consisted of curved twin trapezoidal steel tub girders of Interstate Highway 35 (IH-35) and Highway US 290 bridge interchange in Austin, Texas. The test specimens were assembled in a fabrication shop and field-bolted together once in place. Single-diagonal toplateral bracing elements were used throughout the girder span with internal "K" diaphragms at panel points. External diaphragms were placed between the twin girders at every other panel point.

Permanent metal-deck forms (2.5 in. deep 16-gauge galvanized steel) were fastened to the top flanges with powder-actuated fasteners. Two tests were performed: a tub girder with diaphragm bracing and a tub girder with attached permanent metal deck forms on top of the diaphragm bracing. A crane was used to apply the concentrated load incrementally to the top flanges of one girder. Figure 2.10 shows the location of the applied load and bracing configuration for the second test. 


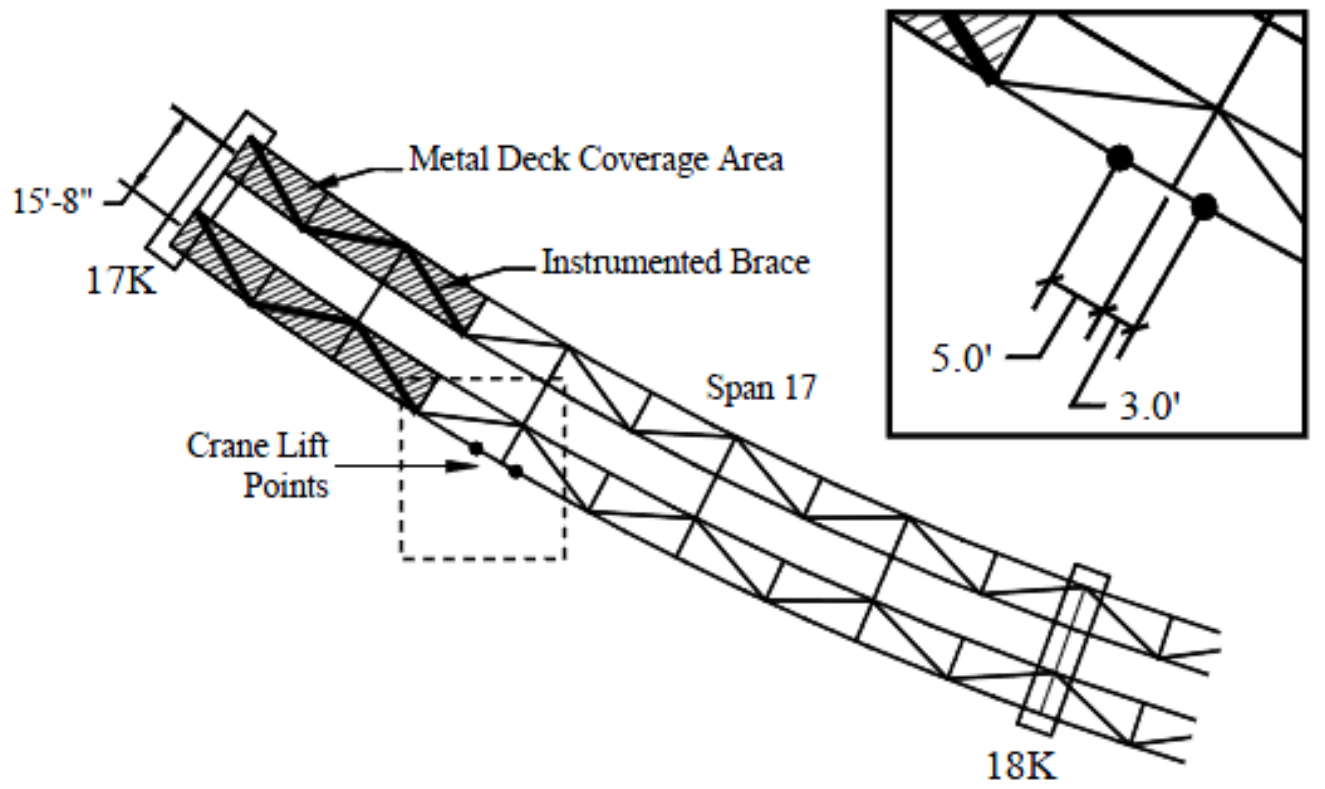

Figure 2.10: Location of Applied Load and Bracing Configuration (Chen, Williamson, Yura, and Frank, 2005)

Finite element analysis using equivalent-plate approximation and the Steel Deck Institute (SDI) reported shear stiffness values of the deck panels reasonably verified the top-lateral forces measured in the field test. The use of metal deck forms significantly decreased top-lateral brace forces, proving its effectiveness as a bracing system.

To further study the effectiveness of permanent metal deck forms as a bracing option, laboratory tests were conducted. Pure torsion and bending laboratory tests were performed on a straight trapezoidal steel box-girder $54 \mathrm{ft}$. long and 54 in. deep. The researchers found the permanent metal-deck forms used as lateral bracing produced significant torsional stiffness increases, ranging between 8 and 12 times that of the unbraced girder. In addition, when the metal-deck and truss system were combined the stiffness increased between 18 and 24 times the unbraced girder. 
In conclusion, the experimental and theoretical torsional stiffness's differed by $10 \%$ to $23 \%$. This was due to the sensitivity of the torsional stiffness to end support movements and displacement corrections made. Truss forces measured under bending loads were in reasonable agreement with expressions developed by Frank and Helwig (1999); small discrepancies were caused by the small magnitude of forces measured in the bending tests. Laboratory results indicated using equivalent flat-plate approximation to model the metal-deck bracing system was valid. The Steel Deck Institute Diaphragm Design Manual (SDI) effective shear stiffness values were used to determine the equivalent plate thickness. SDI Manual shear strength formulas were found to reasonably predict the response of the metal-deck bracing system.

\subsubsection{Texas Prefabricated Steel Tub-Girder System - University of Texas, Austin}

A similar concept to the prefabricated steel tub girder superstructures above, researchers at the University of Texas, Austin and the Texas Department of Transportation (TxDOT) proposed two box girder systems (Freeby, 2005). TxDOT desired a rapid construction option to upgrade and expand nearly 150 bridges along I-35 in central Texas. The two systems included: a steel tub-girder and a prestressed concrete pre-topped U-beam. Only the steel tub-girder is further discussed.

The proposed steel-tub girder system consists of a conventional prefabricated trapezoidal steel girder supporting a cast-in-place concrete deck. To keep the unit composite for all loads and achieve a shallow depth, the beams are shored during concrete deck placement. Multiple girders can be joined with cast in place closure pours for wider bridge options. Figure 2.11 shows a proposed girder design for a 115 foot span, 29.5 inch deep and 8.5 inch slab thickness. 


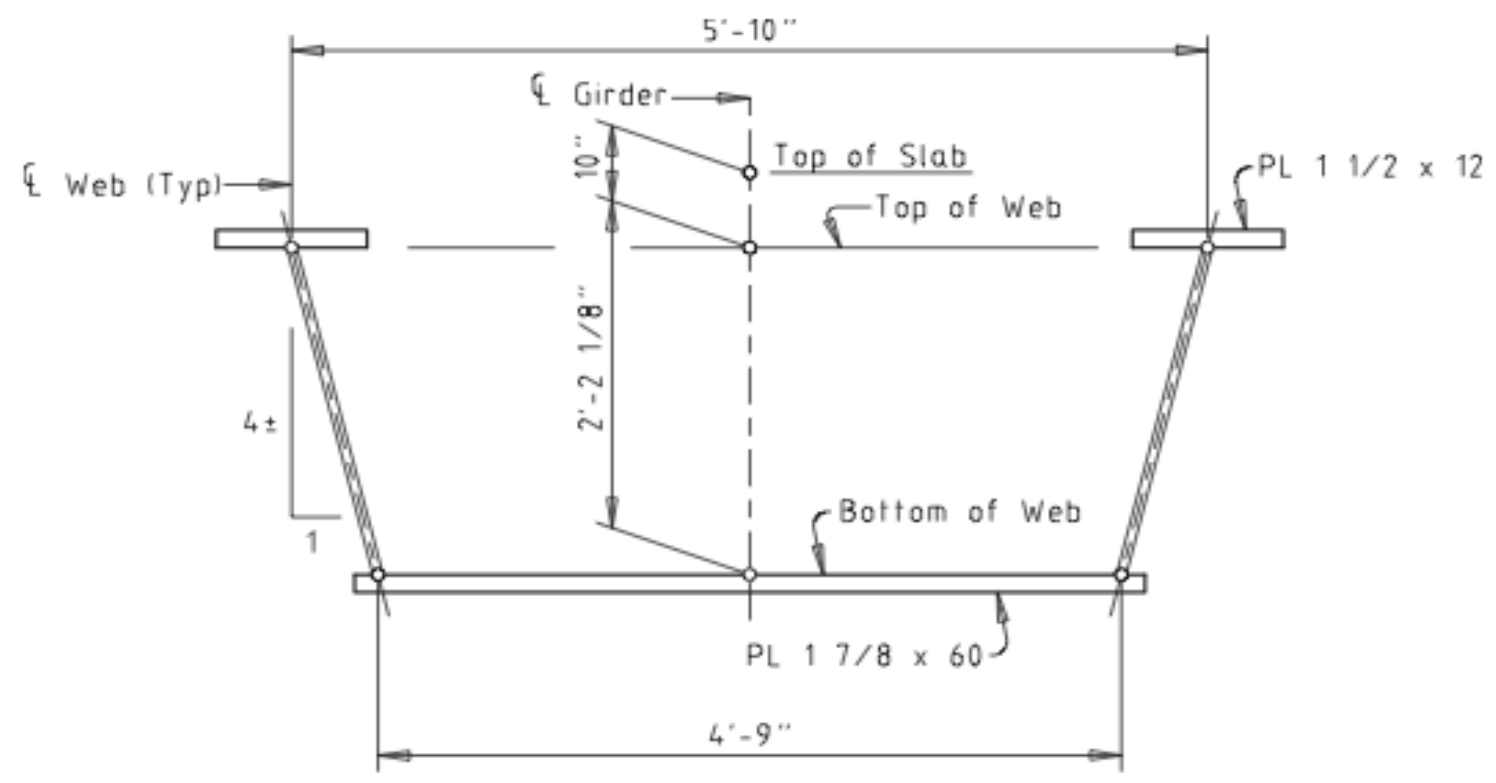

Figure 2.11: Conventional Trapezoidal Steel Tub Girder by (Freeby, 2005)

The steel tub girder is formed from welded steel plates, opposed to the bent steel plate; this gives the advantage of variable widths for the webs and flanges, but comes at the expense of requiring costly welds (Burgueño and Pavlich, 2008). The tub girder and U-beam were developed for maximum span lengths of 115 feet and total depth of 38 inches. Both were found to be a rapid construction option. Due to the high cost of the conventional tub-girder fabrication, the U-beam design outbid the tub-girder option in this particular project.

In 2010, TxDOT proposed a conventionally fabricated steel tub girder bridge system to expand a four-lane I-35 bridge into a six lane bridge. The system used shallow trapezoidal girders for a rapid bridge replacement project. The bridge design consisted of six tub girders next to one another supporting a cast-in-place concrete deck. Shallow trapezoidal steel box girders were found to provide a highly constructible, lightweight, and efficient structure (Chandar et. al., 2010). 


\subsubsection{Short Span Steel Bridge: Inverted Steel Box System - University of Nebraska, Lincoln}

The University of Nebraska system is an inverted folded plate girder having the bottom flanges bent inward (Glaser, 2010). The reason for inverting the steel tub-girder section is to provide easy maintenance and inspection. The girder is cold bent from a single Grade 65 steel plate instead of welded, minimizing fabrication costs. Both composite and non-composite tests were performed. For the purposes of this thesis, only the non-composite test will be reviewed. For the non-composite specimen, bearing and stiffener plates are added to the girder ends to eliminate local deformation. Then, tie plates are bolted to the bottom flanges at a distance of 5 and 10 feet from the center line to control flange separation. Figure 2.12 shows a cross section with a bolted tie plate in place. Testing confirmed that tie plates are both necessary and effective for preventing flange separation at construction load levels and rotation at higher load levels, which cause deformation and buckling in the girder (Glaser, 2010). No undesirable deformations at construction loads were noticed and both specimens displayed stability and ductility through all stages of testing.

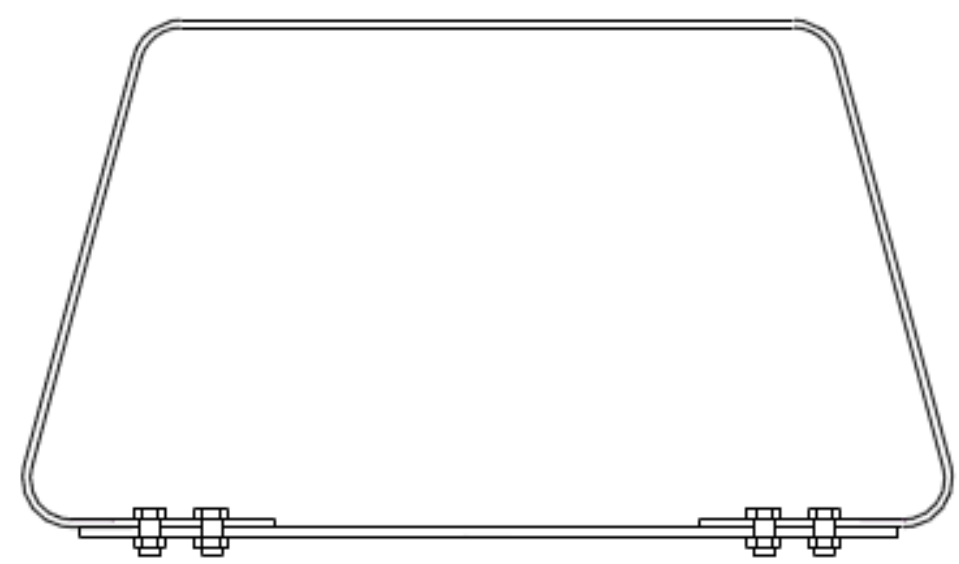

Figure 2.12: Cross Section of Non-Composite Specimen (Glaser, 2010) 


\subsubsection{Conclusion}

Over many years, researchers have sought to prove the efficiency and constructability of steel tub-girder bridge systems for short span bridge applications. However, due to complex fabrication details and lack of stability testing there was minimal industry support to pursue this concept as a viable bridge design. Employing the concept of using press-brake-formed tub girders proves to simplify fabrication details and allow for a more efficient design. Although, previous studies show the need for top-flange lateral bracing to improve the stability of noncomposite tub girders during fabrication, transportation, erection, and deck placement. 


\subsection{TYPES OF BRACING}

In order to improve the stability of non-composite tub girders, the behavior of different bracing options needs to be understood. There are three typical types of bracing systems: top flange lateral bracing, interior diaphragms, and external intermediate cross-frames. Bracing systems that are used to increase the stability of structural systems can be divided into four categories shown in Figure 2.13 (Helwig \& Yura, 2012). In this section, various bracing options for trapezoidal steel tub girders are discussed.

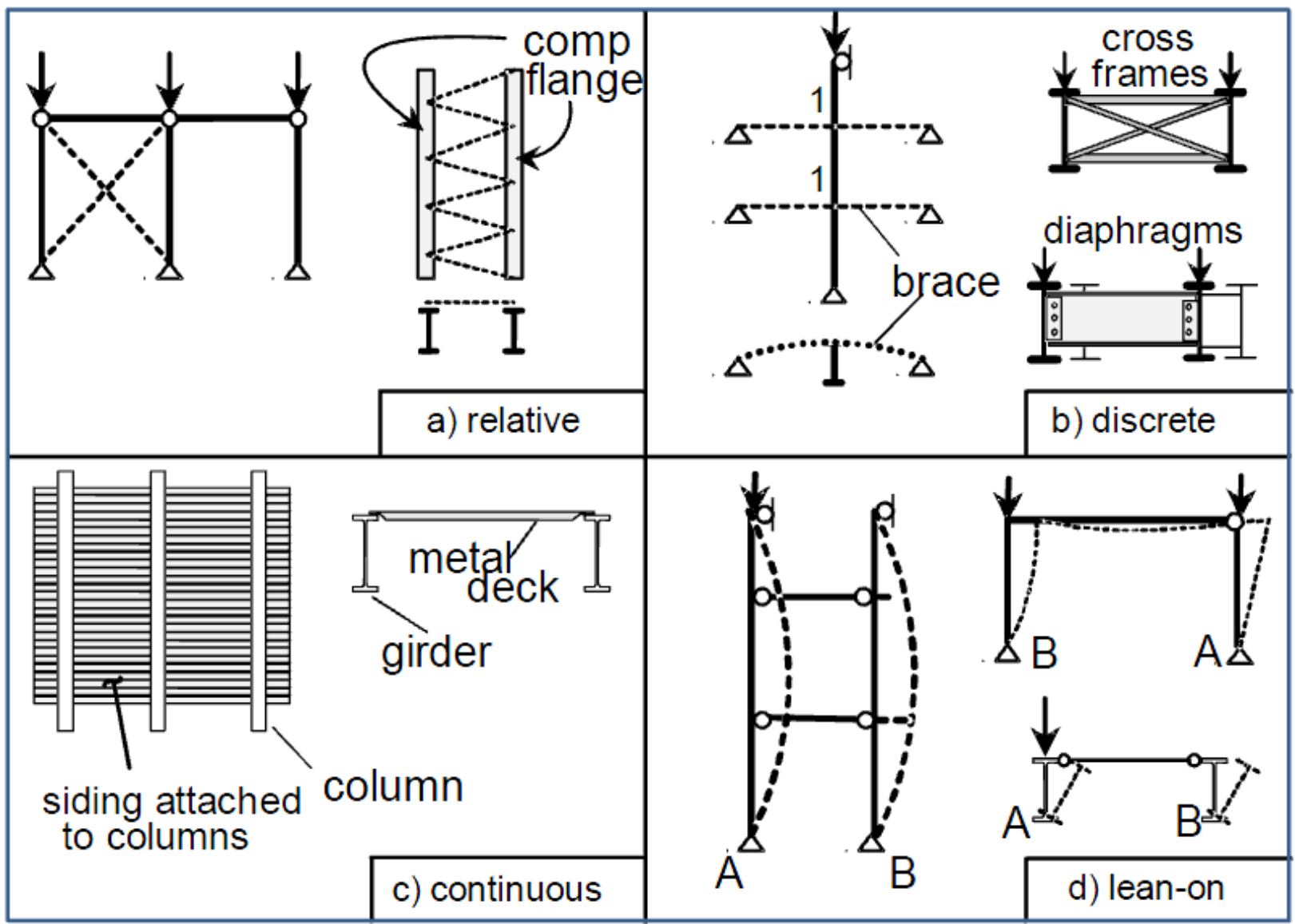

Figure 2.13 Categories of Bracing (Helwig and Yura, 2012) 


\subsubsection{Top Flange Lateral Bracing}

A common type of bracing used in U-shaped girders is a top flange lateral bracing system. Top flange lateral bracing typically consists of a horizontal truss system or stay in place (SIP) metal formwork attached to the top flanges running the entire length of the girder, shown in Figure 2.14 and 2.15, respectively. This type of bracing system is designed to achieve the following objectives: top flange lateral buckling control, increased torsional stiffness and strength, global lateral buckling control, and support of the sloping webs. Tying together the top flanges forms a closed section creating a shear flow path around the cross-section, which substantially increases the torsional stiffness.

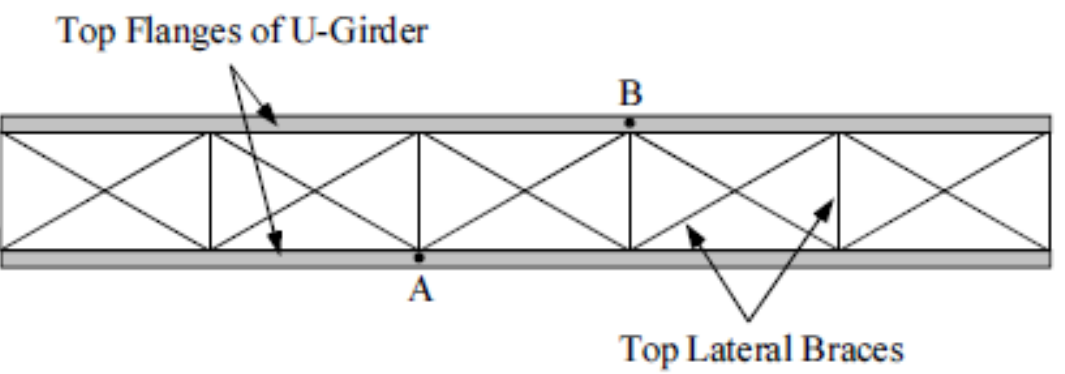

Figure 2.14: Lateral X-Brace (Chen, Yura, and Frank, 2002)

Figure 2.14 shows a lateral X-brace system having brace points A and B, in which lateral bracing resists lateral movement of these points by forcing the top flanges to buckle between brace points while loaded. Diagonal bracing is considered to be relative bracing since the braces control the relative movement of adjacent points along a member. SIP metal formwork consists of very close connection points preventing compression flange lateral buckling therefore; it is considered to be continuous bracing. 


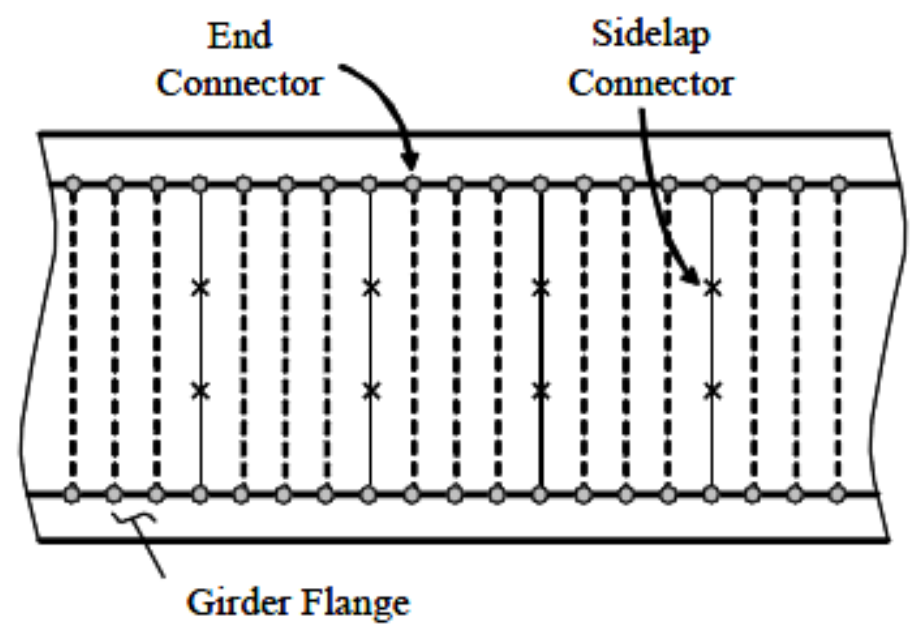

Figure 2.15: Layout of SIP Metal Deck Form (Chen, Yura, and Frank, 2002)

\subsubsection{Interior Diaphragm Bracing}

Another type of bracing system for tub girders is interior diaphragms. The primary objective of diaphragms is to control lateral buckling of the top flanges and warping stresses, preventing tub girder distortion. Some common diaphragm option include: K-, X-, or Z- frames. Solid plates are also common interior diaphragms, and are often used at support locations. Transverse web stiffeners are also used to increase lateral bending stiffness. Interior diaphragm bracing, or nodal bracing, falls into the discrete category by controlling the deformation of a single point on the member. Figure 2.16 shows an example of multiple diaphragm bracing geometries.

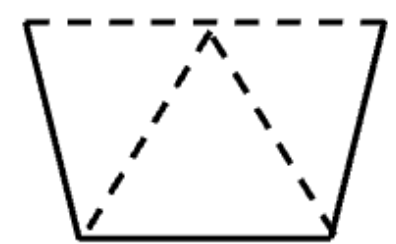

K-Frame

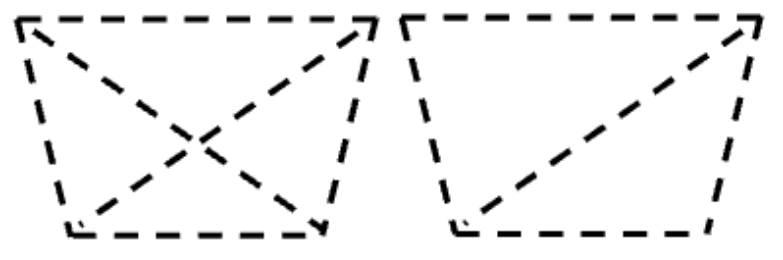

X-Frame

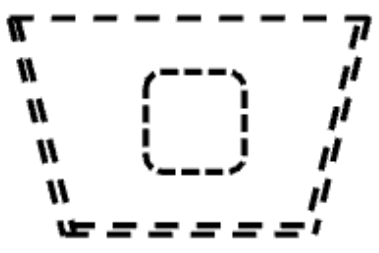

Plate

Figure 2.16 Interior Diaphragm Bracing Layouts for Tub Girders (Helwig and Yura, 2012) 


\subsubsection{Intermediate External Bracing}

Intermediate external diaphragms are used to control girder rotation and deformation between adjacent curved girders during the construction phase. Tying the girders together allows them to act as one unit, instead of two independently moving units. Box girders that are tied together have greater stiffness and strength than separate girders with no interaction (Memberg, Yura, Williamson, and Frank, 2002). Once the concrete deck hardens, the external bracing can be removed in most cases. Figure 2.17 shows a schematic of a twin tub-girder cross-section utilizing a temporary external cross frame.

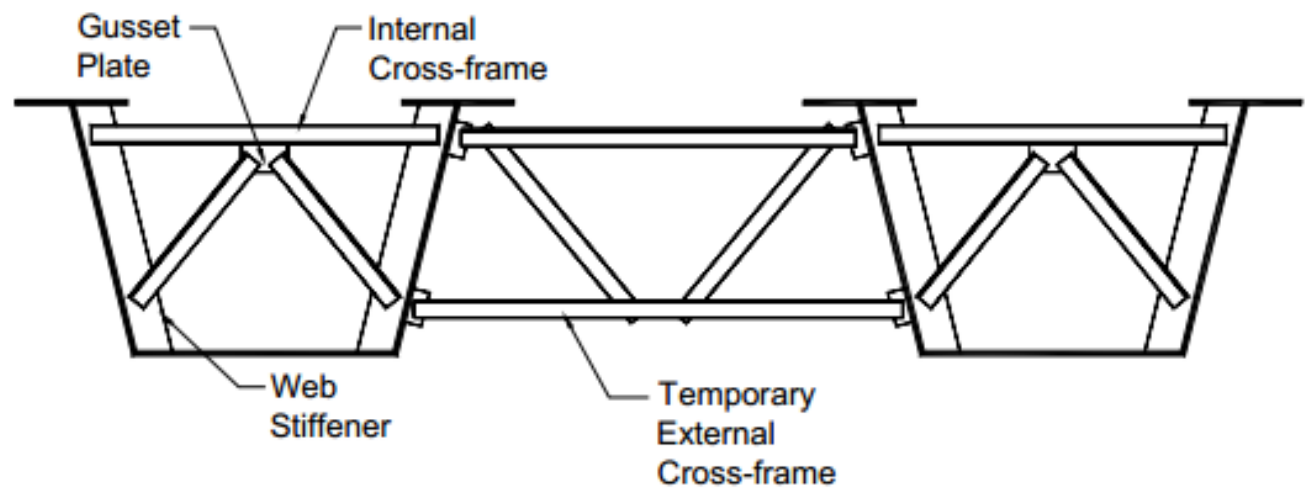

Figure 2.17 External Cross Frames (Cheplak, 2001)

\subsubsection{Conclusion}

The use of stay-in-place metal formwork, opposed to conventional diaphragm and crossframe bracing, is a more recent lateral bracing option. Conventional bracing consists of welding and bolting multiple steel components together, greatly complicating fabrication and erection of tub girders. This complication leads to increased construction cost and time. In addition, the bracing locations of conventional systems are prone to long-term fatigue problems. Therefore, to simplify the fabrication and construction of the cold-formed tub girders in this research, SIP metal formwork was selected as the lateral bracing system. 


\subsection{STABILITY OF NON-COMPOSITE COLD-FORMEd STEEl TUb GIRdERS}

Composite tub girders with a hardened concrete deck form a closed-section and provide an efficient cross section for resisting torsion. Prior to the composite action formed, tub girders act as open, thin-walled sections. This torsional flexibility makes the tub girder susceptible to torsional buckling or torsional deflection problems. Lateral torsional buckling consists of rotation of the cross-section and lateral displacement of the compression flanges. Understanding the stability of non-composite tub girders is crucial when utilizing cast-in-place decks. In this section, local and global buckling behavior of non-composite tub girders is reviewed.

\subsubsection{Buckling Analysis Of Cold-Formed Girders Using CUFSM}

CUFSM is a software program that utilizes finite strip method to analyze the crosssection stability of cold-formed steel members (Schaefer and Ádány, 2006). The local, distortional, and global buckling modes of a given cross section are determined by computing the governing eigenvalue through conventional finite strip method. The finite strip method discretizes a cross section into longitudinal strip elements.

For this study, three different plate thicknesses were evaluated (7/16", 1/2", and 5/8") and six different standard mill plate widths were evaluated (60", 72", 84", 96", 108", and 120") having respective depths of (12", 17", 23", 26", 30", and 34"). All tub girder configurations were assessed under flexural loading. Results showed that no local or distortional buckling modes govern the design for the girders evaluated. Therefore, only global lateral-torsional buckling modes need to be assessed. According to Michaelson (2014), the first order lateraltorsional buckling capacity of a press-brake-formed tub girder without lateral bracing is calculated using Eq. 2.3. 
$M_{o}=\frac{\pi^{2} E I_{y} \beta_{x}}{2 L^{2}}\left[1 \pm \sqrt{1+\frac{4}{\beta_{x}^{2}}\left(\frac{G J L^{2}}{\pi^{2} E I_{y}}+\frac{C_{w}}{I_{y}}\right)}\right]$

Eq. 2.3

Likewise, this moment is cause by a concentrated load at mid-span given in Eq. 2.4.

$P_{o}=\frac{4 M_{O}}{L}$

Eq. 2.4

Second-order effects due to load eccentricities or initial imperfections should also be considered. Therefore, the second-order lateral deflection that arises from an applied moment $M$ on a singly symmetric beam is (Michaelson, 2014):

$u(z)=A_{\phi o}(A F)\left(\frac{M_{o} L^{2}}{\pi^{2} E I_{y}}\right) \sin \left(\frac{\pi z}{L}\right)=\left(\frac{A_{\phi o}}{1-M_{M_{o}}}\right)\left(\frac{M_{o} L^{2}}{\pi^{2} E I_{y}}\right)\left(\frac{\pi z}{L}\right)$

Eq. 2.5

\subsubsection{Coefficient of Monosymmetry}

The monosymmetry constant, $\beta_{x}$, is used to calculate the buckling moment resistance of a laterally unsupported member loaded in the plane of symmerty. A monostmmetric member is symmetric about the vertical axis and the general formula is given by Eq. 2.6.

$$
\beta_{x}=\frac{1}{I_{x}} \int y\left(x^{2}+y^{2}\right) d A-2 Y_{o}
$$

Where $I_{x}$ is the moment of inertia about the $\mathrm{x}$-axis and $Y_{o}$ is the vertical distance from the shear center to the center-of-gravity. When the larger flange is in tesion $Y_{o}$ is a positve value. Integegration is performed over the entire cross section. Note that for doubly-symmetric sections the value of $\beta_{x}$ is zero. 


\subsubsection{Torsional Behavior of Thin-Walled Sections}

Cold-formed steel members are a thin, light, and efficient option for short-span steel bridge applications (Schafer and Ádány, 2006). However, the thin elements of an open crosssection are relatively weak against torsion. Torsional moments are resisted by shear stresses along the girder cross section. Without a closed shear flow path the member lacks the torsional rigidity to remain plane when loaded. Torsion is considered to be uniform or non-uniform dependent on the cross-section presence of warping. In this section, pure torsion, warping torsion, and coefficient of monosymmetry relating to press-brake formed steel tub girders are discussed. The torsional properties are determined by considering the section is made up of straight thin-walled plate elements. The following equations are derived using provisions mentioned by Galambos (1968) and Ziemian (2010). For more a detailed derivation, the reader is referred to (Michaelson, 2014).

\subsubsection{Pure Torsion}

Pure torsion is considered uniform since the stiffness resistance (also known as Saint Venant Stiffness) does not vary along the length of the member. During loading, pure torsion results in pure shear deformation in the plane of the cross-section. The basic governing equation to compute pure torsion for an elastic member is given by Eq. 2.7 (Basler and Kollbrunner, 1969).

$T=G J \phi^{\prime}$

Eq. 2.7

Where $G$ is the shear modulus, $J$ is the St. Venant torsional constant, and $\phi^{\prime}$ is the twisting angle per unit length of the member. The St. Venant torsional constant $J$ measures the resistance of a member to pure torsion. Below are simplified equations for open and closed sections (Boresi and Schmidt, 2003). 


$$
\begin{aligned}
& J_{\text {open }}=\frac{1}{3} \sum_{i=1}^{n} b_{i} t_{i}{ }^{3} \\
& J_{\text {closed }}=\frac{4 A_{o}^{2} t}{U}
\end{aligned}
$$

Where $b_{i}$ and $t_{i}$ are the individual plate lengths and thicknesses. For closed shapes $A_{o}$ and $U$ refer to the area enclosed by the shape and the median circumference of the enclosure. The solution for torsional twist $\phi$ for a simply supported member loaded at midspan can be derived from Eq. 2.7 and is shown below:

$$
\phi=\frac{T L}{4 G J}
$$

To demonstrate the increased torsional stiffnesss with the use of SIP formwork a summarized example is illistrated below (Michaelson, 2014). In this example the applied torque is equal to 108 in-kips to estimate finishing machine loads (NSBA, 2012), length of the member is $456 \mathrm{in}$., shear modulus is $11154 \mathrm{ksi}$, torsional constant for the open section is $2.3447 \mathrm{in}^{4}$, and the torsional constant for the closed section is $6900.0 \mathrm{in}^{4}$.

$$
\begin{aligned}
& \phi_{\text {open }}=\frac{T L}{4 G J_{\text {open }}}=\frac{(108 \mathrm{in}-\mathrm{kip})(456 \mathrm{in})}{4(11154 \mathrm{ksi})\left(2.3447 \mathrm{in}^{4}\right)}=0.47077 \text { radians }=26.97^{\circ} \\
& \phi_{\text {closed }}=\frac{T L}{4 G_{\text {closed }}}=\frac{(108 \mathrm{in}-\mathrm{kip})(456 \mathrm{in})}{4(11154 \mathrm{ksi})\left(6900.0 \mathrm{in}^{4}\right)}=0.00016 \text { radians }=0.0092^{\circ}
\end{aligned}
$$


As expected, the small torsional resistance of the open section causes an angle of twist drastically larger than the closed section. Therefore, the performance of the non-composite girder under torsional loads associated with deck casting would greatly improve with the use of stay-in-place formwork.

\subsubsection{Warping Torsion}

Warping torsion is referred to as non-uniform torsion since the stiffness is associated with the bending deformation of the individual elements. Warping deformations cause out of plane distortion of the cross-section and longitudinal stresses developement in the flanges. The basic governing equation for an elastic member subjected to warping torsion is given in Eq. 2.11 (Basler and Kollbrunner, 1969).

$$
T=-E C_{w} \phi^{\prime \prime \prime}
$$

Where $E$ is the modulus of elasticity and $C_{w}$ is the warping constant. The warping constant measures the resistance of a structural member to warping torsion and is expressed as:

$$
C_{w}=\sum_{i=1}^{n} \frac{A_{i}}{3}\left(\omega_{n i}^{2}+\omega_{n i} \omega_{n(i+1)}+\omega_{n(i+1)^{2}}\right)
$$

In this equation, $\omega_{n}$ is the normalized unit warping (Eq. 2.13-2.14) and $A_{i}$ is the crosssectional area of a given segment.

$$
\begin{aligned}
& \omega_{n i}=\sum_{i=1}^{n} \frac{A_{i}}{2 A}\left(\omega_{o i}+\omega_{o(i+1)}\right)-\omega_{o i} \\
& \omega_{n(i+1)}=\sum_{i=1}^{n} \frac{A_{i}}{2 A}\left(\omega_{o i}+\omega_{o(i+1)}\right)-\omega_{o(i+1)}
\end{aligned}
$$

Where $\omega_{\mathrm{o}}$ is the unit warping across the section with respect to the shear center and is expressed in Eq. 2.15-2.16. The first unit warping value $\left(\omega_{\mathrm{o} 1}\right)$ is zero; there is zero shear stress 
at this location. The remaining $\omega_{o}$ values equal the previous $\omega_{o(i+1)}$ value, since the elements share common ends points.

$$
\begin{aligned}
& \omega_{o i}=\omega_{o(i+1)}(\text { of previous element }) \\
& \omega_{o(i+1)}=\omega_{o i}+\rho_{o i} L_{i}
\end{aligned}
$$

The perpendicular distance between the shear center and longitudinal axis of each element, $\rho$, and the lengths of each element, $L_{i}$, are given in Eq. 2.17-2.18.

$$
\begin{aligned}
& L_{i}=\sqrt{\left(x_{i+1}-x_{i}\right)^{2}+\left(y_{i+1}-y_{i}\right)^{2}} \\
& \rho_{o i}=\left(\frac{x_{i} y_{i+1}-x_{i+1} y_{i}}{L_{i}}\right)-\left(\frac{\left(y_{i+1}-y_{i}\right) X_{o}-\left(x_{i+1}-x_{i}\right) Y_{o}}{L_{i}}\right)
\end{aligned}
$$

\subsubsection{Location of Shear Center}

For singly symmetric thin-walled open sections the centroid and shear center lie on the axis of symmetry, but do not coincide. When loads are applied to open sections away from the shear center, torsion induces warping in the girder. Lateral-torsional buckling is the predominant mode of behavior of unbraced thin-walled steel beams, loaded through the shear center, and bending about the major axis (Gotluru et al., 2000). Therefore, it is important to locate the shear center of the proposed thin-walled tub girder.

For an open thin-walled cross-section the coordinates of the shear center $\left(\mathrm{X}_{\mathrm{o}}, \mathrm{Y}_{\mathrm{o}}\right)$ relative to the centroid are expressed in Eq. 2.19-2.20.

$$
\begin{aligned}
& X_{o}=\frac{I_{w x} I_{x y}-I_{w y} I_{y}}{I_{x y}{ }^{2}-I_{x} I_{y}}=\frac{I_{w y}}{I_{x}} \\
& Y_{o}=\frac{I_{w x} I_{x}-I_{w y} I_{x y}}{I_{x y}{ }^{2}-I_{x} I_{y}}=-\frac{I_{w x}}{I_{y}}
\end{aligned}
$$


Where $I_{x}$ (Eq. 2.21) and $I_{y}$ (Eq. 2.22) are the moments of inertia, $I_{x y}$ is the product of inertia, and $\mathrm{I}_{\mathrm{wx}}$ (Eq. 2.23) and $\mathrm{I}_{\mathrm{wy}}$ (Eq. 2.24) are the warping products of inertia. For crosssection with one axis of symmetry, $\mathrm{I}_{\mathrm{xy}}$ is equal to zero.

$$
\begin{array}{ll}
I_{x}=\sum_{i=1}^{n} \frac{A_{i}}{3}\left(y_{i}^{2}+y_{i} y_{i+1}+y_{i+1}^{2}\right) & \text { Eq. } 2.21 \\
I_{y}=\sum_{i=1}^{n} \frac{A_{i}}{3}\left(x_{i}^{2}+x_{i} x_{i+1}+x_{i+1}^{2}\right) & \text { Eq. } 2.22 \\
I_{w x}=\sum_{i=1}^{n} \frac{A_{i}}{3}\left(\omega_{i} x_{i}+\omega_{i+1} x_{i+1}\right)+\sum_{i=1}^{n} \frac{A_{i}}{6}\left(\omega_{i} x_{i+1}+\omega_{i+1} x_{i}\right) & \text { Eq. } 2.23 \\
I_{w y}=\sum_{i=1}^{n} \frac{A_{i}}{3}\left(\omega_{i} y_{i}+\omega_{i+1} y_{i+1}\right)+\sum_{i=1}^{n} \frac{A_{i}}{6}\left(\omega_{i} y_{i+1}+\omega_{i+1} y_{i}\right) & \text { Eq. } 2.24
\end{array}
$$

\subsection{SIP METAL DECK Forms As A BRACING SySTEM}

Many bridge structures utilize stay-in-place metal deck formwork to support the fresh concrete deck during construction. SIP formwork provides lateral bracing to the girder due to its large shear stiffness. During loading, the SIP forms behave like shear diaphragms and provide bracing to resist lateral displacement of the compression flanges. In the research of Helwig and Frank (1999), an expression to compute the capacity of a girder braced by SIP deck forms was derived (Eq. 2.25).

$$
M_{c r}=C_{b} M_{o}+\frac{3}{8} G^{\prime} S_{d} d
$$

In this expression, $C_{b}$ is the factor for moment gradient, $M_{o}$ is the buckling moment of the girder previously derived in Eq. 2.3, $G^{\prime}$ is the effective shear stiffness of the SIP deck forms, $S_{d}$ refers to the lateral width of the deck forms, and $d$ is the overall girder depth. Note the constant $\frac{3}{8}$ adjusts the moment capacity based on top flange loading conditions. The permanent metal deck forms, when used as top-lateral bracing, can be approximated as an equivalent plate (Chen, 
Yura, and Frank, 2005). The researchers found that the thickness of the equivalent plate can be determined by equating the shear stiffness of the decking and the plate, shown in Eq. 2.26.

$$
G^{\prime}=G t_{e q}
$$

Where $G$ is the shear modulus of steel and $t_{e q}$ is the thickness of the equivalent plate. Note that the shear stiffness is not linear to the thickness of the deck material. The metal deck effective shear stiffness can be determined using Eq. 2.27 found in the SDI Manual (SDI, 1995).

$$
G^{\prime}=\frac{E t}{2.6\left(\frac{s}{d}\right)+\phi D_{n}+C}
$$

Where $E$ is the modulus of elasticity of steel (29000 ksi), $t$ is the base metal deck thickness, $s$ is the flattened width of one rib, $d$ is the corrugation pitch, $\phi$ is the reduction factor for multiple deck spans (1.0 for simple spans), $D_{n}$ is the warping constant of the deck, and $C$ is the connection slip parameter. The warping constant can be determined by Eq. 2.28.

$$
D_{n}=\frac{D}{12 L}
$$

The value $D$ is dependent on the end fastener arrangement used. For deck bracing systems, it is recommended that fasteners be placed in every corrugation valley as dramatic increases in diaphragm stiffness can be achieved at relatively little expense (Currah, 1993). 


\subsection{SUMMARY}

This chapter summarized previous implementations, bracing options, and stability of tub girders for bridge applications. Employing the concept of using cold formed press-brake steel tub girders proves to simplify fabrication details and allows for a more efficient design. It was found that the girder is torsionally unstable under relatively low load levels and requires lateral bracing. To simplify the fabrication and construction of the cold-formed tub girders even further, SIP metal formwork was selected as the most efficient bracing option. There is a need for further stability and behavior evaluation of non-composite press-brake-formed tub girders under loading conditions. 


\section{CHAPTER 3: EXPERIMENTAL TESTING}

\subsection{INTRODUCTION}

This chapter describes the non-composite laboratory tests conducted on press-brake formed shallow steel tub girders in the Major Units Laboratory at West Virginia University. An overview of the test setup, specimen properties, instrumentation, material properties, initial imperfections, and flexural testing is discussed.

\subsection{OVERVIEW OF TeSting APPARATUS}

Flexural testing was conducted on two non-composite press-brake formed tub girders. Simply supported boundary conditions were created by the use of bearing plates fabricated with 2-in-diameter round bars. One end of the girder was a pinned support and the other a roller support. The pinned support was comprised of a 2-in-diameter steel rod welded parallel to the top face of the steel bearing plate (see Figure 3.1). The roller support consisted of a rod free to move in the longitudinal direction inside of a groove milled into the top face of the bearing plate, (see Figure 3.2).

A WT section was bolted to the girders' top flanges at mid-span to support a steel spreader beam and elastomeric pad (see Figure 3.3). The test load was then applied to the spreader beam with a 330-kip MTS servo-hydraulic actuator mounted to a large testing frame. Lateral bracing was added to each end to prevent unintentional rotation at the supports and provide a safe testing environment. The bracing was connected to the girder by connection plates welded to the outside webs and bolted to the testing frame. Figure 3.4 shows a view of a typical test setup. 


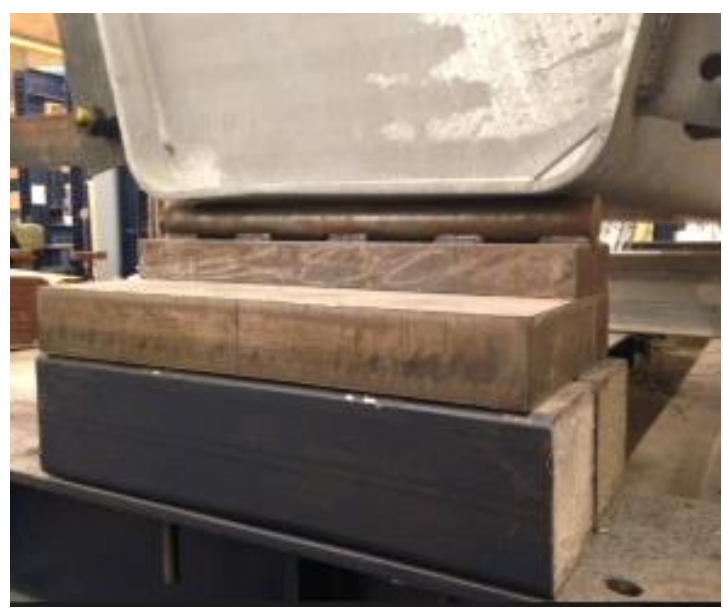

Front View

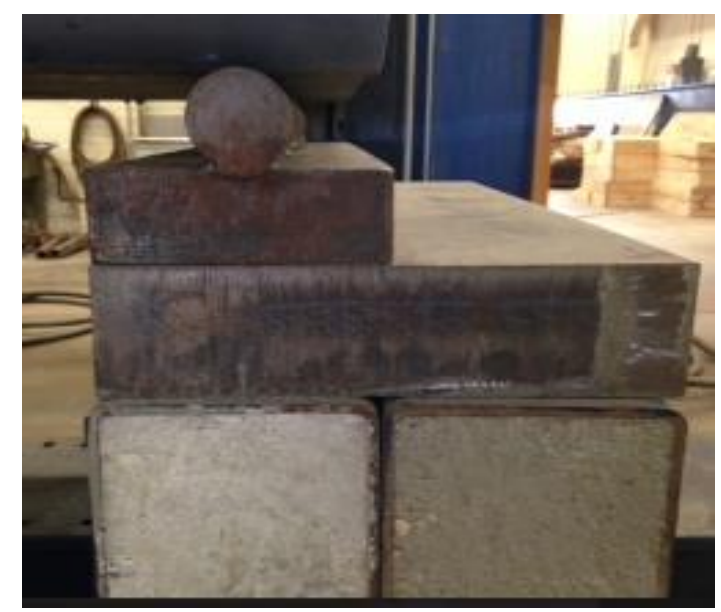

Side View

Figure 3.1: Pinned Support

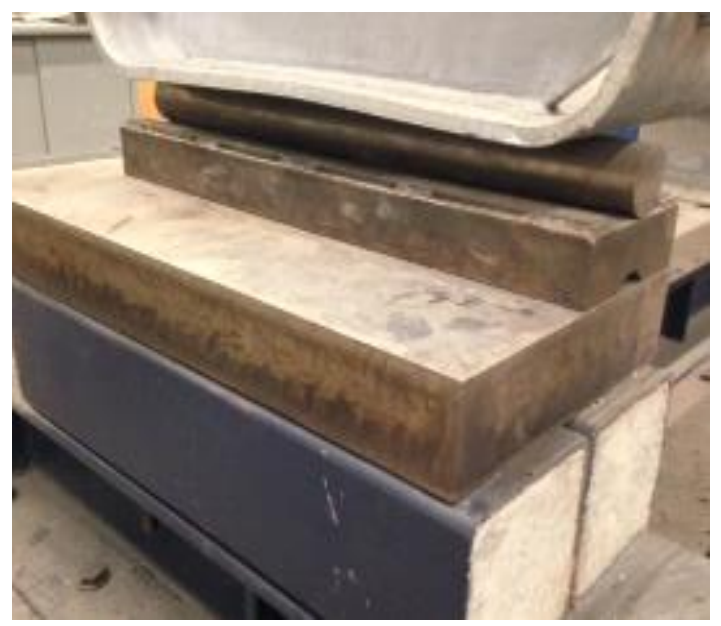

Front View

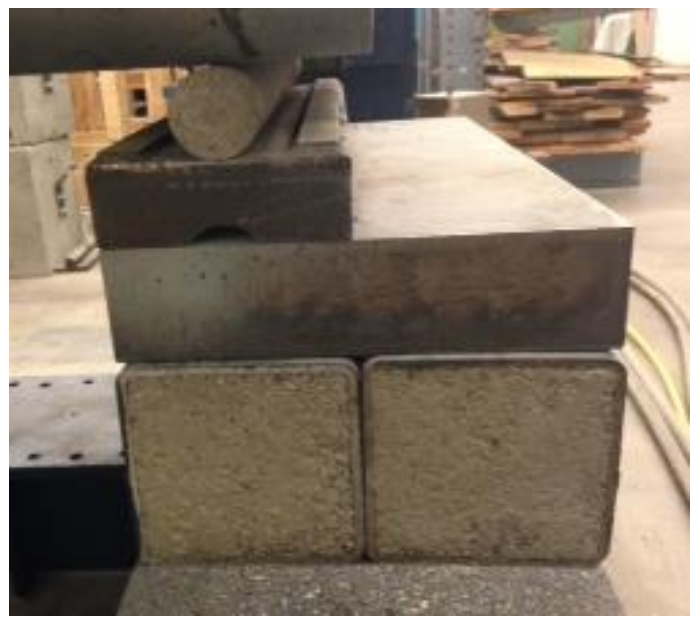

Side View

Figure 3.2: Roller Support 


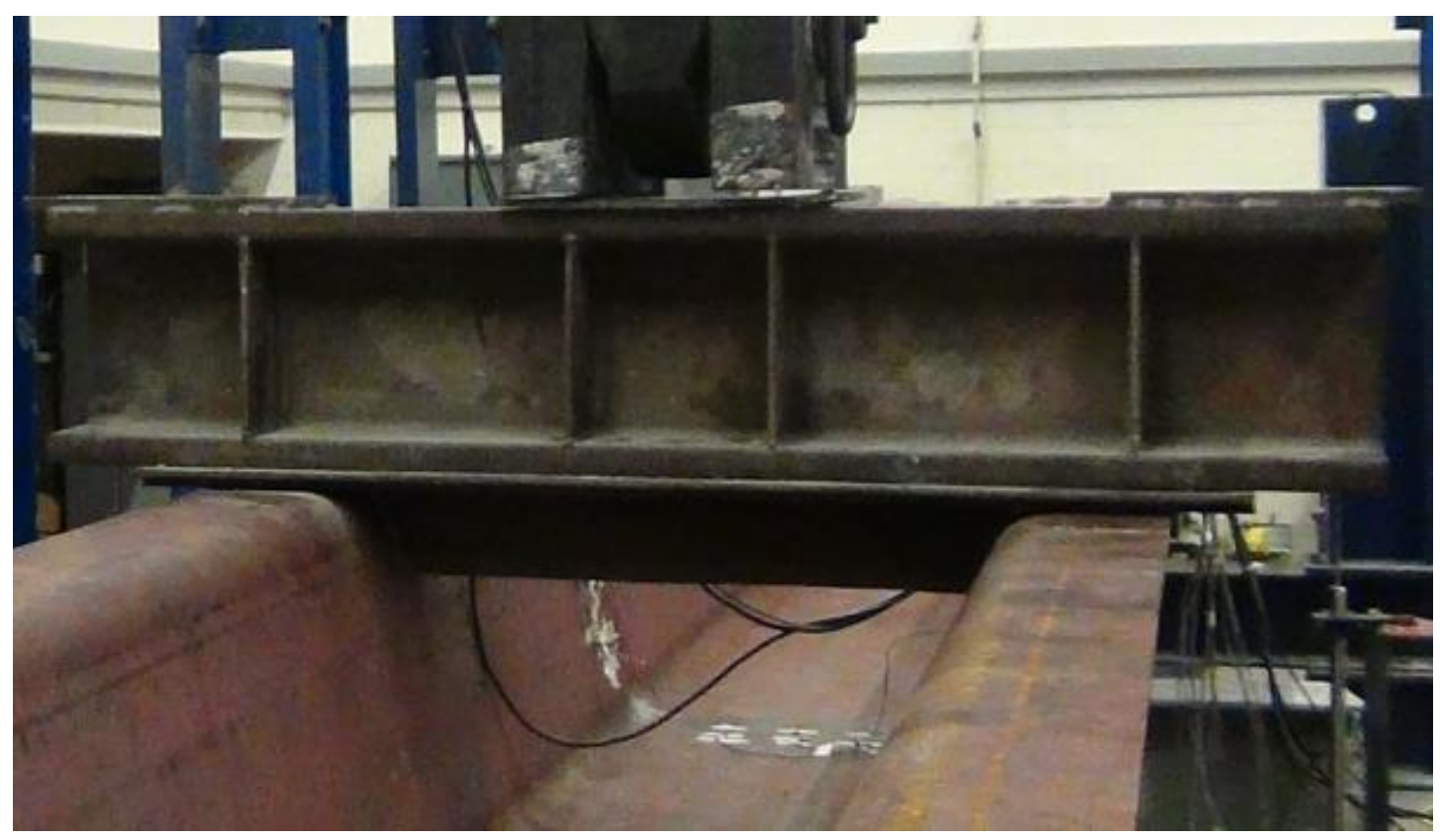

Figure 3.3: Typical Spreader Beam with Elastomeric Pads

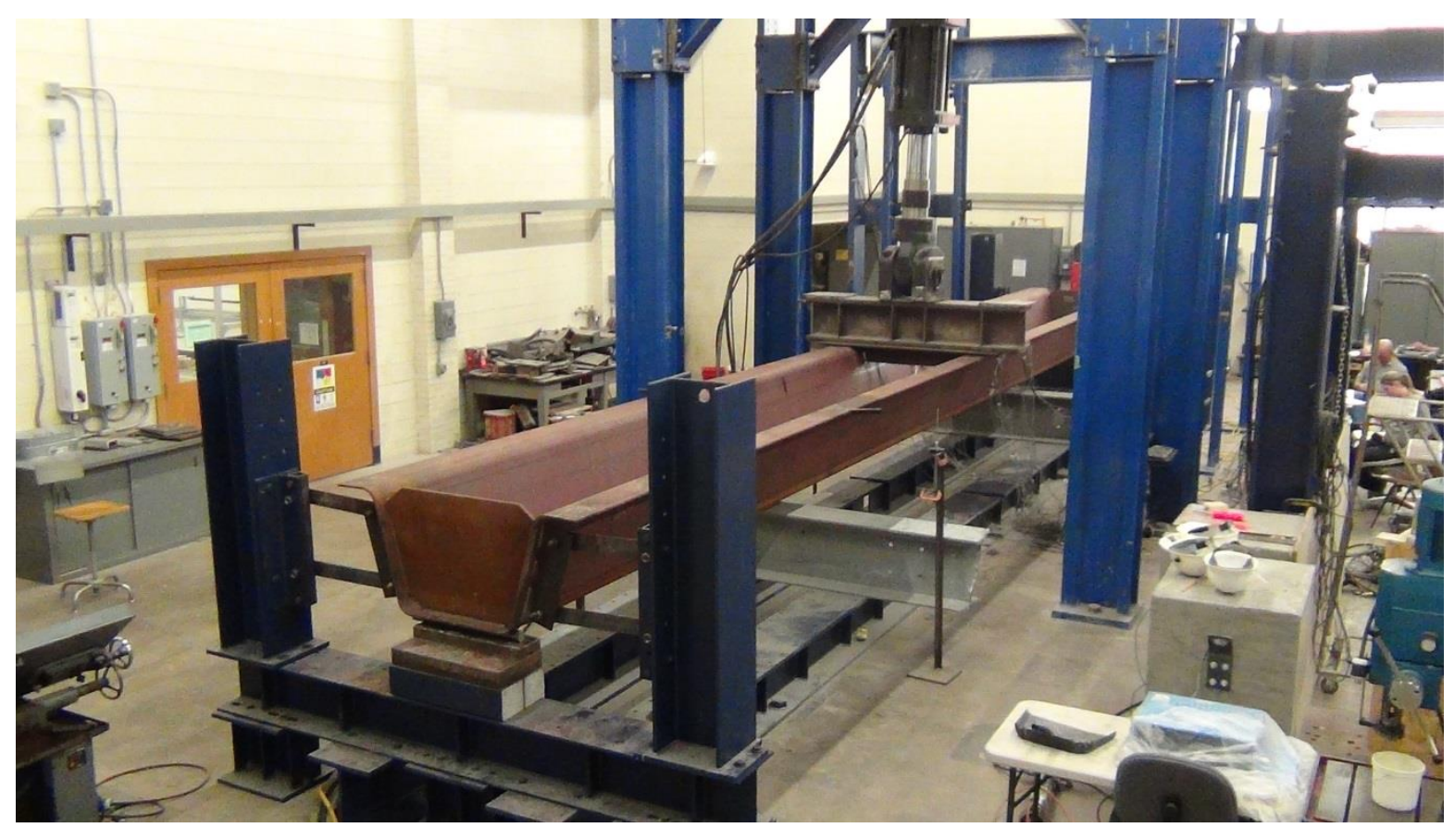

Figure 3.4: View of Typical Test Setup 


\subsection{SPECIMEN Dimensions ANd Properties}

Two different plates were used to fabricate the girder specimens. The plate used for Experiment \#1 consisted of HPS-50W weathering steel. The plate used for Experiment \#2 consisted of HPS-50 steel and was galvanized (hot-dipped) at AZZ Galvanizing Service (located in Canton, $\mathrm{OH}$ ) prior to its arrival at West Virginia University. Each specimen was 38 feet in length and fabricated from an 84 " x $7 / 16$ " x 480 " steel plate. Fabrication was performed by American Tank \& Fabricating (located in Cleveland, $\mathrm{OH}$ ) using a large capacity press-brake.

Through a series of design studies, Michaelson (2014) determined the optimum crosssection, using 84" x 7/16" plate, was found to have a top flange width of 6 inches and a total girder depth of 23 inches. All plates were bent such that the inside bend radius shall be equal to five times the thickness. Figure 3.5 shows a cross-sectional view of the press-brake-formed tub girder dimensions. Section properties for the test specimens are summarized in Table 3.1. The section properties were found using equations derived in Chapter 2. In addition, end bearing plates were utilized at support locations to prevent premature bearing failure during testing shown in Figure 3.6.

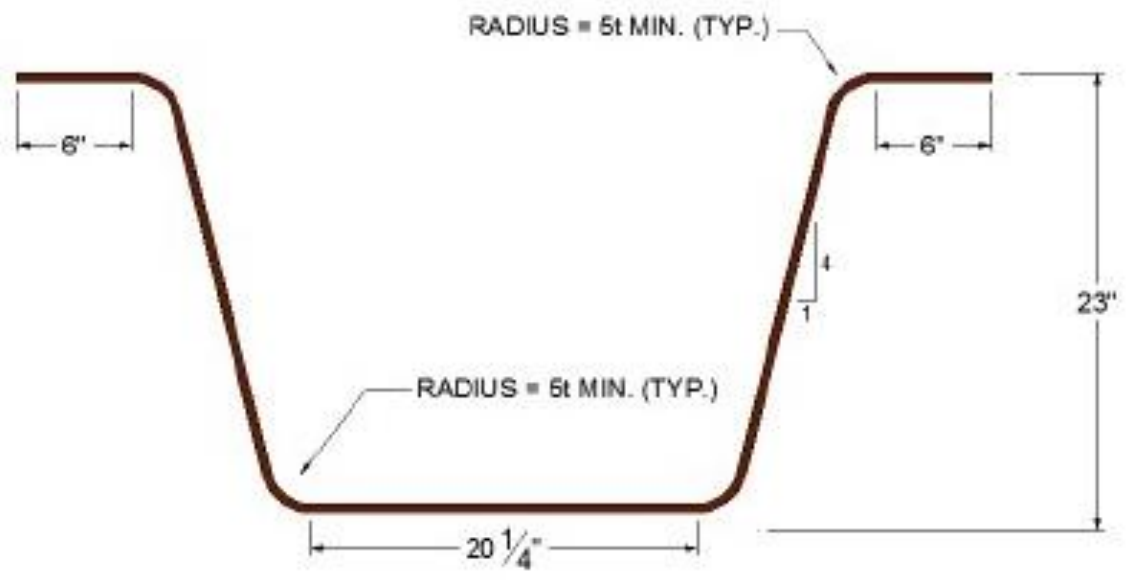

Figure 3.5 Test Specimen Dimensions 
Table 3.1: Section Properties

\begin{tabular}{|c|c|}
\hline Property & Value \\
\hline $\mathrm{A}\left(\right.$ in $\left.^{2}\right)$ & 36.75 \\
$\mathrm{~L}$ (in) & 456 \\
$\mathrm{E}(\mathrm{ksi})$ & 29000 \\
$\mathrm{G}(\mathrm{ksi})$ & 11154 \\
$\mathrm{I}_{\mathrm{x}}\left(\right.$ in $\left.^{4}\right)$ & 2893.1 \\
$\mathrm{I}_{\mathrm{y}}\left(\right.$ in $\left.^{4}\right)$ & 8049.6 \\
$\mathrm{~J}_{\text {open }}\left(\right.$ in $\left.^{4}\right)$ & 2.3447 \\
$\mathrm{~J}_{\text {closed }}\left(\right.$ in $\left.^{4}\right)$ & 69000 \\
$\mathrm{C}_{\mathrm{w}}$ (in & \\
$\beta_{x}$ (in) & 139952 \\
\hline
\end{tabular}

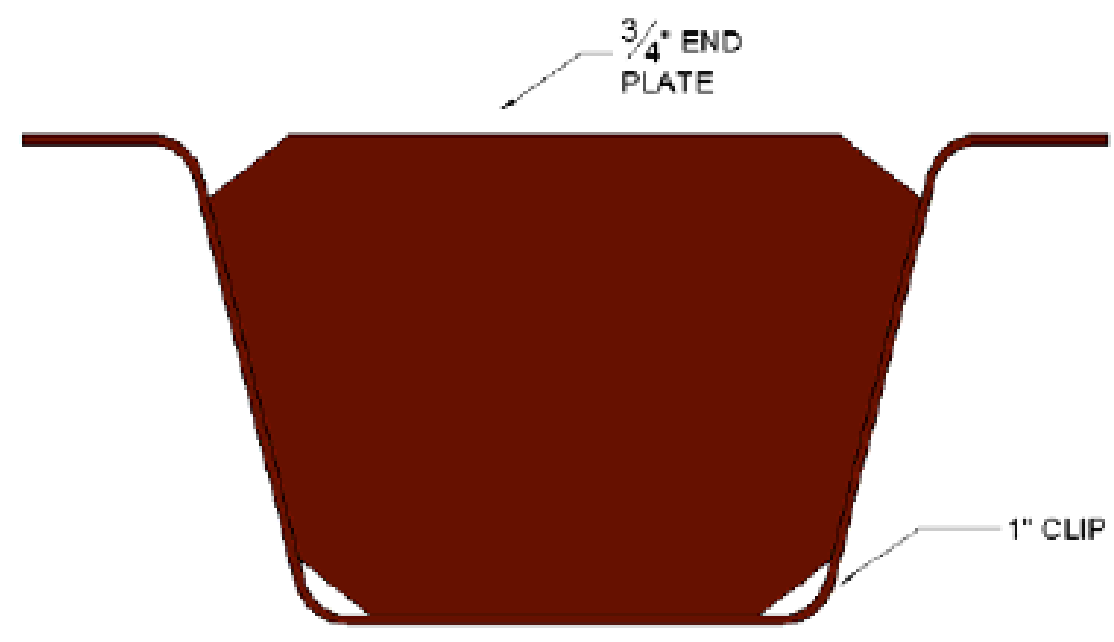

Figure 3.6 End Bearing Plate 


\subsection{INSTRUMENTATION}

During testing, strain and vertical deflection data were collected using StrainSmart (Micro-Measurements, Inc., 2010) and Micro-Measurements Model 5100 Scanner data acquisition systems. Vertical deflections of the specimen were determined by linear variable displacement transducers (LVDTs). The load was applied and measured using an MTS 330-kip servo hydraulic actuator.

\subsubsection{Instrumentation Layout}

Two types of foil-resistor strain gages were used to measure strain: uniaxial and rectangular strain gages. Six uniaxial gages were placed on the top and bottom of the bottom flange to measure tensile strains. In addition, six rectangular rosettes were placed along the quarter points of the flat portion of each web to measure bending and shear strains. To avoid bearing effects at load locations, all 18 strain gages were placed along a cross section at a distance $2 d$ (46 in.) away from the load application. Where $d$ is the total depth of the steel girder. Figure 3.7 illustrates the strain gage layout.

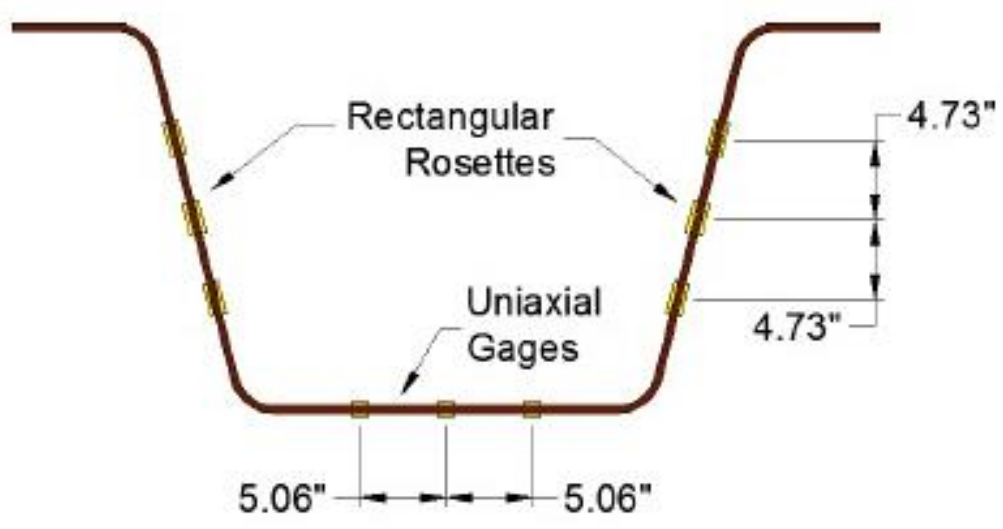

Figure 3.7 Strain Gage Layout 
Vertical deflections were measured with four LVDTs; two at mid-span $(0.5 L)$ and two at quarter points $(0.25 L)$, where $L$ is the girder span length. Equal-leg angles were welded to the top flanges to support the LVDTs and prevent damage of the instruments. The LVDT measurements were averaged to determine vertical deflections at the respective locations on the girder. To ensure accurate results, all LVDT's were leveled in all directions prior to testing. Figure 3.8 shows a quarter point LVDT in place.

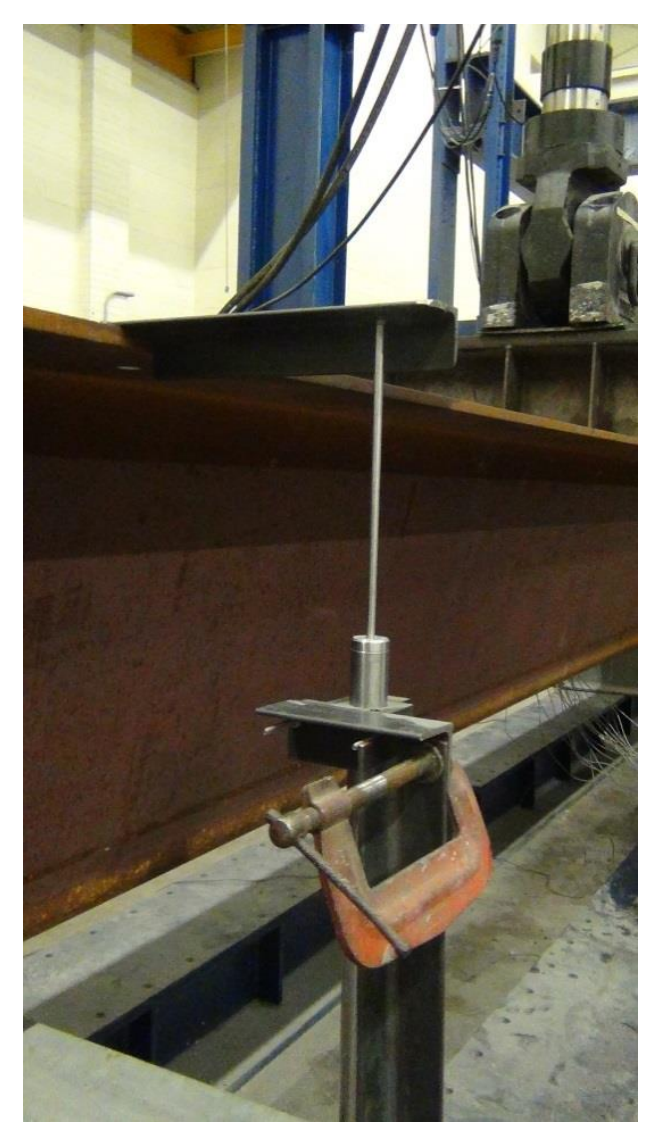

Figure 3.8 Quarter Point L VDT 


\subsection{Steel Material Properties}

Five tensile coupons were obtained in the transverse and longitudinal directions of rolling during the press-brake operation. The coupons were tested by Turner-Fairbank's Highway Research Center. Figure 3.9 shows the coupon test results; this data was used in the analytical modeling of Chapter 5.

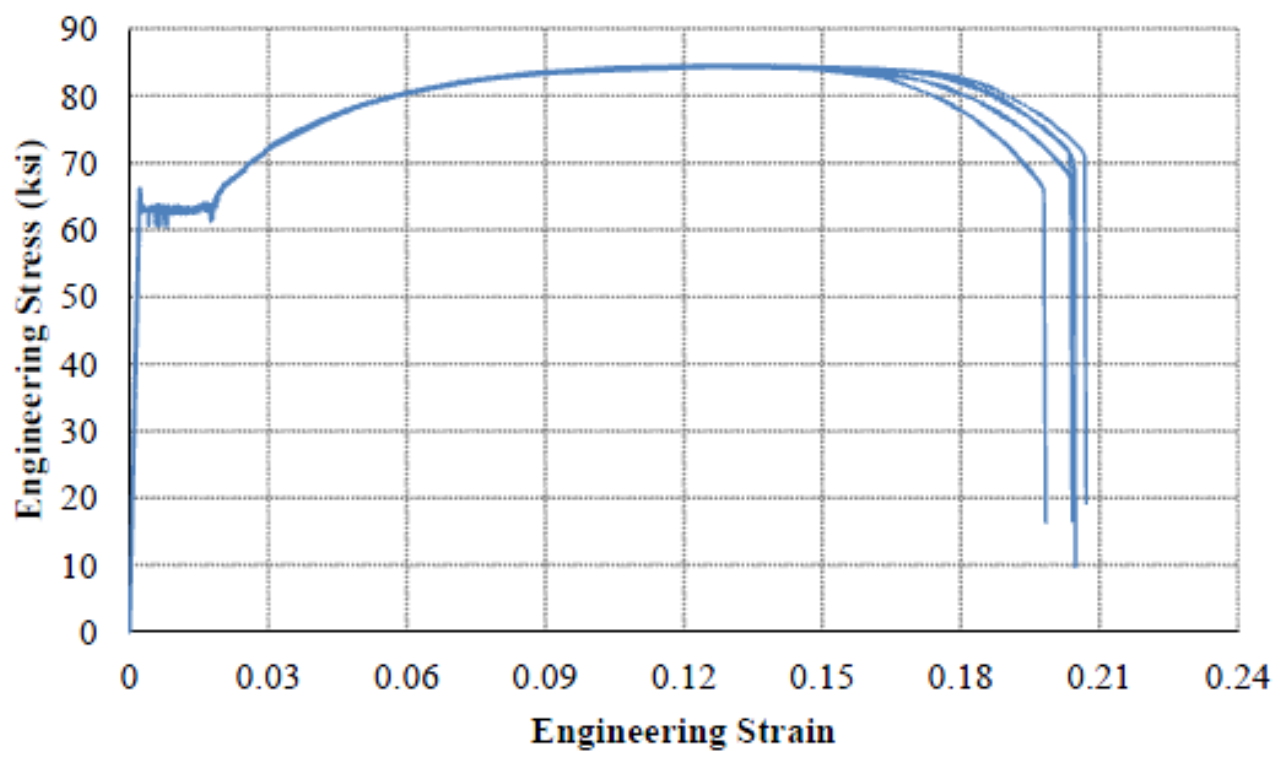

Figure 3.9: Coupon Tensile Testing Results (Michaelson, 2014)

\subsection{INITIAL IMPERFECTIONS}

Prior to testing the galvanized girder specimen for Experiment \#2, an initial twist was apparent. As shown in Figure 3.10 and 3.11, specimen \#2 has a slight twist to the right side without load present. To determine which geometric imperfections caused the initial twist, a digital level was used to measure the inclination of the webs and flanges. The measurements of both specimens are compared with ideal values and plotted in Figures 3.11-3.5. Specimen \#1 (weathering) is represented by the red line and specimen \#2 (galvanized) is represented by the grey line. 


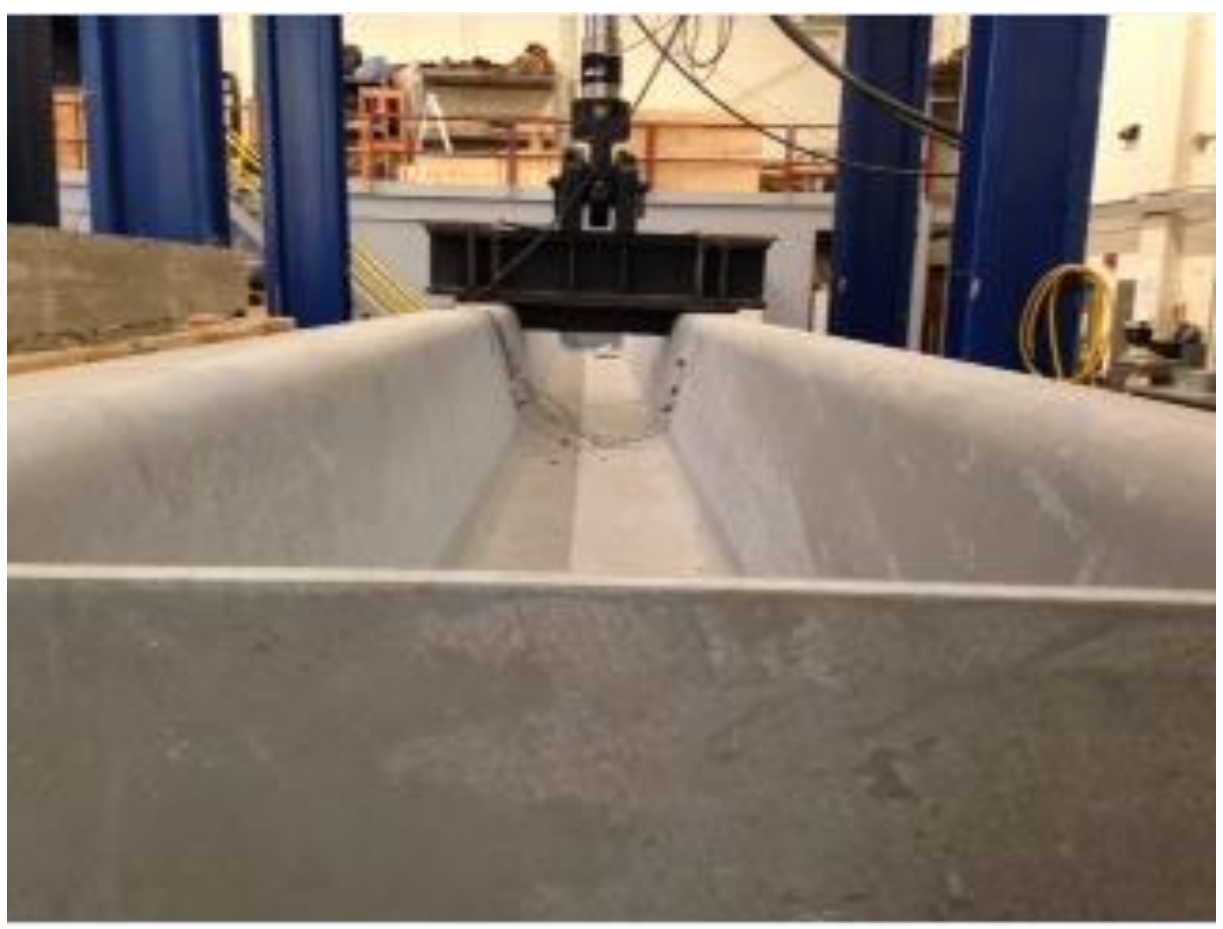

Figure 3.10: Initial Twist of Specimen \#2

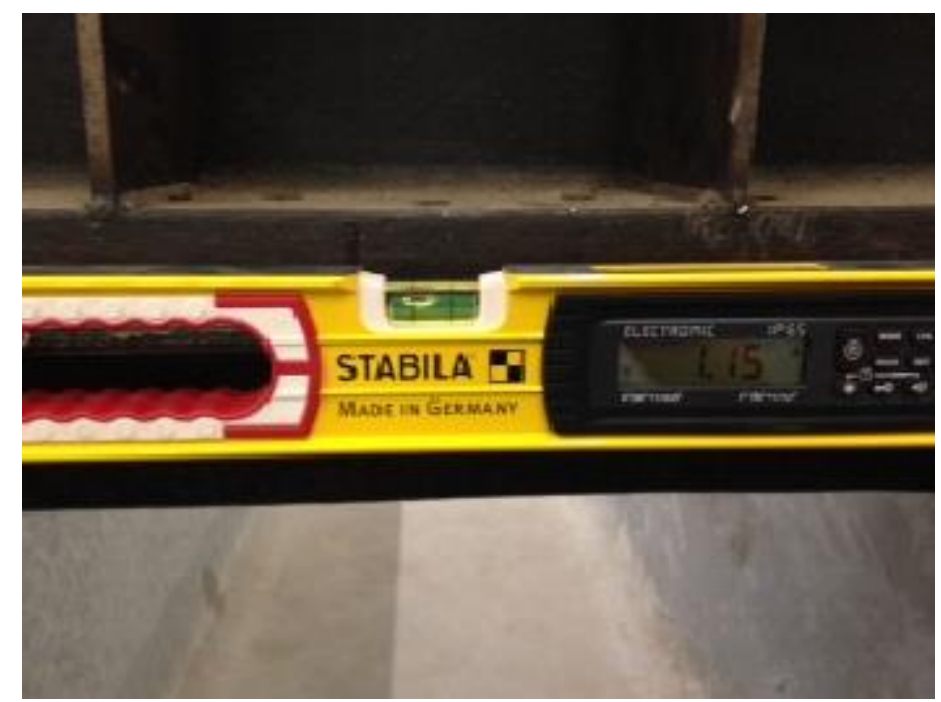

Figure 3.11: Initial Mid-span Inclination of Specimen \#2 


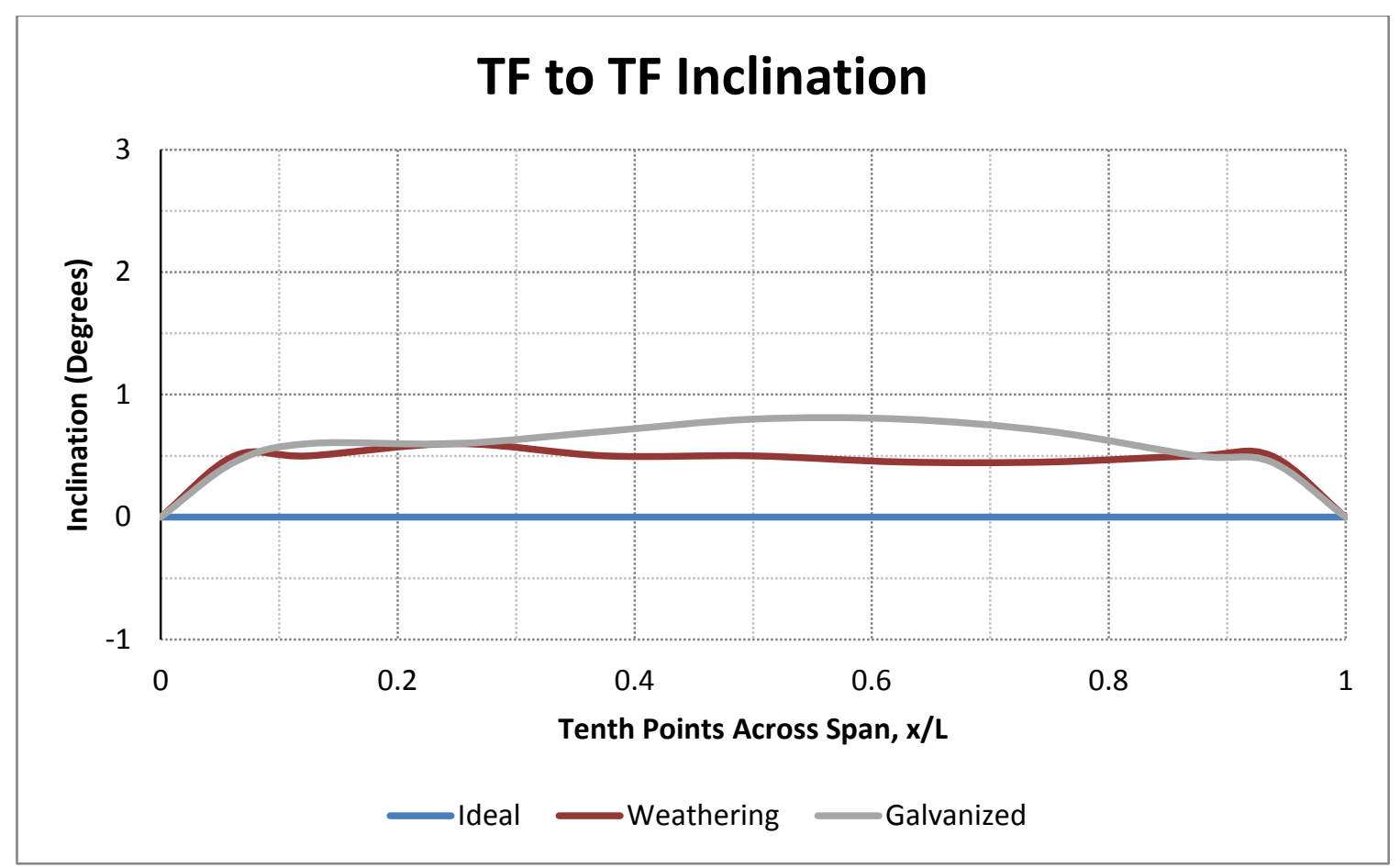

Figure 3.12: TF to TF Inclination

Measurements were taken at tenth points along the girder span. Ideally, there should be no inclination present. Figure 3.12 shows the inclination measurements from top-flange to topflange. As represented by the positive values, both girders proved to have an initial twist to the right side. The weathering girder was consistent around $0.5^{\circ}$ for the entire span length. However, the galvanized girder had greater inclination values concentrated around mid-span. This is why no initial twist was visually apparent for the weathering girder in experiment \#1. 


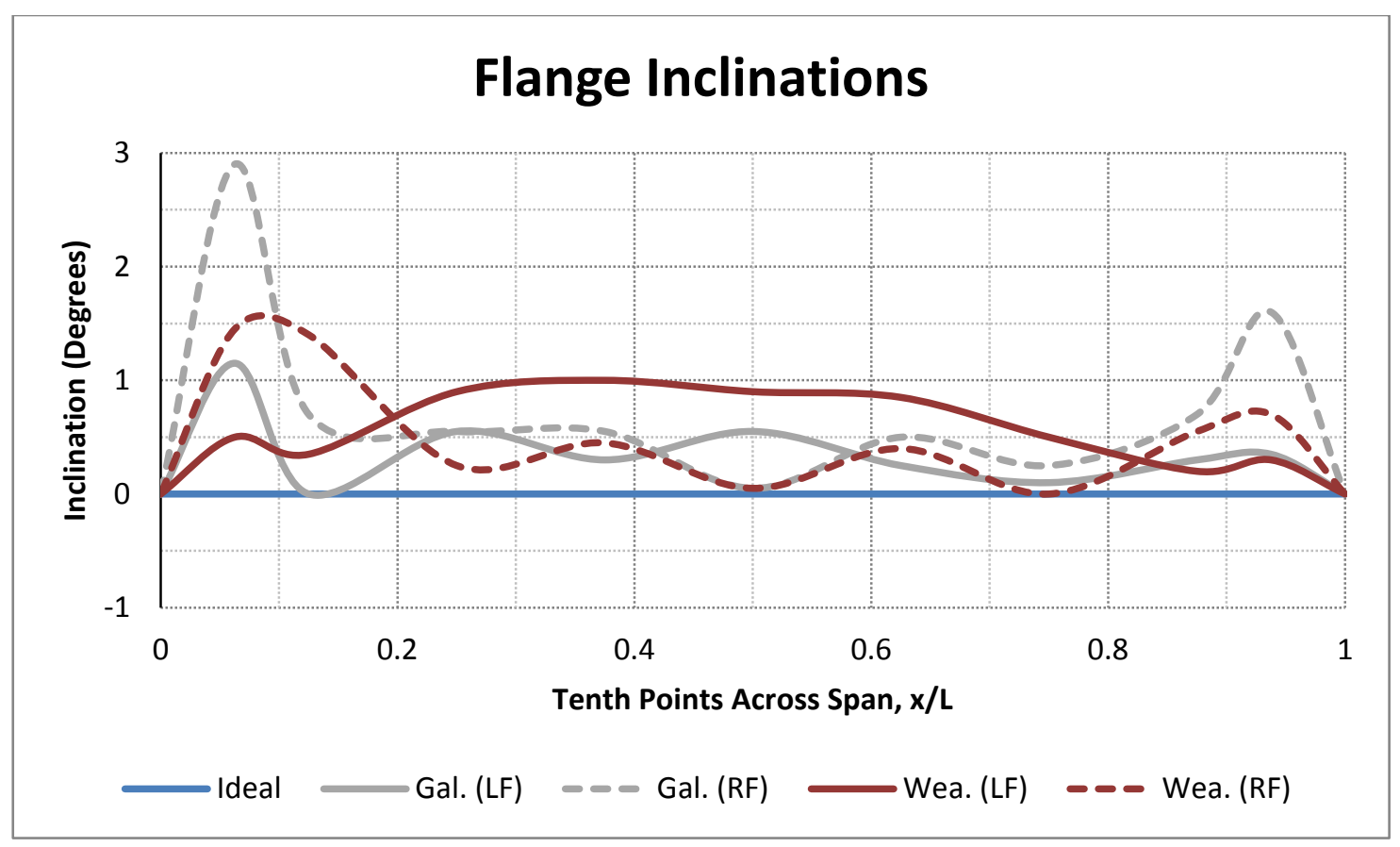

Figure 3.13: Flange Inclinations

Figure 3.13 compares the inclinations of both the left and right flanges for the ideal, galvanized, and weathering girders. Again, there should be zero inclination present. The majority of the flange values show flange tilt to the outside (see Figure 3.14)

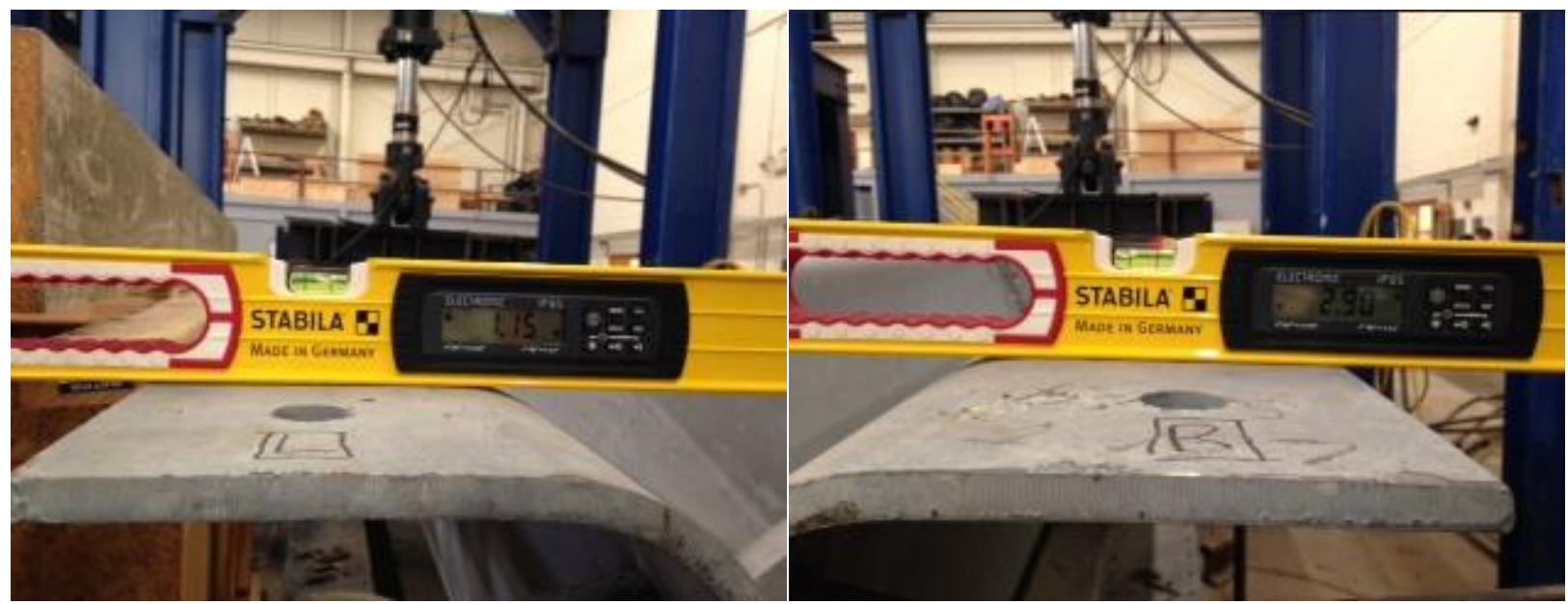

Left Flange

Right Flange

Figure 3.14: Galvanized Girder Flange Levels 


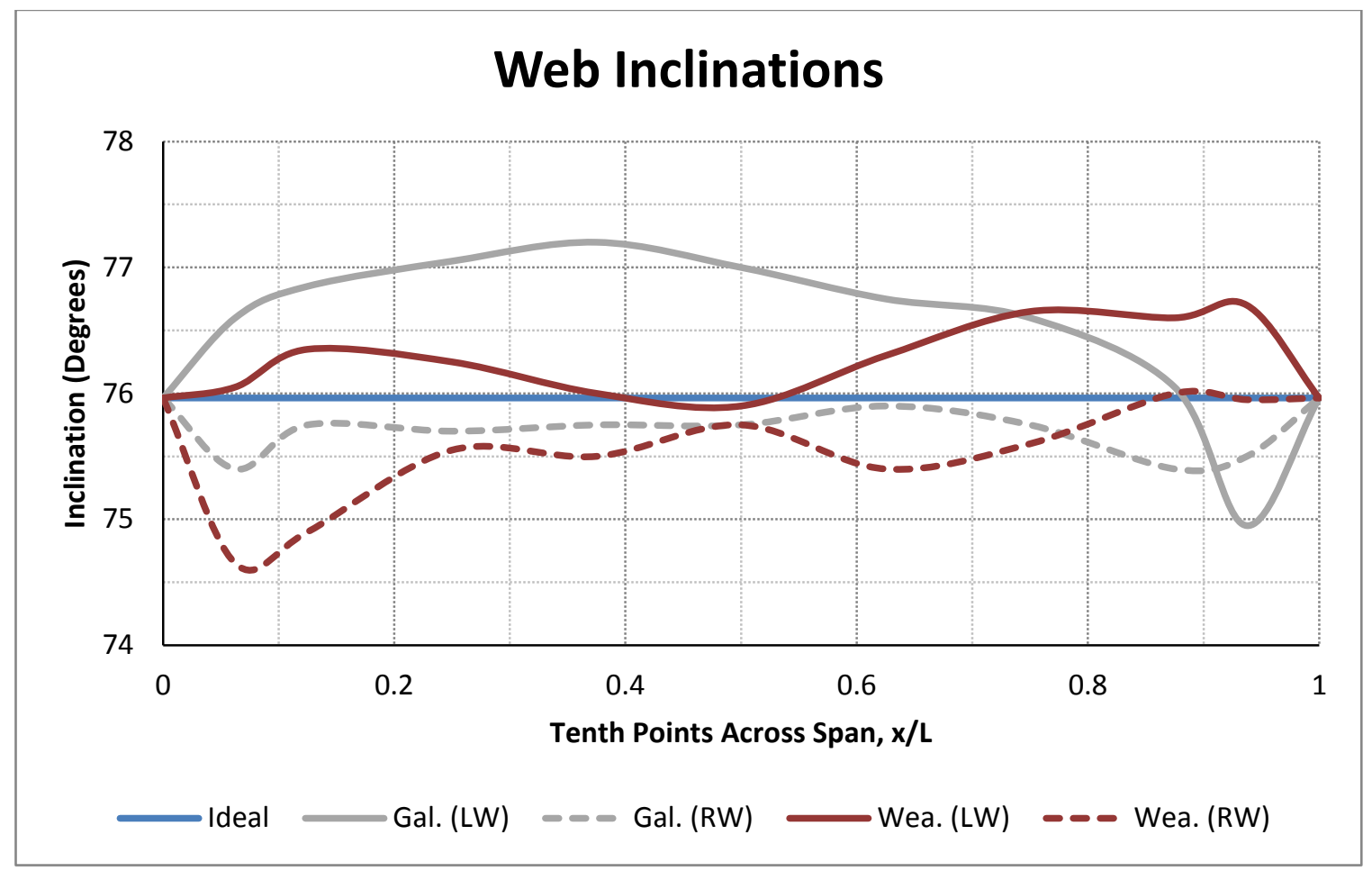

Figure 3.15: Web Inclinations

Figure 3.15 compares the web inclinations for the ideal, galvanized, and weathering girders. The ideal web inclination should equal $76^{\circ}$, which is the 1:4 slope ratio of the web. Notice that the right webs of both girders have lower web inclinations signifying the webs are bent outward toward the right side. On the other hand, the left webs tend bend inward toward the tubs center due to the higher inclination values.

\subsection{FleXURAL TeSTing}

Flexural testing was conducted on simply-supported non-composite press-brake tub girder specimens in three-point bending (see Figure 3.16). Once the girders were installed in the testing frame and instrumented, they were loaded to failure. 


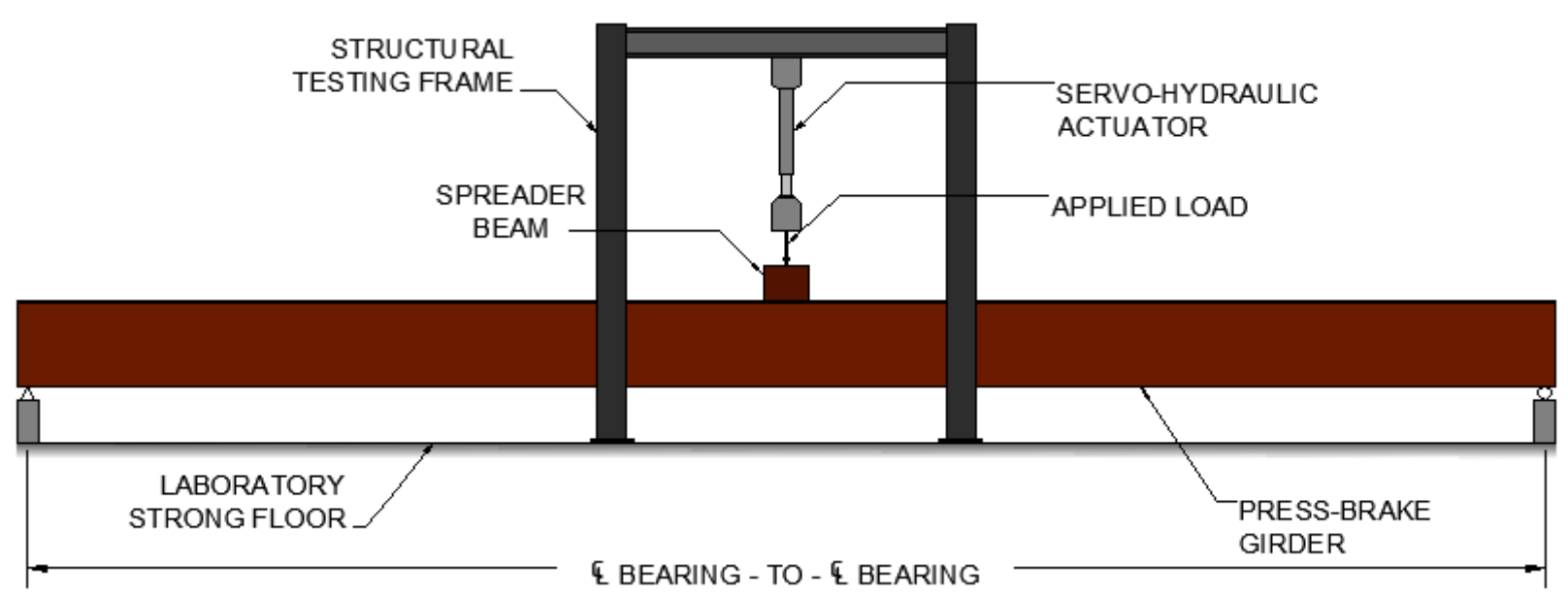

Figure 3.16: Test Setup Schematic

\subsubsection{Testing Procedure}

As previously discussed, the test load was applied at mid-span using a MTS 330-kip servo-hydraulic actuator which was mounted to a large structural reaction frame. The MTS actuator was equipped with an internal load cell used to acquire the load at mid-span. Load was applied to a steel spreader beam resting on a WT section, bolted between the top flanges, to minimize bearing effects. To insure a safe testing environment and accurate data collection, each girder specimen was loaded in stroke control. Each load step consisted of applying small increments of displacement (typically between 0.05 and 0.10 in.). Approximately 5 minutes was taken between load steps to allow for the stabilization of the applied load. Strain and vertical deflection data were collected using StrainSmart (Micro-Measurements, Inc., 2010) and MicroMeasurements Model 5100 Scanner data acquisition systems. Vertical deflections of the specimen were determined by linear variable displacement transducers (LVDTs). Chapter 4 further discusses the resulting experimental data. 


\section{CHAPTER 4: EXPERIMENTAL RESULTS AND ASSESSMENT}

\subsection{INTRODUCTION}

The following chapter provides the experimental results obtained from the flexural testing described in Chapter 3. Calculation of the predicted buckling capacity, second-order effects, and comparisons of both experiments are further explained.

\subsection{Theoretical Buckling CaPaCity}

Using Eq. 2.3 and the specimen properties of Table 3.1, the first-order lateral-torsional buckling capacity of the press-brake-formed tub girder is calculated as follows:

$$
\begin{gathered}
M_{o}=\frac{\pi^{2} E I_{y} \beta_{x}}{2 L^{2}}\left[1 \pm \sqrt{1+\frac{4}{\beta_{x}{ }^{2}}\left(\frac{G J L^{2}}{\pi^{2} E I_{y}}\right)+\frac{C_{w}}{I_{y}}}\right]= \\
\frac{\pi^{2}(29000 \mathrm{ksi})\left(8049.6 \mathrm{in}^{4}\right)(-19.704 \mathrm{in})}{2\left(456 \mathrm{in}^{2}\right.}\left(1-\sqrt{1+\frac{4}{(-19.704 i n)^{2}}\left(\frac{(11154 k s i)\left(2.3447 \mathrm{in}^{4}\right)(456 \mathrm{in})^{2}}{\pi^{2}(29000 \mathrm{ksi})\left(8049.6 \mathrm{in}^{4}\right)}\right)+\frac{\left(139952 \mathrm{in}^{4}\right)}{\left(8049.6 \text { in }^{4}\right)}}\right) \\
M_{o}=10590 \text { in - kip }
\end{gathered}
$$

Therefore, the critical load at mid-span is:

$$
\begin{gathered}
P=\frac{4 M_{o}}{L}=\frac{4(10590 \text { in-kip })}{456 i n} \\
P=92.3 \mathrm{kip}
\end{gathered}
$$




\subsection{EXPERIMENT \#1}

The first experiment consisted of the weathering-steel girder specimen described in Chapter 3. Figure 4.1 shows the mid-span load-deflection results for specimen \#1. As can be seen from the plot, the load deflection curve is linear up to a load of approximately 94 kips and 2.25 inches of vertical deflection. This 94 kip critical load, producing a moment at mid-span of 10,700 in-kips, coincides with the theoretical critical load of 92.3 kips and moment of 10,590 inkips. At this point the girder suddenly failed in a lateral-torsional buckling mode previously discussed in Section 2.4. The failure mode is shown in Figures 4.2 and 4.3. Due to excessive lateral deflection and twist, testing was terminated after the failure load was reached. It should be noted that the girder failed elastically, returning to its original shape after the load was removed. Figure 4.4 shows the inclination of the girder after loading.

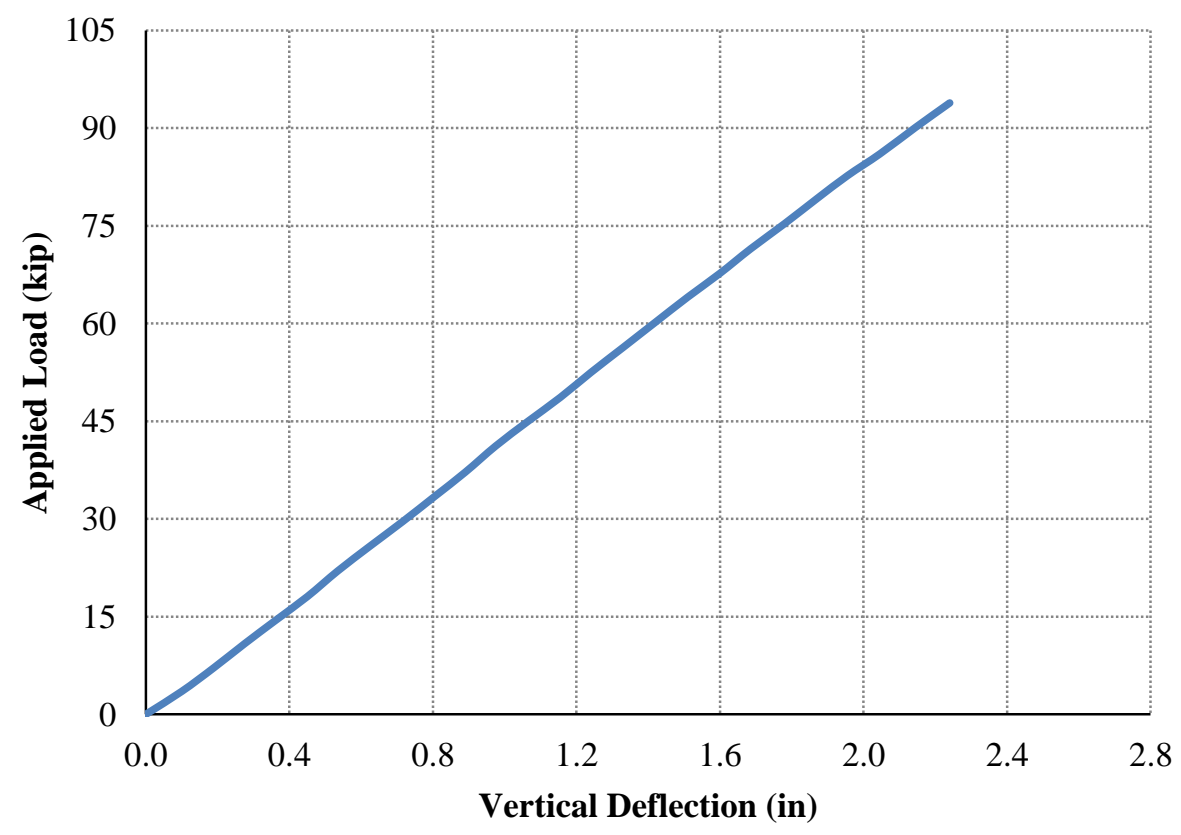

Figure 4.1: Load-Deflection Data from Experiment \#1 


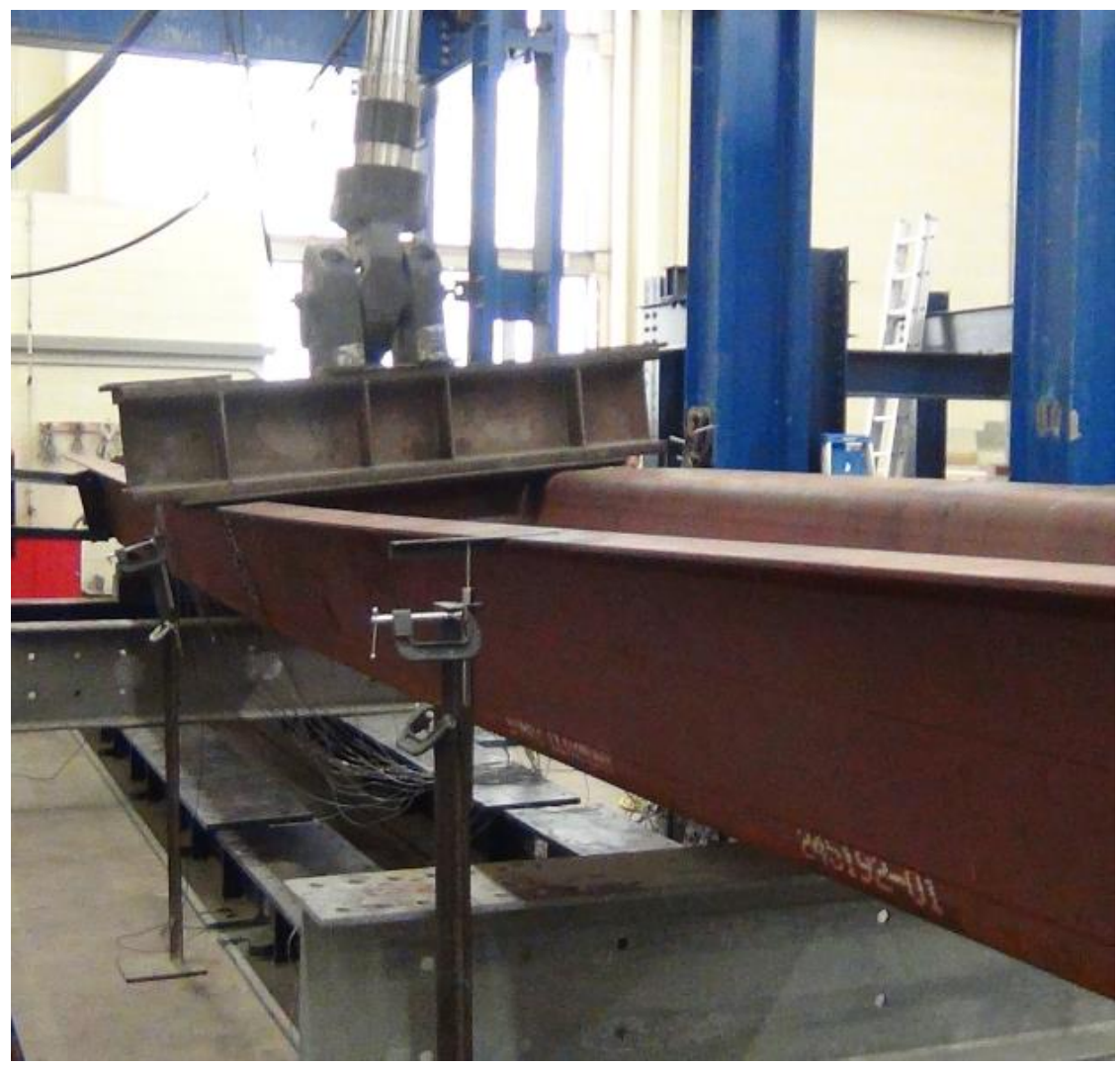

Figure 4.2: Side View of Lateral Torsional Buckling of Specimen \#1

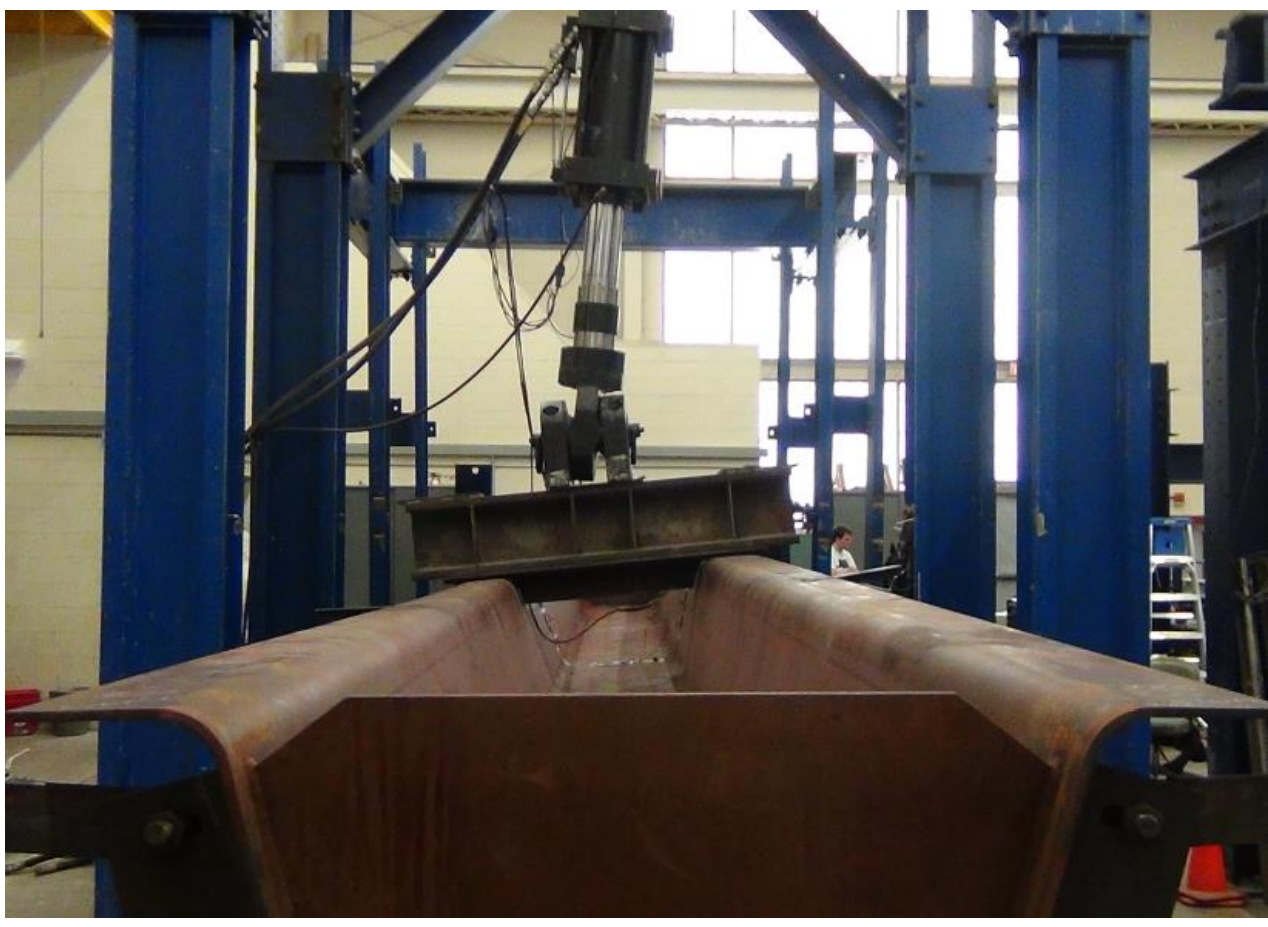

Figure 4.3: Front View of Lateral Torsional Buckling of Specimen \#1 


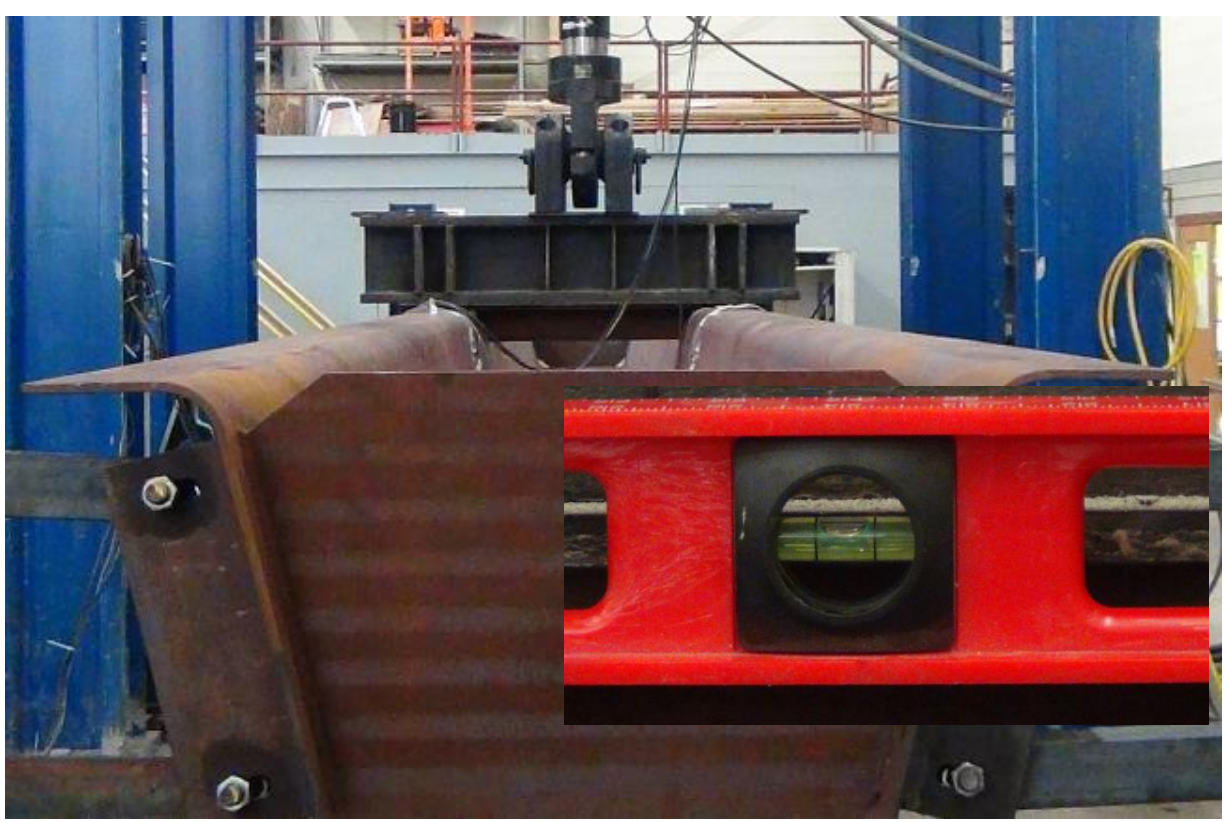

Figure 4.4: Post Loading of Specimen \#1

\subsection{EXPERIMENT \#2}

The second experiment consisted of the galvanized steel girder specimen described in Chapter 3. The mid-span load-deflection results for specimen \#2 are shown in Figure 4.5 and illustrate a linear load-deflection relationship. Similarly to experiment \#1, flexural testing of specimen \#2 was terminated due to excessive lateral deflection and twist from lateral-torsional buckling phenomena. A critical load of approximately 33 kips and 0.73 inches of vertical deflection was reached just before loss of capacity occurred. The critical load of 33 kips produced a mid-span moment of approximately 3,700 in-kips. Figure 4.6 illustrates the midspan moment comparisons of the experimental and FEA results. The galvanized girder specimen performed with only about one third of the capacity of both specimen \#1(10,700 inkips) and the FEA model (11,400 in-kips). The loss of capacity is a direct result of second order effects stemming from the girders initial imperfections previously discussed in Section 3.6. The failure mode is illustrated in Figures 4.7 and 4.8. 


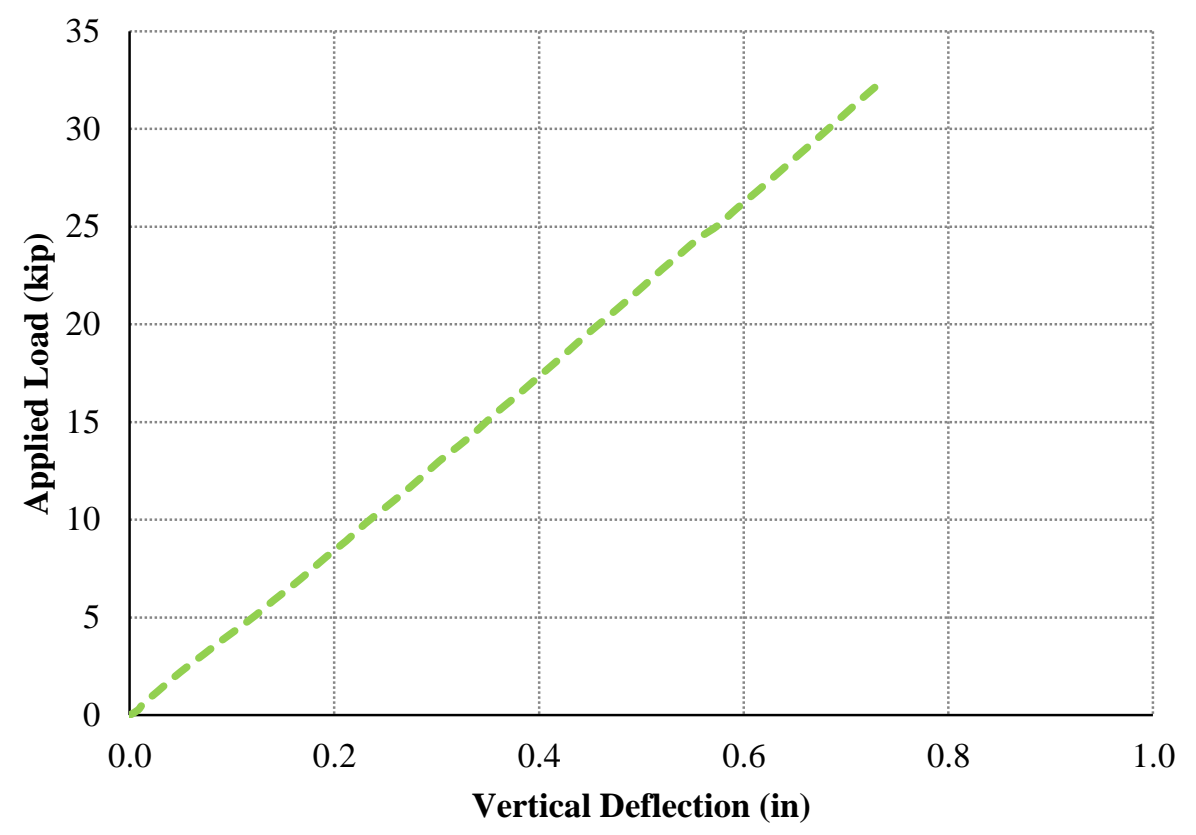

Figure 4.5: Load-Deflection Data from Experiment \#2

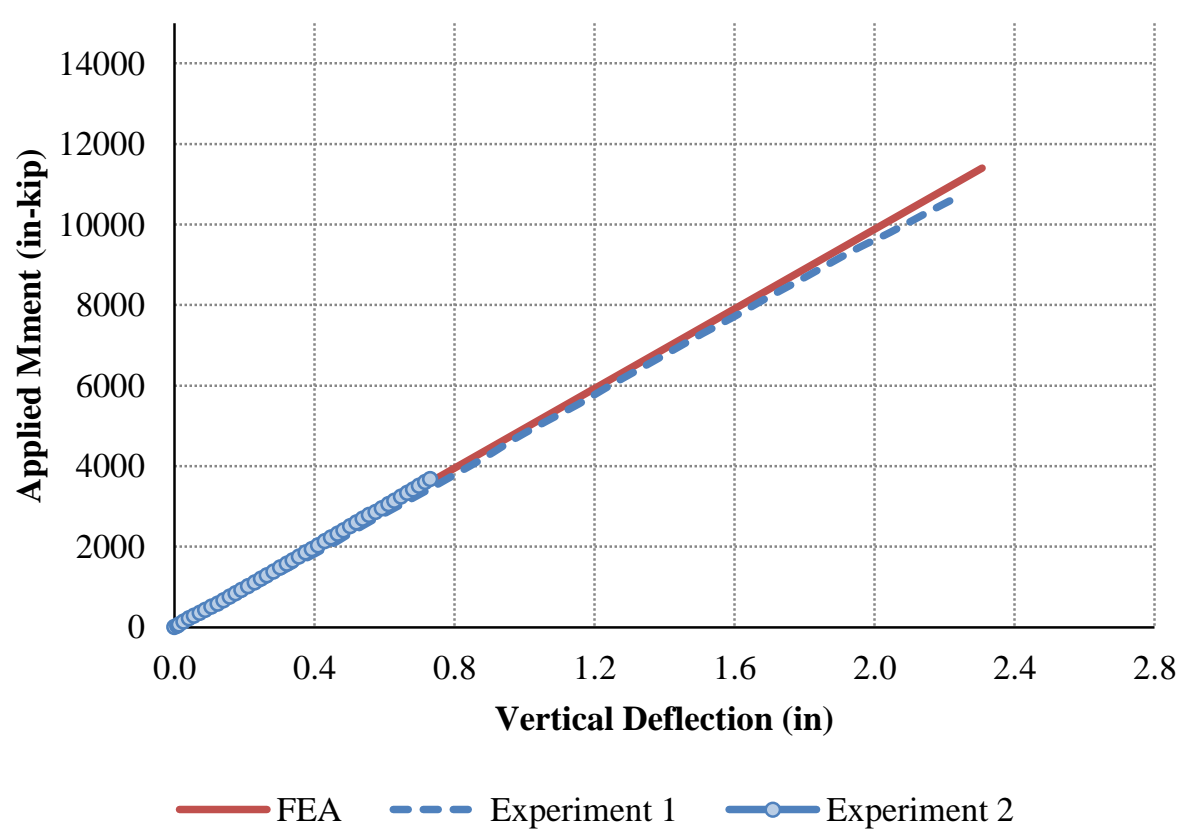

Figure 4.6: Mid-span Moment Comparison 


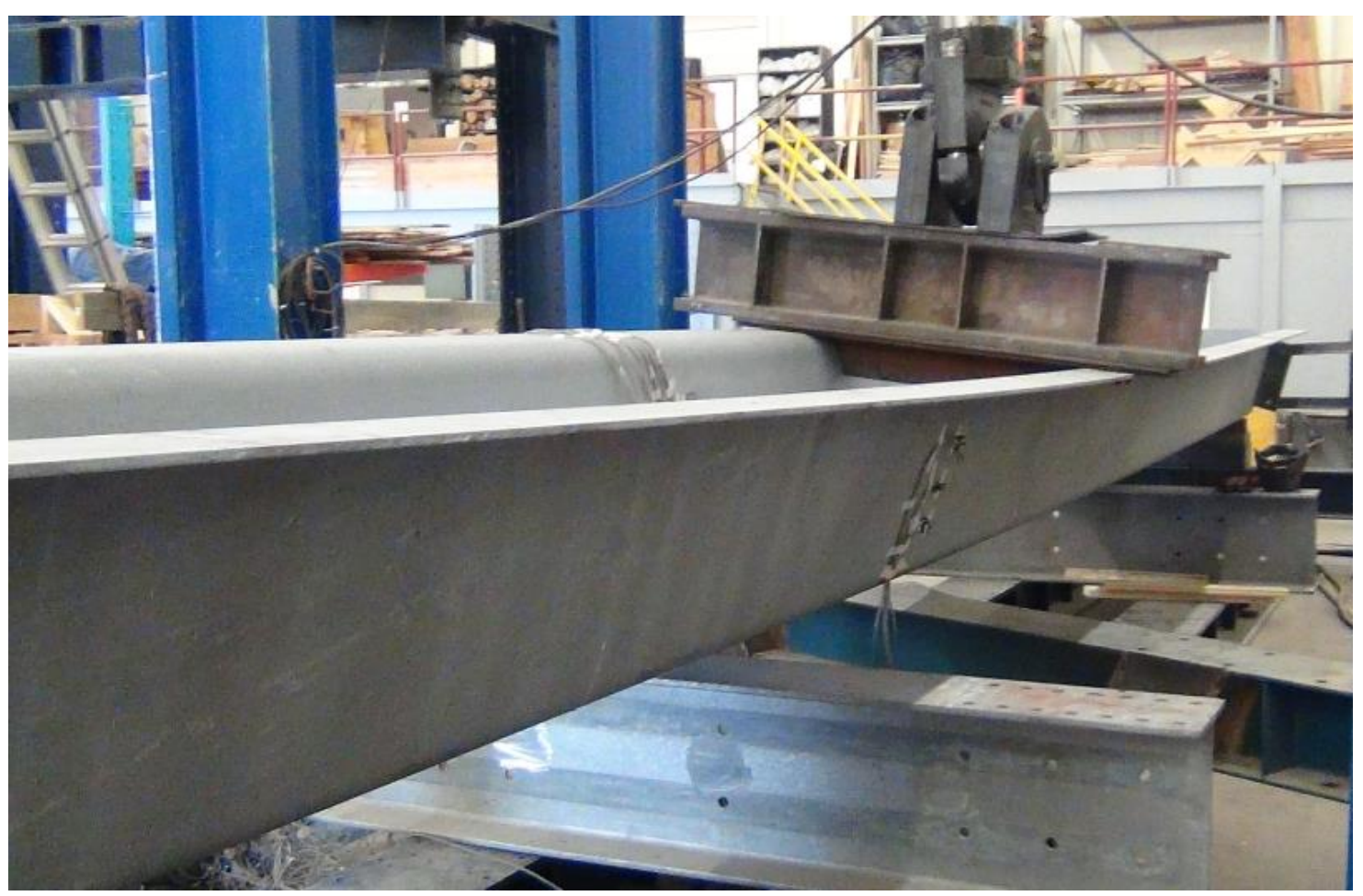

Figure 4.7: Side View of Lateral Torsional Buckling of Specimen \#2

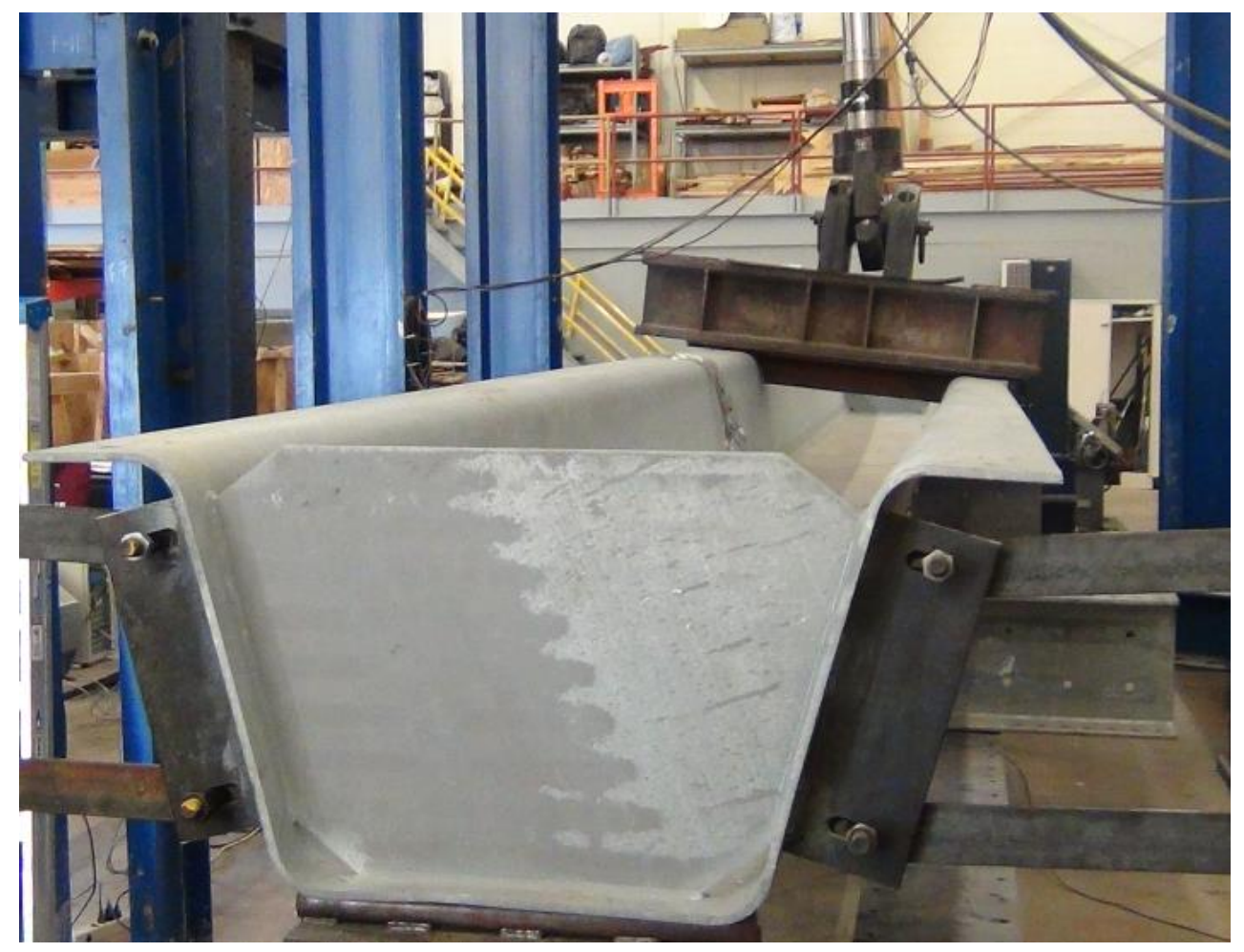

Figure 4.8: Front View of Lateral Torsional Buckling of Specimen \#2 


\subsection{LVDT RESULTS}

The following section documents and compares the LVDT readings with the finite element analysis (FEA) discussed in Chapter 5. The left and right side LVDT results were averaged to determine the total deflection at each instrument location. Figure 4.9 shows the girder deflections at quarter point locations. Experiment \#1 reached a vertical deflection of approximately 1.57 inches, nearly on par with a deflection of 1.59 in. from the FEA model. The deflection of experiment \#2 was approximately 0.44 inches. The mid-span deflections are illustrated in Figure 4.10. The deflection of experiment \#1 is 2.25 inches, just shy of the FEA model vertical deflection of 2.3 inches. The deflection of experiment \#2 is 0.73 inches. Notice that the deflections at both locations coincide well with the FEA results.

\section{Deflection at $0.25 \mathrm{~L}$}

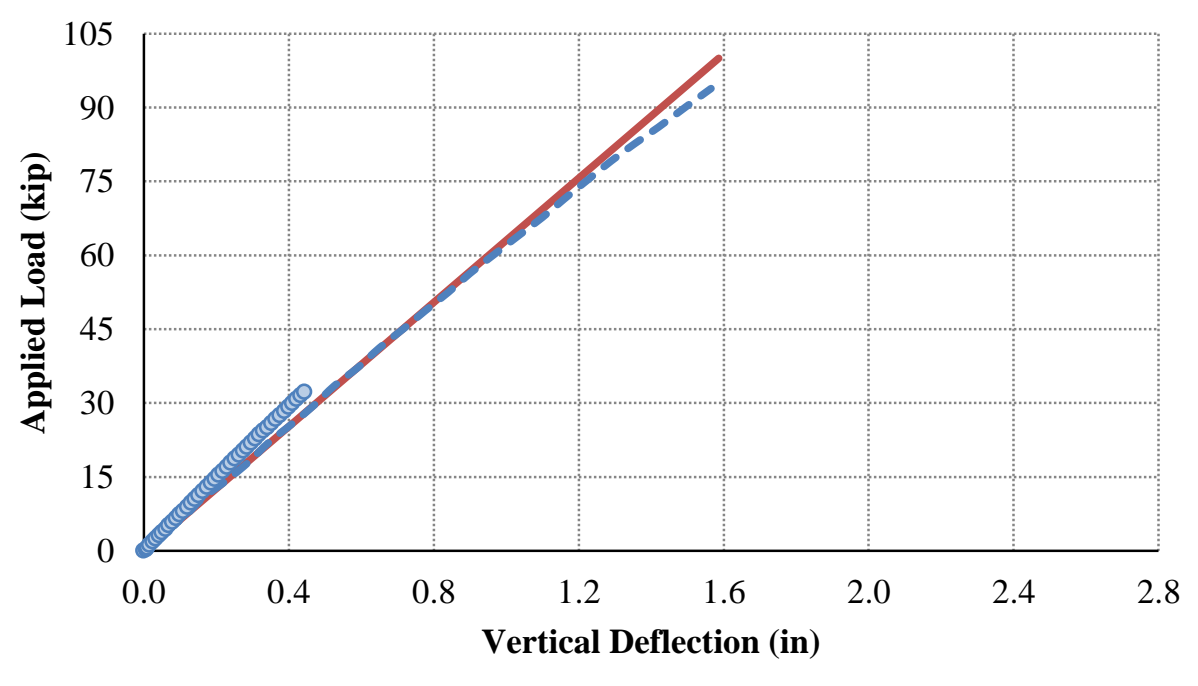

$\longrightarrow$ FEA $\quad-\infty$ Experiment $1 \longrightarrow$ Experiment 2

Figure 4.9: Deflection at Quarter Points 


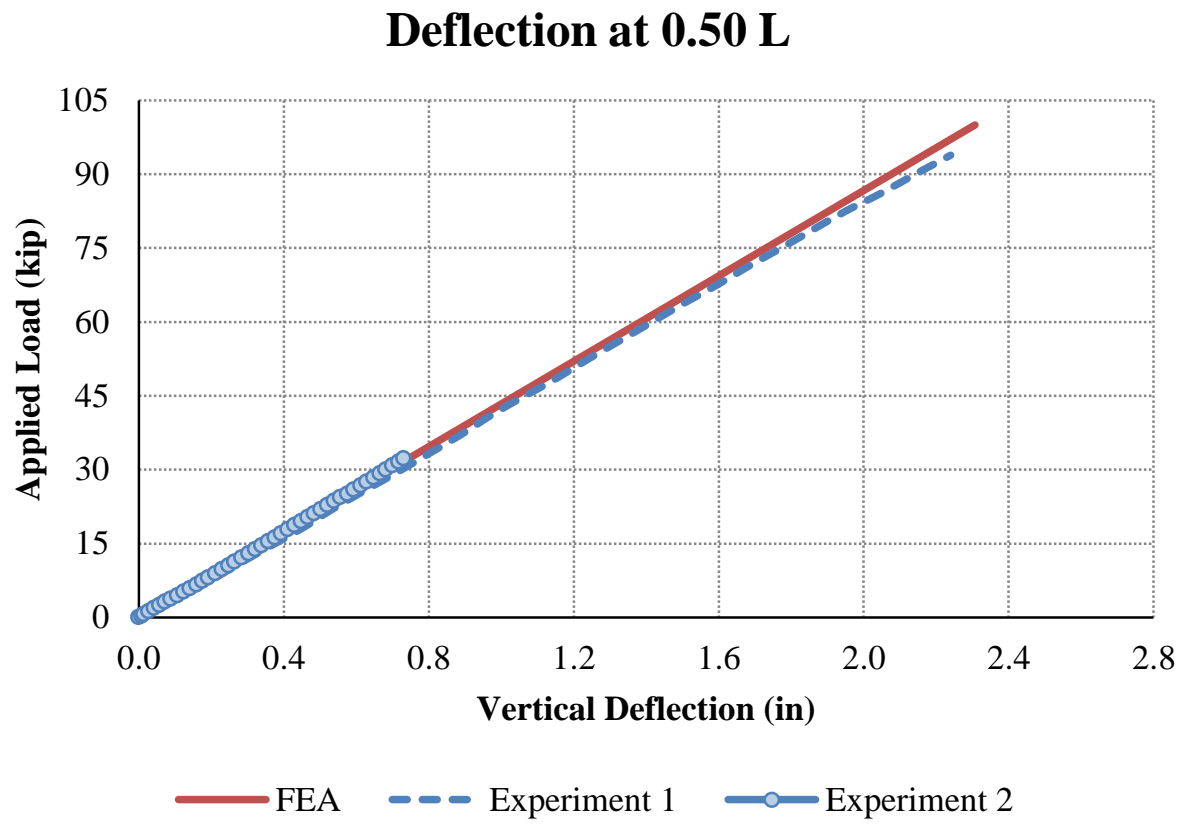

Figure 4.10: Deflection at Mid-span

\subsection{ASSESSMENT OF SECOND-ORDER EFFECTS}

The critical values of load determined from experiment \#1 are based on first-order evaluations of capacity. However, if second-order effects due to initial imperfections are considered, these critical values are significantly reduced based on limits of tolerable deformation. Figure 4.11 shows a plot of second-order amplification of lateral deflection of a tub girder with an initial twist of $1.15^{\circ}$ at mid-span having an initial lateral deflection of 0.98 inches. This initial twist and deflection represents the geometric imperfections of specimen \#2 discussed in Section 3.6. 


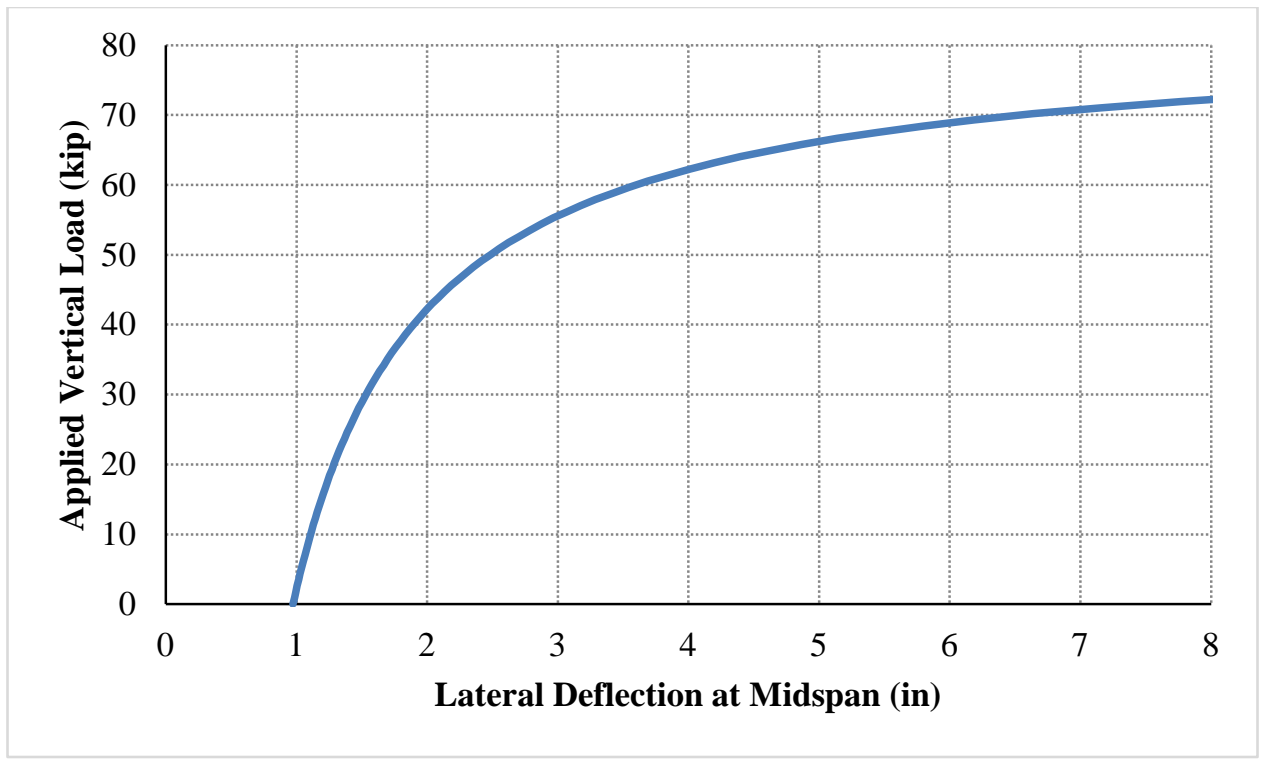

Figure 4.11: Second-Order Lateral Deflections (Michaelson, 2014)

\subsection{SUMMARY}

The preceding chapter discussed the flexural testing results on two shallow steel pressbrake-formed tub girder specimens. Both girders suddenly failed from elastic lateral-torsional buckling before yielding of the steel could occur. It was found that the girders are susceptible to lateral-torsional buckling and torsional instability under relatively low load levels. Secondorder effects, specifically initial imperfections, were found to greatly reduce the critical load values resulting in loss of capacity. It was also noticed that both specimens exhibited lateraltorsional buckling toward the direction of greatest initial imperfections, the right side.

Therefore, the failure modes of these specimens are governed by the section's stability. This data will be used to validate analytical studies on the system in Chapter 5. 


\section{Chapter 5: Finite Element ANAlysis}

\subsection{INTRODUCTION}

This chapter discusses a three-dimensional nonlinear finite element modeling procedure used to accurately assess the behavior and capacity of non-composite press-brake formed steel tub girders. Specifically, details such as element selections, material modeling, application of geometric imperfections, application of residual stresses, and Riks algorithm are discussed.

\subsection{Finite Element Modeling TechniQue}

Finite element analysis (FEA) modeling was conducted using the commercial program ABAQUS (Dassault Systemes, 2010). Contained in this section is a description of the modeling techniques used to accurately capture non-composite steel tub girder behavior and how these techniques were implemented using Abaqus software. Modeling results were also compared with experimental data to assess their validity and accuracy.

\subsubsection{Shell Element Selection}

Abaqus (2010) provides complete geometric modeling capabilities with a variety of available element types. General shell elements with reduced integration (S4R) are used for modeling the steel girders in this study. As shown by several researchers (Barth, 1996; Yang, 2004; Roberts, 2004; Righman, 2005), S4R shell elements are very accurate in modeling the physical behavior of non-composite steel plate girders. These 4-node general-purpose elements are intended to provide accurate solutions for both thin and thick shells, using classical (Kirchoff) shell theory when appropriate for thin shells and (Mindlin) shell theory as the thickness increases. 
These elements allow for finite membrane strains and rotations of the shell, change in shell thickness as a function of the membrane strain, and transverse shear deformation. Therefore, they are suitable for large-strain analysis involving inelastic deformation of materials. The S4R element is a first-order element having only one integration point used to form the element stiffness matrix. S4R elements offer many advantages over traditional shell elements these include: strains and stresses are computed at the locations providing optimal accuracy and fewer integration points result in reduced computing time and storage requirements.

The primary disadvantage of using reduced integration is that deformation modes which cause no strain at the integration points may develop. This may lead to inaccurate results if these zero-energy modes propagate through the structure in a phenomenon commonly known as hourglassing. However, this can be prevented by the user by introducing a small artificial stiffness associated with zero-energy deformation modes using the *SECTION CONTROLS command in an Abaqus input file (Michaelson, 2014).

\subsubsection{Steel Material Modeling}

An elastic-plastic constitutive law including strain hardening effects is used to model the steel elements. The steel was modeled using the *PLASTIC command in the Abaqus input file. This designates a material with a standard von Mises yield surface, an associated plastic flow rule, and isotropic work hardening. According to Yang (2004), this type of material model has been found to be suitable in representing rate-independent behavior of a metal subjected to monotonic loading, where creep effects are not important.

Figure 5.1 shows the multi-linear relationship used to represent the stress-strain characteristics used in the material modeling. The solid red line represents the typical stressstrain relationship and can be established by seven key points along the curve. The equations 
for these points are defined in Table 5-1. Table 5.2 lists the average steel plate properties used in the calculations. The engineering stress-strain is then converted to true stress-strain, dashed blue line in Figure 5.1, by Equations 5.1-5.2. These true stress-strain values are required for input into an Abaqus input file.

$$
\begin{aligned}
& \varepsilon_{\text {true }}=\ln \left(1+\varepsilon_{\text {eng }}\right) \\
& \sigma_{\text {true }}=\sigma_{\text {eng }}\left(1+\varepsilon_{\text {eng }}\right)
\end{aligned}
$$

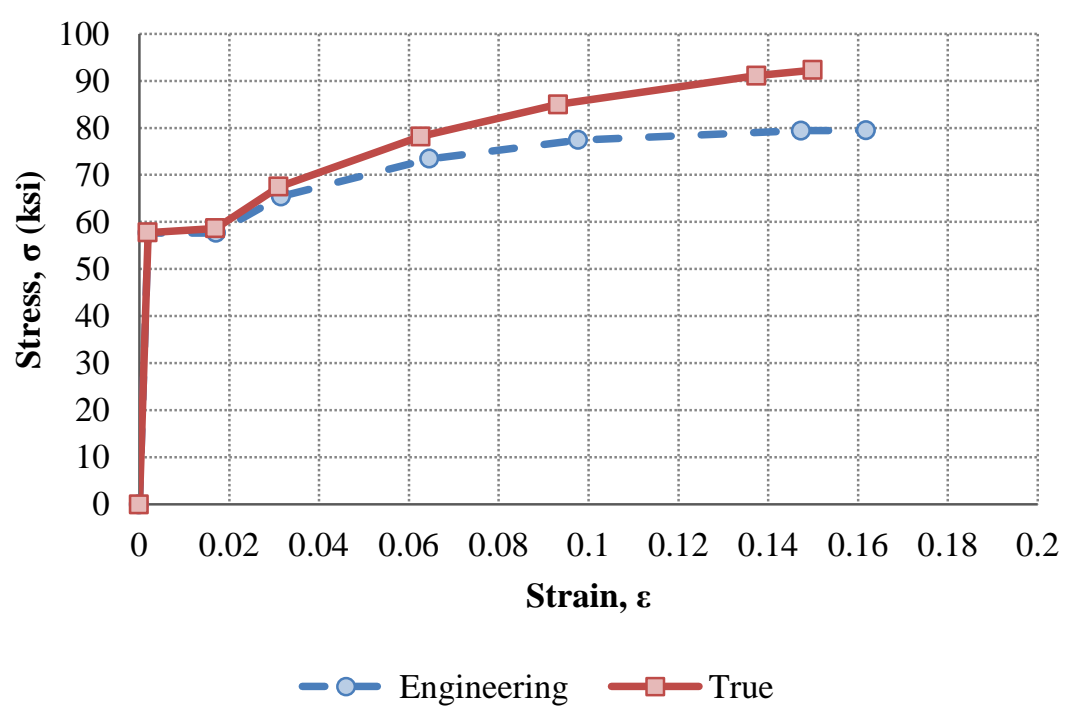

Figure 5.1: Multi-linear Stress-Strain Curve 
Table 5.1: Expressions for Computing Steel Stress-Strain Behavior (Galindez, 2009) Point Strain Stress
$1 \quad \varepsilon_{1}=\frac{\sigma_{y}}{E}$
$\sigma_{1}=\sigma_{y}$
2
$\varepsilon_{2}=\varepsilon_{s t}$
$\sigma_{2}=\sigma_{y}$
$3 \quad \varepsilon_{3}=\frac{1}{10}\left(\varepsilon_{u}-\varepsilon_{s t}\right)+\varepsilon_{s t}$
$\sigma_{3}=\frac{E_{s t}}{10}\left(\varepsilon_{u}-\varepsilon_{s t}\right)+\sigma_{y}$
$4 \quad \varepsilon_{4}=\frac{2}{7}\left(\varepsilon_{6}-\varepsilon_{3}\right)+\varepsilon_{3}$
$\sigma_{4}=\frac{4}{7}\left(\sigma_{6}-\sigma_{3}\right)+\sigma_{3}$
$5 \quad \varepsilon_{5}=\frac{2}{7}\left(\varepsilon_{6}-\varepsilon_{3}\right)+\varepsilon_{4}$
$\sigma_{5}=\frac{2}{7}\left(\sigma_{6}-\sigma_{3}\right)+\sigma_{4}$
$6 \quad \varepsilon_{6}=\varepsilon_{u}-\frac{1}{10}\left(\varepsilon_{u}-\varepsilon_{s t}\right)$
$\sigma_{6}=\left(\frac{\sigma_{y}}{\sigma_{0.2 \%}}\right) \sigma_{u}-\frac{100}{E_{s t}}\left(\varepsilon_{u}-\varepsilon_{s t}\right)$
7
$\varepsilon_{7}=\varepsilon_{u} \quad \sigma_{7}=\left(\frac{\sigma_{y}}{\sigma_{0.2 \%}}\right) \sigma_{u}$

Table 5.2: Average Steel Plate Properties (Galindez, 2009)

Property

Average Value

Modulus of Elasticity, $E$ (ksi) 29559

Static Yield Stress, $\sigma_{y}(\mathrm{ksi})$

60.962

Offset Yield Stress, $\sigma_{0.2 \%}(\mathrm{ksi})$

63.050

Strain at the Onset on Strain Hardening, $\varepsilon_{s t}(\%)$

1.7883

Strain Hardening Modulus, $E_{s t}(\mathrm{ksi})$

1033.5

Tensile Stress, $\sigma_{u}(\mathrm{ksi})$

Strain at the Tensile Stress, $\varepsilon_{u}(\%)$

13.165 


\subsubsection{Von Mises Yield Criterion}

The von Mises yield criterion defines the elastic limit of a material under combined states of stress. Dating from 1913, the von Mises yield criterion is one of the most commonly used yield criteria for metal materials (Righman, 2005). In general, the yield stress is a function of the state of stress, $\sigma_{i j}$, and one of more material constants that are determined experimentally $\left(k_{1}, k_{2}, \ldots\right)$. The von Mises criterion represents a circular cylinder in principle stress space, as shown in Fig. 5.2(a). The criterion states that yielding begins when the strain energy of distortion reaches a critical value $k$, represented in Eq. 5.3.

$f\left(J_{2}\right)=J_{2}-k=0$

Where $J_{2}=0.5 s_{i j} s_{i j}$ and $k=\frac{\sigma_{o}}{\sqrt{3}}$, in which $\sigma_{o}$ is the uniaxial yield stress of the material. Thus, if $f\left(J_{2}\right)<0$ the material will behave elastically and if $f\left(J_{2}\right)=0$ yielding will occur.

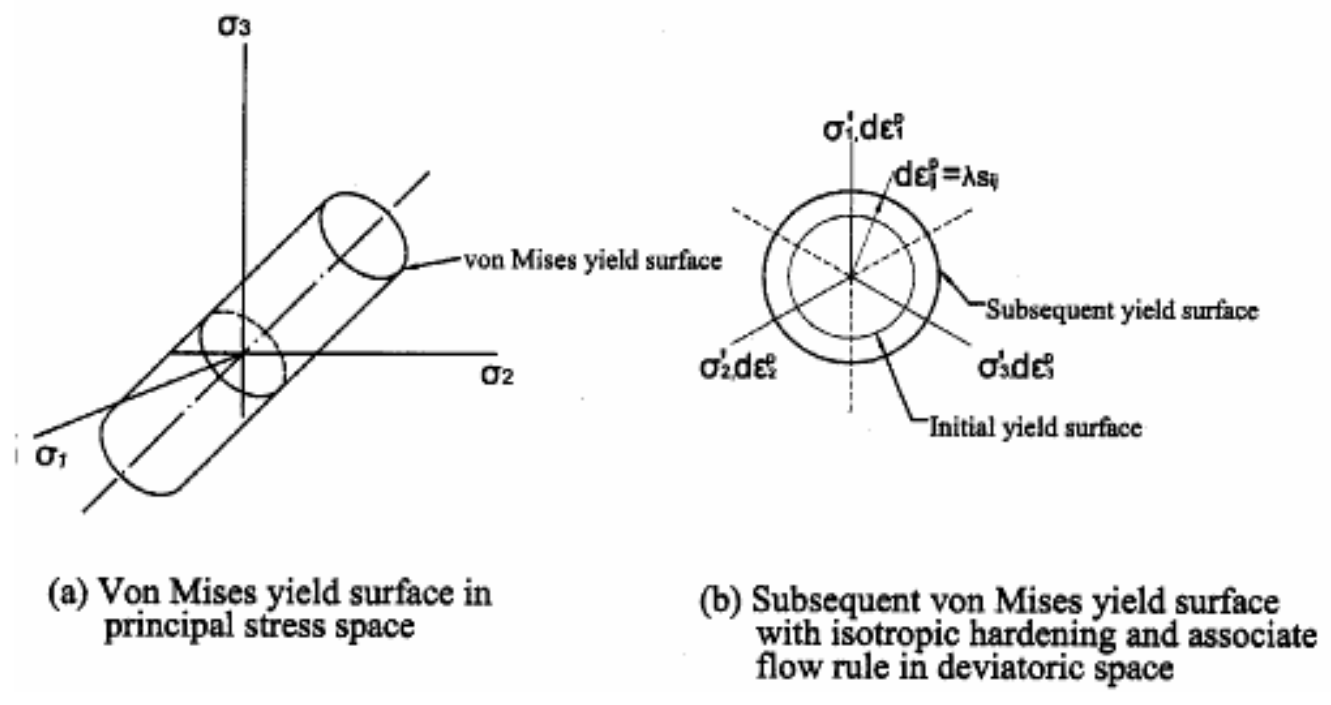

Figure 5.2: Von Mises Yield Criteria (Righman, 2005) 


\subsubsection{Associated Flow Rule}

The associated flow rule defines the direction and relative magnitudes of the plastic strain increment vector $d \varepsilon_{i j}^{p}$ once the elastic limit is exceeded. In 1928, von Mises proposed the concept of the plastic potential function, $\mathrm{g}\left(\sigma_{\mathrm{ij}}\right)$, which is the scalar function of the stresses. The associated flow rule says that the yield function and plastic potential function coincide and is defined by Eq. 5.4 for the von Mises criteria. This implies that the plastic flow develops normal to the yield surface $\frac{\partial f}{\partial \sigma_{i j}}$. The positive scalar factor $d \lambda$ is nonzero when plastic deformation occurs.

$d \varepsilon_{i j}^{p}=d \lambda \frac{\partial f}{\partial \sigma_{i j}}=d \lambda s_{i j}$

\subsubsection{Isotropic Hardening}

The hardening rule specifies the manner the initial yield surface changes during plastic flow. Isotropic hardening is the simplest hardening rule and is based on the assumption that the initial yield surface expands uniformly, without distortion or translation, as plastic flow occurs. According to Righman (2005), this hardening rule generally gives realistic results except in cases where complex loading paths with stress reversals are considered. For isotropic hardening, the size of the yield surface is governed by the value of $k^{2}$ where the effective strain, $\varepsilon^{p}$, depends on the loading history. This yield surface equation is defined by Eq. 5.5. For the von Mises yield function, $\mathrm{F}\left(\sigma_{\mathrm{ij}}\right)=\mathrm{J}_{2}$, and is defined in Eq. 5.6. Von Mises criteria with associated plastic flow and isotropic hardening are illustrated in deviatoric space, Figure 5.2 (b).

$$
\begin{aligned}
& \mathrm{F}\left(\sigma_{i j}\right)=k^{2} \varepsilon^{p} \\
& J_{2}=0.5 s_{i j} s_{i j}=k^{2} \varepsilon^{p}
\end{aligned}
$$




\subsubsection{Modeling of Geometric Imperfections}

In non-composite girders, because elements in compression are not restrained by the concrete deck, the girder can experience a variety of buckling modes. These modes include: lateral torsional buckling, local flange buckling, and local web buckling. Therefore additional considerations, such as, incorporating geometric imperfections of the girder during fabrication and residual stresses due to flame cutting and welding must be taken to ensure accurate modeling of structural behavior of steel flexural elements.

The nonlinearity in response due to the presence of initial imperfections of the girder had a measurable impact on girders response under flexural loads as a result of the girder's susceptibility to various buckling modes. The modified Riks method of analysis discussed in Section 5.2.3.1 is a type of post-buckling analysis used in this study. In order to have a continuous response, as opposed to bifurcation, geometric imperfection patterns are introduced to the "perfect" girder geometry. This allows some degree of buckling to occur before the critical load is reached, simulating the response of "actual" girders. Therefore, the introduction of geometric imperfections is a critical step in this type of analysis.

In welded plate girders, initial geometric imperfections are generally generated during the fabrication and welding process and result in initial out-of-flatness of the steel plates. Three types of geometric imperfections are considered in this work: an out-of-flatness of the web, a tilt of the compression flange, and a lateral sweep of the compression flange. These imperfections are shown in Figure 5.3. 

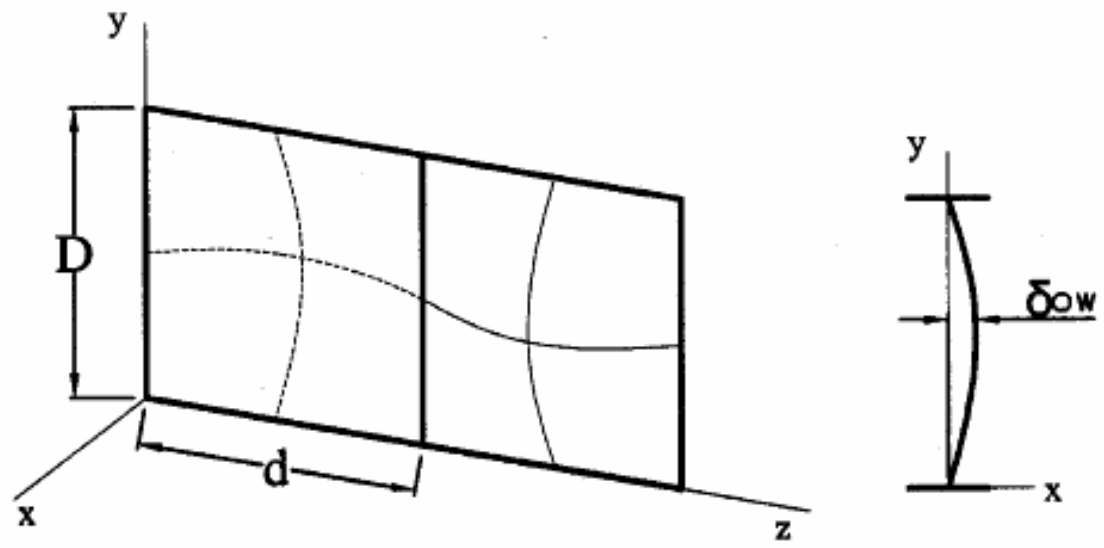

(a) Initial out-of-flatness of the web
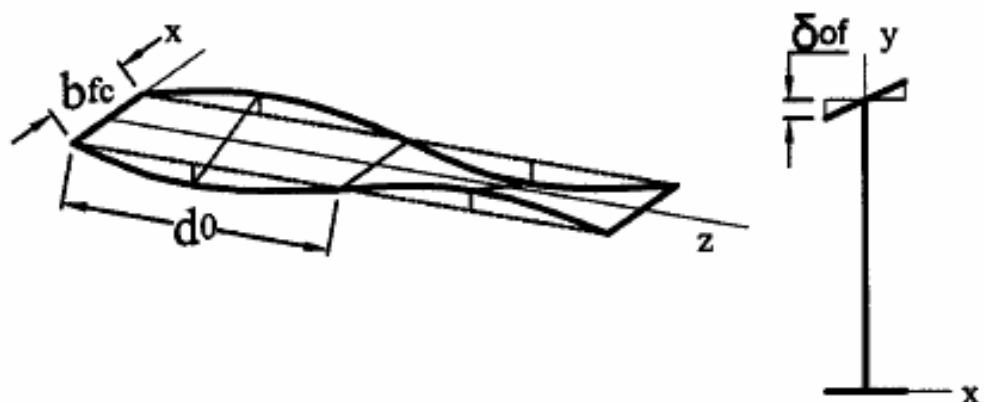

(b) Initial tilt of the compression flange
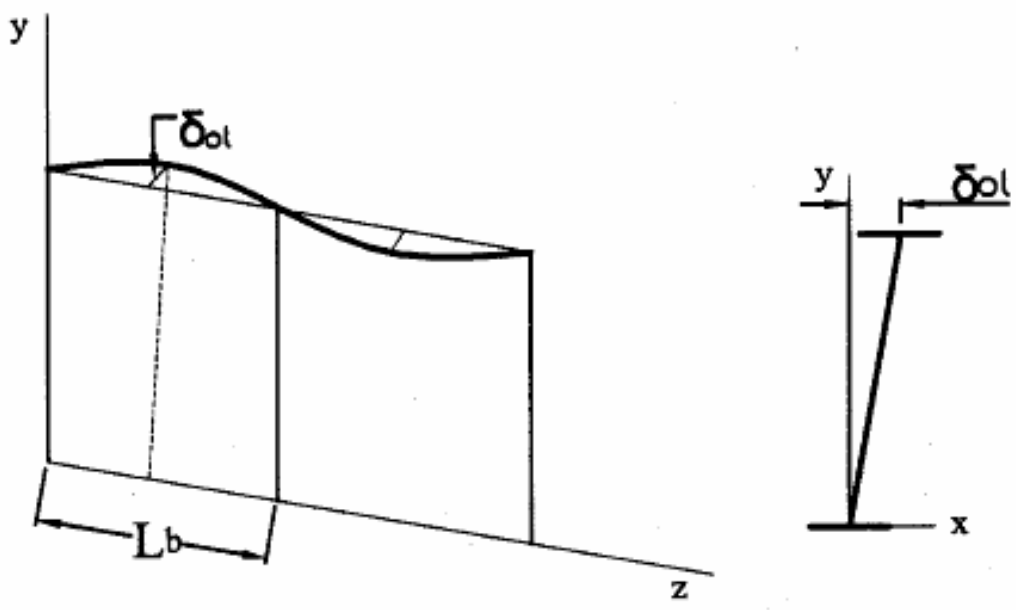

(c) Initial lateral sweep of the compression flange

Figure 5.3: Initial Geometric Imperfections (Righman, 2005) 


\subsubsection{Modified Riks Algorithm}

The girders studied in this work are analyzed using the modified Riks algorithm available in ABAQUS (2010). This solution method captures the nonlinear load deflection response of the FEA model at and beyond maximum loading. The modified Riks method is capable of obtaining a complete nonlinear solution and giving information on girder behavior in both loading and unloading regions (Yang, 2004).

It is assumed the loading is proportional and the response is smooth (no sudden bifurcations). Furthermore, this method uses the load magnitude as an additional unknown and solves simultaneously for loads and displacements. Because the progress of the solution is independent of the load increment, Abaqus uses the "arc length" to control the increment size. The arc length is the distance along the static equilibrium path in the load-displacement space. This value is initially proved by the user and later adjusted by the Abaqus automatic load increment algorithm, which is based on convergence rate.

The essence of this method is that the solution is viewed as the discovery of a single equilibrium path in a space that is defined by the nodal variables and loading parameter. The solution is found during each increment by moving a given distance along a tangent to the current solution point and searching for equilibrium in the plane that not only passes through the point, but also is orthogonal to the same tangent line (Yang, 2004). This is shown in Figure 5.4. The total path length is determined by the load magnitudes the user specifies. The user also determines the number of increments. 


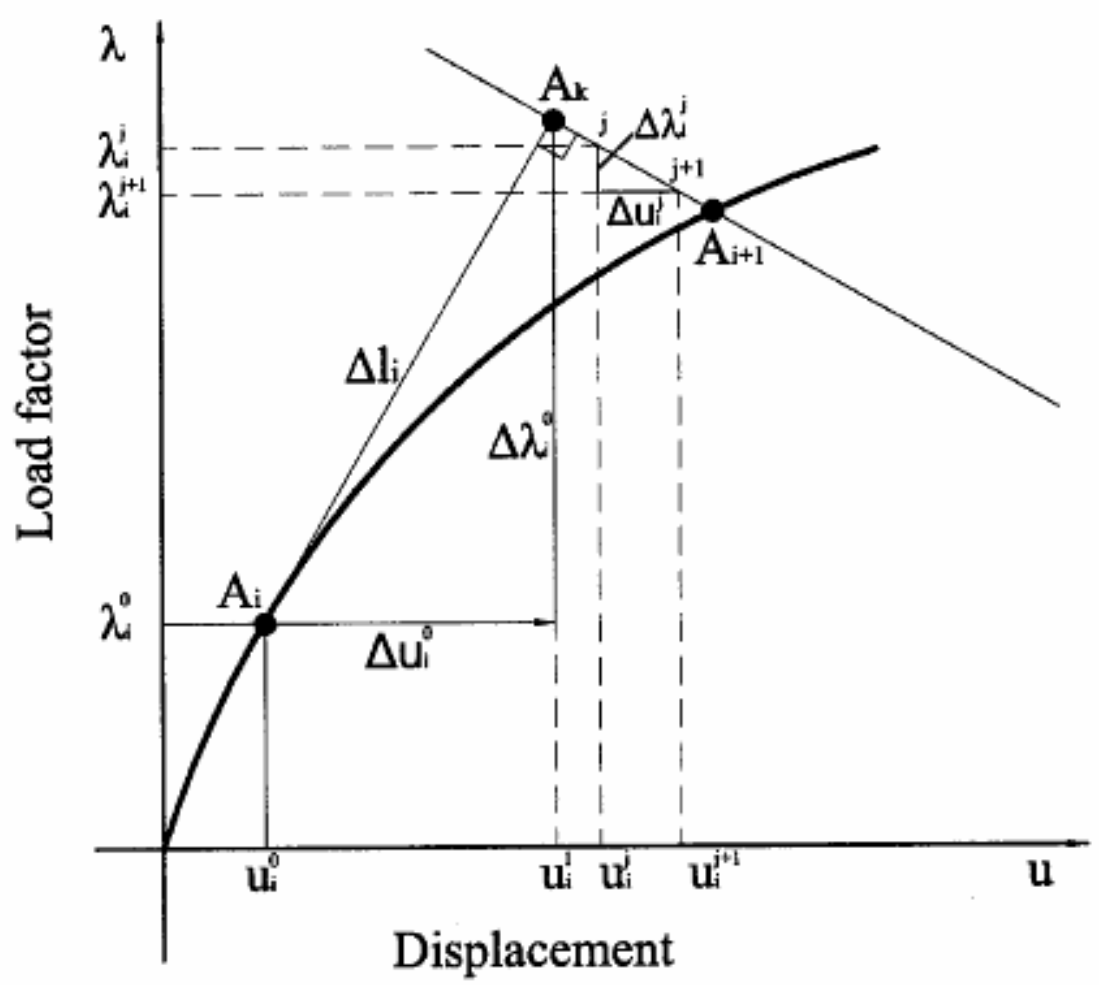

Figure 5.4: Modified Riks Algorithm

\subsubsection{Specification of Imperfections}

The values prescribed for these three imperfections are based on maximum allowable tolerances specified by the American Welding Society (AWS) and engineering judgment (Yang, 2004). These imperfection values summarized below are the exact values applied to the input file. AWS specifies alternative tolerances for the initial out-of-flatness of the web, depending on if the girder is stiffened. For girders with one-sided transverse stiffeners, the maximum

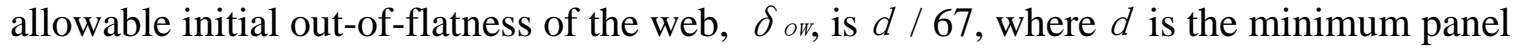
dimension, either the web depth $(D)$ or distance between stiffeners $\left(d_{o}\right)$. Alternatively, the maximum allowable value is $D / 150$ for unstiffened girders. In this study $\delta_{\text {ow }}$ is prescribed to be equal to $d / 100$, which is chosen to represent a midpoint between the above two requirements. 
This maximum value of distortion occurs at the center of each web panel and the amount of outof-flatness at all other locations in the web panel decreases in a half sine wave pattern, in both the $\mathrm{X}$ and $\mathrm{Y}$-directions. Furthermore, the direction of $\delta_{\text {ow }}$ alternates in adjacent web panels.

The maximum allowable tilt of the flanges, $\delta_{o f}$, specified by AWS is equal to $b_{f} / 100$ or $1 / 4$ in., whichever is greater. However, it is felt that it is unlikely that the distortion of the flange would be this severe in girders with relatively short panel lengths. Therefore, $\delta_{o f}$ is assigned to be the lesser value of $b_{f_{c}} / 150$ or $0.3 d_{o} / 150=d_{o} / 500$. This results in values slightly less than that permitted by AWS for girders with long panel lengths (i.e., $b_{f c}<0.3 d_{o}$ ), while for short panels, $\delta_{o f}$ may be significantly less than AWS tolerances. The maximum value of $\delta_{o f}$ occurs at the horizontal center of each web panel along the flange edge. The value of $\delta_{o f}$ decreases in a sinewave pattern along the length of the girder and also decreases linearly along the width of the flange. The direction of $\delta_{o f}$ also alternates in adjacent panels.

AWS limits the variation in straightness of welded girders to 1/960th of the girder length. In this work, a lateral sweep of the compression flange $\left(\delta_{o L}\right)$ is specified to be somewhat less than this limit, with a maximum value equal to $L_{b} / 1500$, where $L_{b}$ is the distance between lateral bracing. This value is prescribed at the center of the lateral bracing segment at the webcompression flange junction. The value of $\delta_{o L}$ varies in a sine wave pattern along the longitudinal direction of the girder and varies linearly along the depth of the girder. As with the other imperfections, the direction of $\delta_{o L}$ alternates in adjacent lateral bracing segments. Furthermore, $\delta_{o L}$ and $\delta_{o w}$ are prescribed in the same direction within each web panel so that the effects of these two imperfections are cumulative. 


\subsubsection{Modeling of Residual Stresses}

The longitudinal residual stresses in welded I-girders are primarily caused by flame cutting of the plates and longitudinal welding between the flanges and the web. Typically, the tensile residual stresses are essentially equal to the yield stress of the material within a small area, termed the heat affected zones, while a smaller, near-constant self-equilibrating compression stress is developed within the other regions of the plates. The residual stress distribution may be idealized by assuming that when the section is free of external forces, the residual stresses over the entire cross-section must satisfy equilibrium and sum to zero.

In this study, residual stress effects are represented by specifying initial stress conditions at the beginning of the analysis through a user-defined sub-routine, which automatically applies a prescribed magnitude of initial (residual) stress to each element depending on the elements location in the girder. When initial stresses are given, the initial stress state may not be in exact equilibrium for the finite element matrix. Therefore, an initial step is included to allow Abaqus to check for equilibrium and iterate, if necessary, to achieve equilibrium. Specifically, a *STATIC step, where girder dead load is also applied, is implemented before the Riks analysis to insure that equilibrium is satisfied once residual stresses have been included.

The residual stress pattern that is used in this study is shown in Figure 5.5. This stress distribution is considered a reasonable approximation of the actual residual stresses induced by welding and flame cutting in typical plate girders (Righman, 2005). 


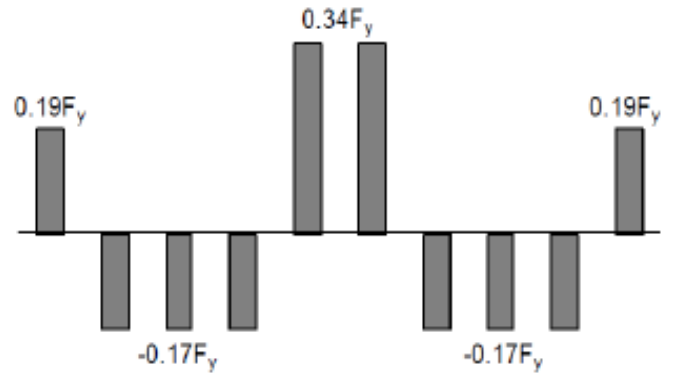

(a) Residual Stress Pattern for Flanges

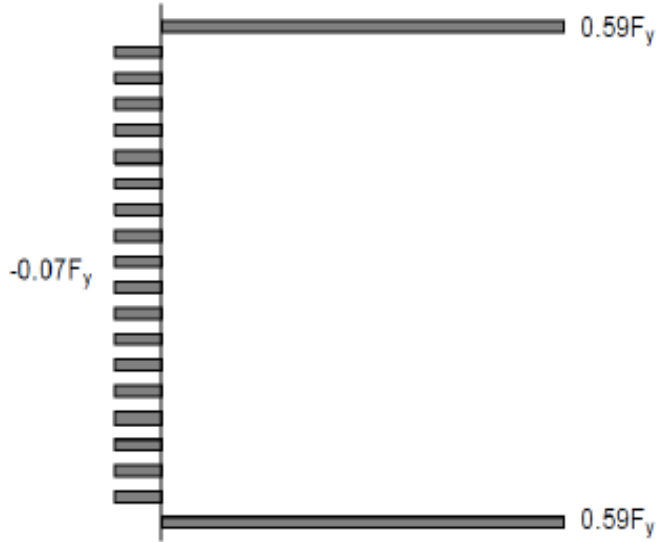

(b) Residual Stress Pattern for Webs

Figure 5.5: Residual Stress Pattern (Righman, 2005)

\subsection{FEA VERIFICATION STUDY}

Assumptions related to initial imperfections, residual stresses, etc., can potentially affect the numerical results. Therefore, to assess the validity of these modeling techniques, previous laboratory experiments are used as a benchmark. The focus of this section is to correlate FEA predictions with results from two representative experimental tests: the "D" girder by Schilling and Morcos (1988) and the "HT-29" girder by Lay et. al (1964).

Three steel I-shaped plate girders (labeled as "S" for Shallow, "M" for Medium, and "D" for Deep) were tested to study the moment-rotation characteristics of steel girders. Three point bending tests were carried out with simply supported conditions at both ends and a concentrated load at mid-span. Specimen " $D$ " is chosen for the verification of this study. Figure 5.6 illustrates the "D” girder configuration. 

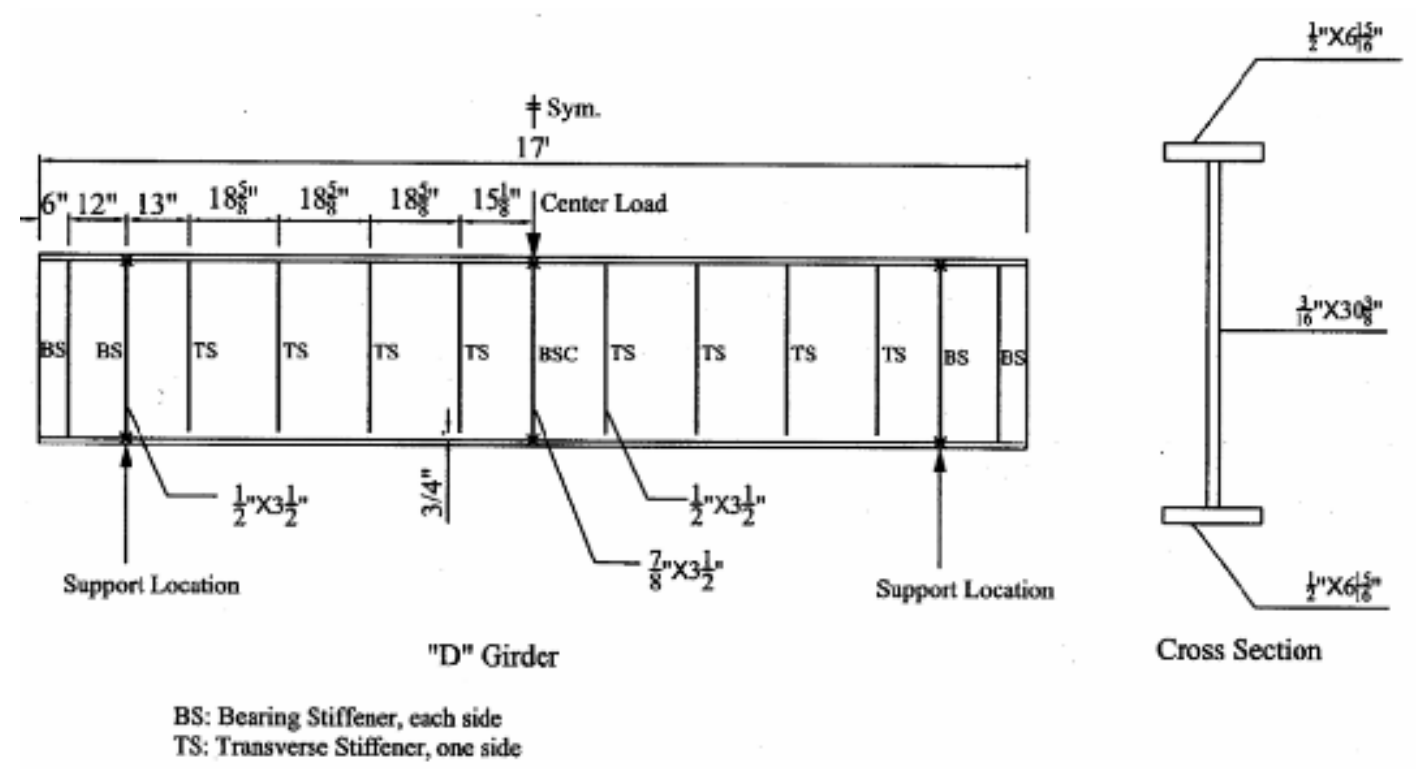

TS: Trunsverse Stiffener, one side

Figure 5.6: "D" Girder Configuration (Schilling and Morcos, 1988)

The selection of relatively large elements will result in unrealistically low predicted strengths due to the effects of stress concentrations, while relatively small elements can cause an overestimate of the energy dissipation capacity (Righman, 2005). To avoid these situations and obtain accurate results, an appropriate mesh density must be selected. Yang (2004) determined that the ideal mesh density was a combination of 10 elements across the flange width and 20 elements throughout the web height; this resulted in less than $1 \%$ error when compared to experimental results. This comparison is illustrated in Figure 5.7. As shown, the proposed modeling technique is efficient in capturing the nonlinear behavior of this experiment. Thus, this mesh density was used for this evaluation. 


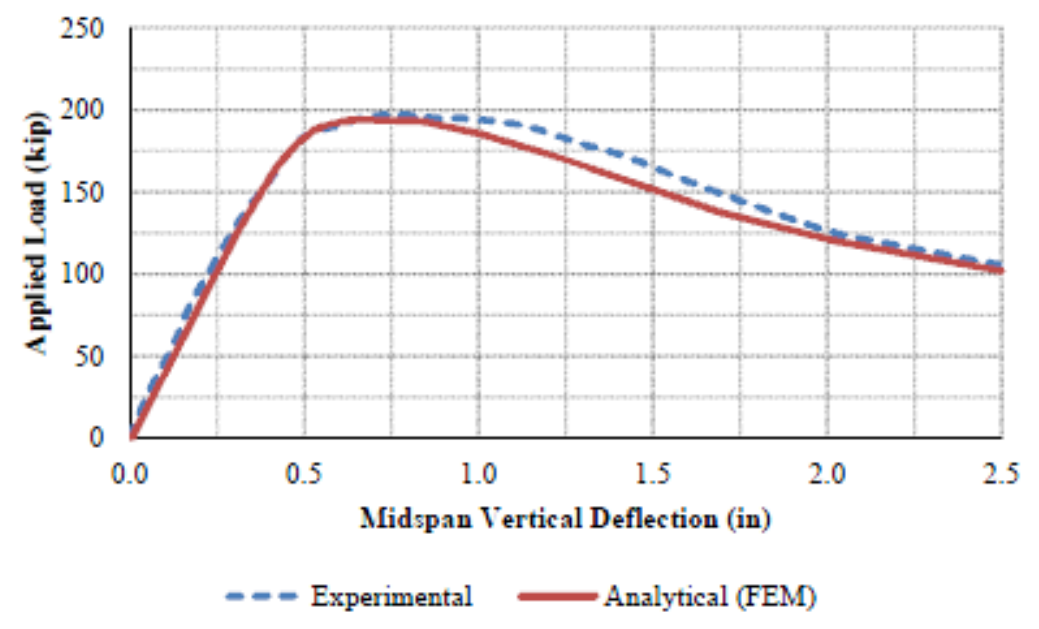

Figure 5.7: Comparison of Schilling and Morcos (1988) “D" Girder and FEA Results

In 1964, Lay et. al. tested steel elements to failure to assess the impacts of utilizing plastic design procedures for structural steel. Girder test "HT-29" was a uniform bending test on a rolled W10 x 25, shown in Figure 5.8.

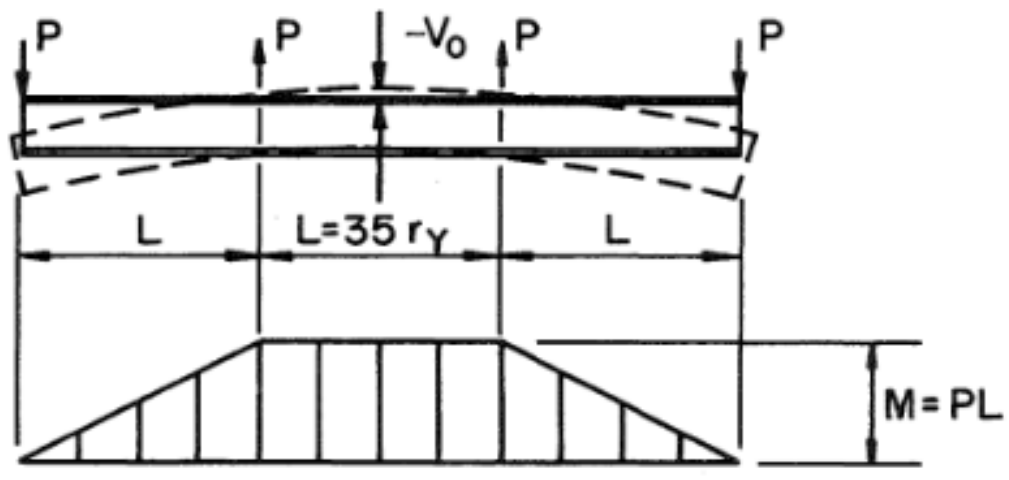

Figure 5.8: “HT-29" Girder Test (Lay et. al. 1964) 
Using the same mesh density described above, a finite element model was created to model the "HT-29" girder. The load-deflection curve from experimental testing was compared with the FEA results shown in Figure 5.9. As shown, the proposed modeling technique is efficient in capturing the nonlinear behavior of this experiment.

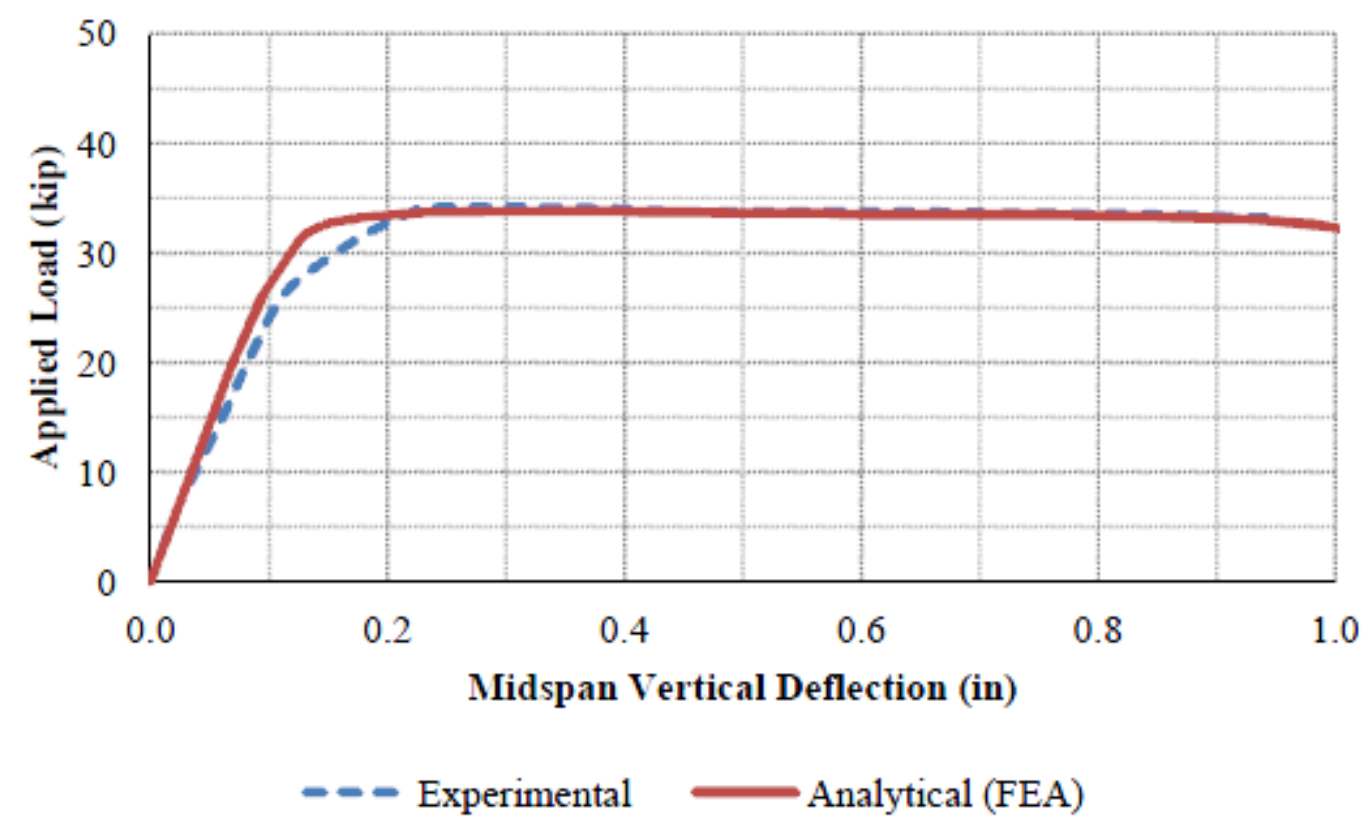

Figure 5.9: Comparison of Lay et. al (1964) "HT-29" Girder Test and FEA Results

\subsection{Modeling of Press-Brake Tub Girder Flexural Tests}

A typical FEA mesh and deformed shape are shown in Figure 5.10 and 5.11, respectively. As shown, shell elements are used to simulate the behavior of the girder and WT section. A linear analysis utilizing this mesh is compared to the experimental results discussed in Chapter 4. Note that additional comparisons for individual gages and instruments are shown in Chapter 4 results. As shown in Figure 5.12, the model accurately captures the girder behavior. 


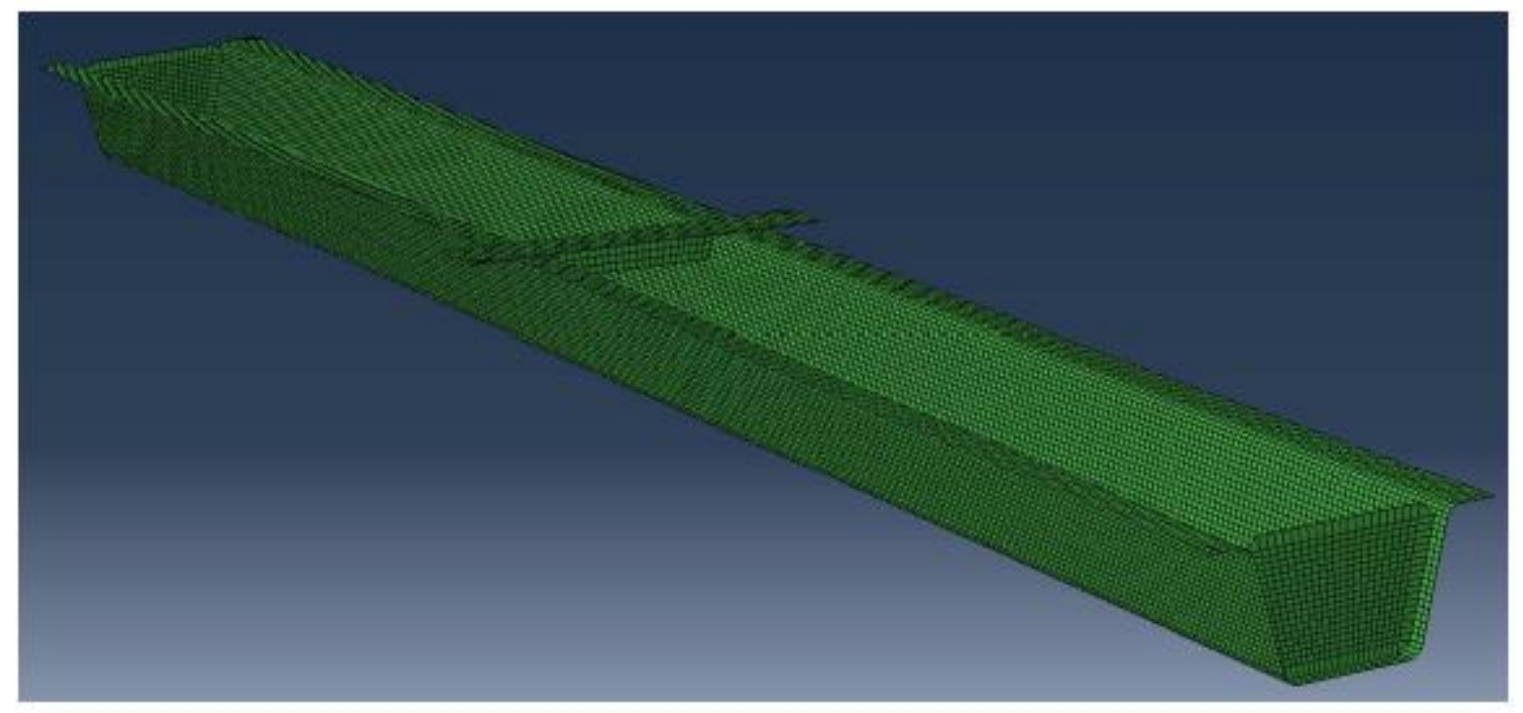

Figure 5.10 Finite Element Model of Non-composite Press-Brake-Formed Tub Girder

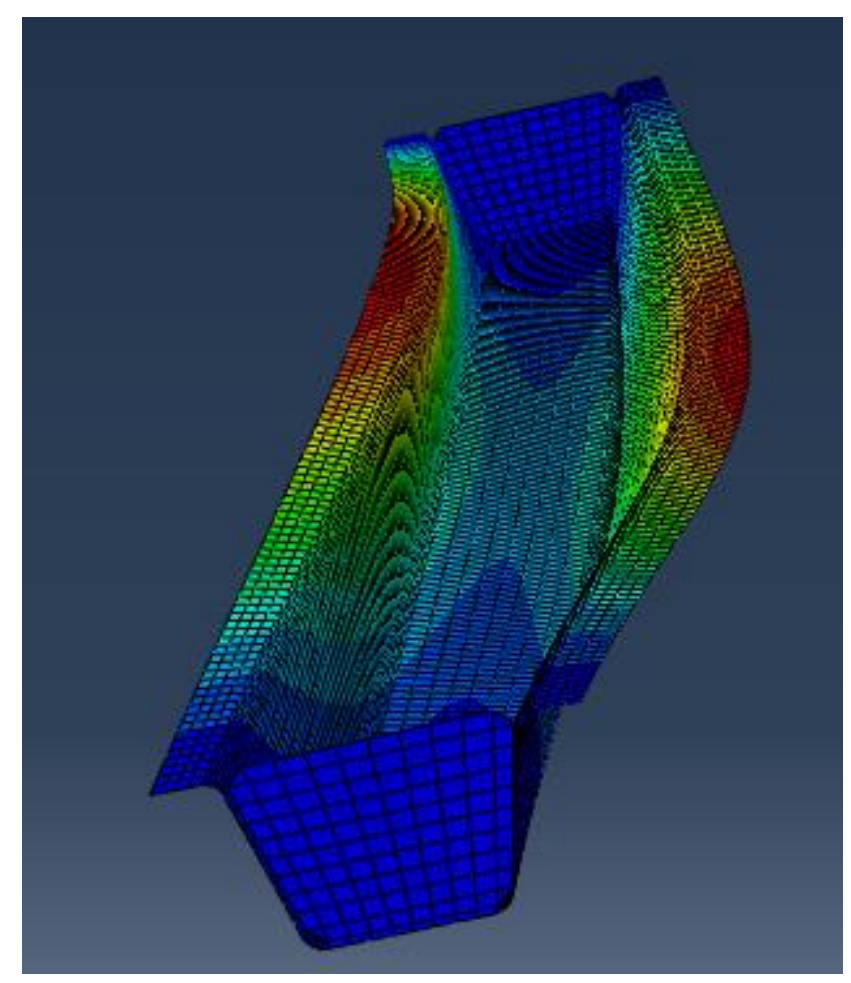

Figure 5.11 Buckled Shape of Non-composite Press-Brake-Formed Tub Girder 


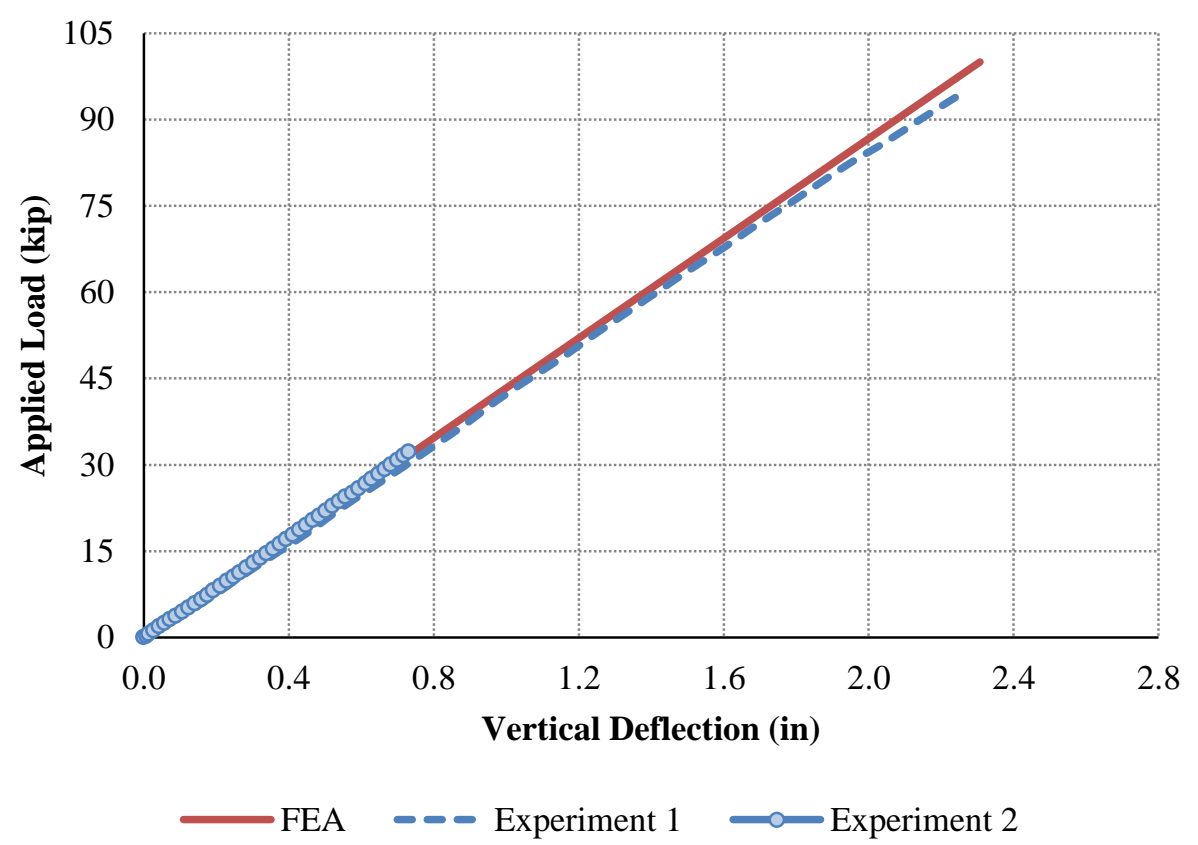

Figure 5.12: Comparison of Experimental and Analytical Results

\subsection{CONCLUSION}

The contents of this chapter have detailed the FEA modeling technique used to assess the press-brake tub girder system. The accuracy of these techniques have been verified by previous tests as well as the experimental results in Chapter 4. The results of these assessments show that the FEA modeling technique accurately captures the behavior of the proposed press-brakeformed tub girder system. In addition, the FEA model represented lateral torsional buckling failure mode similar to that which was present in the experimental tests. 


\section{Chapter 6: Project Summary ANd Concluding ReMarks}

\subsection{Project Summary}

The scope of this project was focused on developing a more complete understanding of the stability and torsional behavior of non-composite press-brake formed tub girders for short span bridge applications. This was achieved by performing the following tasks:

- A literature review focused on reviewing past studies relating to trapezoidal steel tub girders in bridge applications was conducted in Chapter 2. Particular attention is paid to the stability of these girders in a non-composite state and the effect of bracing options on stability.

- With the assistance of Michaelson (2014), behavioral studies were performed to assess the applicability of the current AASHTO LRFD Specifications in predicting the capacity of the proposed system. Improved expressions to compute the non-composite capacity were developed.

- In Chapter 3, destructive flexural testing of two non-composite girders was performed to physically verify their buckling capacity and behavior. Appropriate instrumentation was provided to obtain the load-deflection response for each girder.

- FEA models were developed in Chapter 5 to simulate the nonlinear material and geometric behavior of the steel girder specimens. The results were verified by existing experimental data and previous research studies. 


\subsection{CONCLUSIONS}

From this study, the following conclusions regarding the stability and behavior of noncomposite press-brake-formed tub girders can be drawn:

1. Employing the concept of using cold formed press-brake tub girders proves to simplify fabrication details and allows for a more efficient design. Fabricated from readily available standard mill plate in about thirty minutes allows for quick production.

2. It was found that the girder is susceptible to lateral-torsional buckling and torsional instability under relatively low load levels. Previously tested composite specimen experienced a maximum deflection of approximately 3.1 inches and an average maximum applied load of approximately 304 kips at the moment of failure (Michaelson, 2014).

3. However, this can be abated by installing SIP formwork prior to girder erection, which would increase the torsional stiffness by bracing the girder against lateral-torsional buckling. Closing the girder with SIP formwork substantially improves the performance of non-composite girders under torsional loads.

4. Second-order effects, specifically initial imperfections, can significantly reduce critical load values resulting in loss of capacity. This was noticed when specimen \#2, having greater initial imperfections than specimen $\# 1$, only reached about a third of the capacity of specimen \#1.

5. The FEA model employed in this study is suitable in assessing the behavior of noncomposite press-brake-formed steel tub girders. Figure 5.12 illustrates the coinciding experimental and FEA results. 


\subsection{RECOMMENDATIONS FOR CONTINUED RESEARCH}

The following recommendations for future work are given based on this study:

1. This research is based solely on the stability and behavior of unbraced non-composite tub girders. Thus, experimental and analytical investigation on evaluating bracing methods such as SIP metal formwork should be performed to evaluate the stiffening capabilities.

2. In addition to evaluating SIP metal formwork performance, various gage deck thicknesses and fastener demands should be explored to ensure an effective design and adequate strength.

3. To further understand the lateral torsional buckling behavior, experiments should be conducted to define the LTB curve. This could be done by testing on shorter specimens to determine the anchor points $L_{p}$ and plot the available flexural strength vs. unbraced length. In addition, results should be compared to AISC Specification flexure equations in Chapter F (AISC, 2012). 


\section{REFERENCES}

AISC. (2012). Steel Construction Manual. American Institute of Steel Construction, Chicago, Illinois.

Barth, K. E. (1996). Moment-Rotation Characteristics for Inelastic Design of Steel Bridge Beams and Girders. School of Civil Engineering. West Lafayette, IN, Purdue University. Doctor of Philosophy.

Basler, K. and Kollbrunner, C. F. (1969). Torsion in Structures. Springer-Verlag, Berlin, Germany.

Boresi, A. P. and R. J. Schmidt (2003). Advanced Mechanics of Materials. Hoboken, NJ, John Wiley \& Sons, Inc.

Burgueño, R. and B. S. Pavlich (2008). Evaluation of Prefabricated Composite Steel Box Girder Systems for Rapid Bridge Construction. East Lansing, MI, Michigan State University.

Chandar, G., M. D. Hyzak, et al. (2010). Rapid Economical Bridge Replacement. Modern Steel Construction. Chicago, IL, National Steel Bridge Alliance. 2010.

Chen, B. S. (1999). “Top-Flange Lateral Bracing of Steel U-Shaped Girders.” Masters Thesis, University of Texas at Austin, May.

Chen, B.S. and Yura, J. and Williamson, E. and Frank, K. (2005). "Top-Lateral Bracing System for Trapezoidal Steel Box-Girder Bridges," Report No. 0-1898-4, Center for Transportation Research, The University of Texas at Austin, August

Cheplak, B. A., Memberg, M., Frank, K. H., and Yura, J. A. (2002), "Field Measurements of Diaphragm and Top Lateral Members of Three Trapezoidal Composite Box Girder Bridges.” Research Report 1896-1, Center for Transportation Research, University of Texas at Austin, Oct.

Currah, R.M. (1993). "Shear Strength and Shear Stiffness of Permanent Steel Bridge Deck Forms," theses presented to The University of Texas at Austin, in partial fulfillment of the requirements for the degree of Master of Science in Engineering.

Dassault-Systèmes (2010). Abaqus/CAE. Providence, RI, Dassault Systèmes Simulia Corp.

Frank, Z. and Helwig, T. A. (1999). "Behavior of Steel Box Girders with Top Flange Bracing." Journal of Structural Engineering, American Society of Civil Engineers, Vol. 125 , No. 8 , August. 
Freeby, G.A. (2005). “Texas's Totally Prefabricated Bridge Superstructures,” Transportation Research Record: Journal of the Transportation Research Board, CD 11-S, Transportation Board of the National Academies of Sciences, Washington, D.C., pp. 169-174.

Galambos, Theodore V. (1968). Structural Members and Frames. Prentice-Hall, Inc., Englewood Cliffs, New Jersey.

Glaser, L. A. (2010). Constructability Testing of Folded Plate Girders. Department of Civil Engineering. Lincoln, NE, University of Nebraska-Lincoln. Master of Science.

Gilchrist, C., Yura, J. and Frank, K. (1997). "Buckling Behavior of U-Shaped Girders,” Report No.1395-1, Center for Transportation Research, The University of Texas at Austin, June.

Gotluru, B. P. and Schafer, B.W. and Pekoz, T. (2000). "Torsion in thin-walled cold-formed steel beams," Cornell University, Ithaca, NY and Simpson, Gumpertz, and Heger, Arlington, MA, Feb.

Helwig, T. A. and K. H. Frank (1999). "Bending Behavior of Composite Girders with Cold Formed Steel U Section." ASCE Journal of Structural Engineering 125(11):

Helwig, T. A. and Yura, J (2012). "Steel Bridge Design Handbook: Bracing System Design," Report No. 12-052-Vol. 13, HDR Engineering, Inc., Office of Bridge Technology, The University of Texas at Austin, Nov.

Lay, M., Adams, P., and Galambos, T. "Experiments on High Strength Steel Members," Fritz Engineering Laboratory Report No. 297.8, Fritz Engineering Laboratory, Lehigh University, Bethlehem, PA. 1964.

Memberg, M. and Yura, J. and Williamson, E. and Frank, K. (2002). "A Design Procedure for Intermediate External Diaphragms on Curved Steel Trapezoidal Box Girder Bridges," Report No. 0-1898-1, Center for Transportation Research, The University of Texas at Austin, Oct.

Michaelson, G. K. (2014). Development and Feasibility Assessment of Shallow Press-BrakeFormed Steel Tub Girders for Short-Span Bridge Applications. Doctor of Philosophy, West Virginia University, Morgantown, WV.

Micro-Measurements, Inc. (2010). StrainSmart. Raleigh, NC, Micro-Measurements, Inc.

Nakamura, S. (2002). "Bending Behavior of Composite Girders with Cold Formed Steel U Section." ASCE Journal of Structural Engineering 128(9): 8.

NSBA (2012). Design Example 2A: Two-Span Continuous Straight Steel I-Girder Bridge. $\underline{\text { Steel }}$ Bridge Design Handbook. Washington, DC, National Steel Bridge Alliance.

Righman, J. E. (2005). Rotation Compatibility Approach to Moment Redistribution for Design 
and Rating of Steel I-Girders. Department of Civil \& Environmental Engineering. Morgantown, WV, West Virginia University. Doctor of Philosophy.

Roberts, N. R. (2004). Evaluation of the Ductility of Composite Steel I-Girders in Positive Bending. Department of Civil \& Environmental Engineering. Morgantown, WV, West Virginia University. Master of Science.

SDI. (1995). Steel Deck Institute Diaphragm Design Manual. 2nd Edition. Steel Deck Institute, St. Louis, Missouri.

Schafer, B. W. and S. Ádány (2006). Buckling analysis of cold-formed steel members using CUFSM: conventional and constrained finite strip methods 18 th International Specialty Conference on Cold-Formed Steel Structures. Orlando, FL.

Schilling, C. and S. Morcos. Moment-Rotation Tests of Steel Girders with Ultra-Compact Flanges. Project 188 Autostress Design of Highway Bridges. American Iron and Steel Institute, 1988.

Southwell, R. V. (1932). "On the Analysis of Experimental Observations in the Problems of Elastic Stability." Proceedings of the Royal Philosophical Society of London, Series A, Vol. 135, April, p. 601.

Taly, N. and H. Gangarao (1979). "Prefabricated Press-Formed Steel T-Box Girder Bridge System." AISC Engineering Journal 16(3): 9.

Tricon Precast, Con-Struct Prefabricated Bridge System. Standard plans. Tricon Engineering Group, Ltd. 2008.

Yang, L. (2004). Evaluation of Moment Redistribution for Hybrid HPS 70W Bridge Girders. Department of Civil \& Environmental Engineering. Morgantown, WV, West Virginia University. Master of Science.

Ziemian, R. D. (2010). Guide to Stability Design Criteria for Metal Structures, John Wiley \& Sons, Inc. 